\title{
From Chatter to Action: An Index of Sustainability Sentiment*
}

\author{
Daniele Ballinari $^{\dagger} \quad$ Ola Mahmoud ${ }^{\ddagger}$
}

November 30, 2021

\begin{abstract}
Investments in sustainable assets have grown at a rapid pace over the last decade. Theory partially attributes this increase to changes in investor taste for sustainability. We develop a novel and direct measure of market-wide aggregate investor sentiment for sustainability and present evidence that it has a significant impact on asset prices. Using microblogging data from a social media investing platform, we construct a daily index capturing investor taste for environmental-, social-, and governance issues. We find that (i) sustainability sentiment temporarily increases during market downturns; (ii) positive sentiment shocks drive prices of sustainable stocks above their fundamental value, which is corrected in the long run, whereas negative shocks predict long-term asset price decreases for sustainable stocks; and (iii) sentiment forecasts flows into sustainable mutual funds.
\end{abstract}

Keywords: investor sentiment; sustainable investing; ESG; asset pricing

JEL: G12; G40; Q01

${ }^{*}$ We declare that we have no financial interests that relate to the research conducted in this paper. We are grateful to the WWZ Förderverein of the University of Basel for funding this research project. We thank Francesco Audrino and Fabio Sigrist for providing access to the StockTwits data. For helpful comments and suggestions, we thank Francesco Audrino, Zhi Da, Eric Jondeau, Lucian Taylor, the participants of the Brown Bag Economics Seminar at the University of St.Gallen, and the participants of the Risk Seminar at UC Berkeley.

${ }^{\dagger}$ Faculty of Business and Economics, University of Basel, Peter Merian-Weg 6, 4002 Basel, Switzerland; daniele.ballinari@unibas.ch

${ }^{\ddagger}$ Institute of Economics, University of St. Gallen, Varnbüelstrasse 19, 9000 St. Gallen, Switzerland; ola.mahmoud@unisg.ch 


\section{Introduction}

Classical models in financial economics do not account for sustainable investments, which consider not only financial objectives but also environmental, social, and governance ("ESG") criteria. However, assets in dedicated sustainable investing strategies have grown at a rapid pace over the last decade (McKinsey, 2017). As of 2020, sustainable investments totalled USD 35.3 trillion, which amounts to more than a third of all assets in five of the world's biggest markets (GSIA, 2020). The growth in sustainable assets is arguably being fuelled, at least in part, by rising investor preferences for sustainability. Indeed, evidence on increased investor preferences for sustainability is mounting (Barber, Morse, and Yasuda, 2021; Bauer, Ruof, and Smeets, 2021; Bollen, 2007; Hartzmark and Sussman, 2019; Hong and Kostovetsky, 2012). Theoretical models have recently suggested that such sentiment for holding sustainable assets is time varying and can affect asset prices. Most notably, Pástor, Stambaugh, and Taylor (2020) introduce an ESG factor, which captures changes in attitudes towards sustainability. This factor affects the relative performance of assets classified according to their sustainability by boosting highly scored assets and punishing less sustainable ones. In particular, if aggregate investor sentiment for sustainability increases at some point in time sufficiently, sustainable assets will outperform their less sustainable counterpart despite having lower expected returns on average.

In this paper, our point of departure is the theory that changes in agents' taste for sustainable investments can impact asset prices (Heinkel, Kraus, and Zechner, 2001; Pástor, Stambaugh, and Taylor, 2020; Pedersen, Fitzgibbons, and Pomorski, 2020). While the assumption that investor sentiment for sustainability is on the rise now has some empirical support in the literature, much less is known about the aggregate market taste for sustainability, the stability and change of such sentiment over time, and the extent to which it affects asset prices. Emulating the traditional literature on general investor sentiment in the stock market (Baker and Wurgler, 2007), we thus address the following questions. First, how do we measure (changes in) investor sentiment for sustainability? Second, does investor sentiment for sustainability affect stock prices?

In the first part of the paper, we construct a novel and direct index of market-wide aggregate investor sentiment for sustainability. Our measure of sustainability sentiment uses messages shared on the social networking investment platform StockTwits. StockTwits is specifically designed for investors and traders to share their opinions, such as bullish and bearish sentiment, about stocks. Similar to Twitter, it allows its users to share short messages of 1,000 characters 
(140 characters before 2019). StockTwits has been previously employed as a data source by Cookson and Niessner (2020) to measure investor disagreement. The authors showed that sentiment expressed in StockTwits reveals investors' true opinions, that adherence to an investment philosophy on StockTwits reflects adherence to an investment model in reality, and that disagreement measured using StockTwits messages significantly predicts abnormal trading volume. For our purpose of extracting sentiment for the specific topic of sustainability, the advantage of StockTwits as a data source compared to other existing approaches is threefold. First, changes in investor preferences for sustainability are not easily observable or tested, and the emerging approach to empirically capture such preferences has been by using financial market based proxies, specifically mutual fund flows (Brière and Ramelli, 2021; Hartzmark and Sussman, 2019). As Da, Engelberg, and Gao (2015) point out, such proxies have the disadvantage of being the equilibrium outcome of many economic forces other than investor sentiment. The sentiment index based on online investor messages, on the other hand, is a more direct measure of sentiment that predicts market based trading proxies, as we will show in this paper. Second, compared with other direct measures of sentiment, such as experimental and survey data, which only provide a snapshot of investor beliefs, our sentiment measure is available at a high frequency and is time varying. Third, our approach to extracting sustainability sentiment based on a selection of relevant keywords appearing in the social media messages enables us to disentangle sustainability sentiment from general bullish and bearish market sentiment.

Indeed, since we are not simply capturing bearish or bullish sentiment in general, but rather changes in taste towards a specific qualitative property of stocks, the key to the construction of our index is the identification of relevant sustainability sentiment-revealing search terms. The construction of our sustainability sentiment measure thus involves two key steps. First, we identify all messages with sustainability related content. To this end, we generate a list of over 400 keywords that are likely used when discussing environmental, social, or governance topics on the social media platform. Second, we generate our sustainability sentiment index by selecting all StockTwits messages that contain words from our keyword list and classify selected messages as having either a positive or negative sentiment connotation. We then aggregate the identified messages to a daily sentiment score, which is interpreted as the difference between the share of bullish and bearish messages shared about sustainability issues. Finally, we disentangle investor sustainability sentiment from other sentiment confounders by orthogonalizing our index with respect to a market-wide global social media sentiment index. 
An analysis of the properties of our index yields several novel insights regarding the nature of sentiment for sustainability. For example, because StockTwits users can classify themselves on the platform according to their trading profile, we analyze the profile of investors that tend to discuss sustainability related topics. We find significantly more professional investors, investors that follow a fundamental, value, or growth strategy, and investors with a long-term investment horizon discussing sustainability issues compared with, for example, technical, momentum, and short-term investors. Moreover, our index displays a clear regime dependency. More specifically, investor sentiment for sustainability is negatively correlated with the market return and positively correlated with indices that proxy market uncertainty, such as the VIX and FEARS (Da, Engelberg, and Gao, 2015) indices. While general market sentiment is known to be negatively associated with high volatility (Baker and Wurgler, 2007; Barberis, Shleifer, and Vishny, 1998), our results are consistent with a body of mounting evidence of a positive association between measures of risk and measures of sustainability (Albuquerque, Koskinen, and Zhang, 2018; Ding, Levine, Lin, and Xie, 2020; Dunn, Fitzgibbons, and Pomorski, 2017; Goldberg and Mouti, 2019).

We also investigate the relationship between our sentiment index and other non-market based variables that may be related to investor sentiment for sustainability. Variables we consider are the Google search volume of sustainable investment search words, as a proxy for attention, the sustainability news sentiment and volume based on RavenPack news analytics, as well as changes in the media climate change concern index of Ardia, Bluteau, Boudt, and Inghelbrecht (2021). Time series correlations between our sentiment index and both measures of attention and news sentiment are very low and insignificant. We find instead that higher attention and news about ESG-related topics are related to higher disagreement in investor sentiment for sustainability. To address potential drivers of our sentiment index, we use a Vector Autoregression framework to analyze lead-lag relations between our sustainability sentiment index and the other indices. We find that news related to sustainability leads investor sentiment for sustainability, which is consistent with the intuitive notion that investors react to given positive or negative news about a sustainability related topic by discussing the issue on social media. On the other hand, we do not find any significant lead-lag relationship between sentiment and attention.

In the second part of the paper, we relate our index to trading activity and asset prices. Building upon the theoretical model of Pástor, Stambaugh, and Taylor (2020), we hypothesize that higher sustainability sentiment predicts higher realized returns for sustainable stocks and lower realized returns for their less sustainable counterparts. Using ESG ratings provided by 
MSCI, we create a portfolio that is long in the stocks with the highest sustainability rating, and short in the stocks with the lowest ratings. The results of a simple trading strategy confirm our hypothesis: higher sustainability sentiment predicts in the short run (up to one month) significantly positive returns for the long-short portfolio. Our findings are robust to a wide array of measurement choices and controls. Notably, we asses the robustness of our results in a predictive regression framework controlling for other factors that forecast the returns of sustainable stocks, such as attention or news articles about ESG-related topics, sentiment about the stocks, and firm-specific characteristics. Moreover, our results show that while after positive shocks to sustainability sentiment the higher returns revert in the long run, the lower returns observed after negative shocks are more persistent and only revert slowly. We also show that positive and negative shocks in investor sentiment for sustainability predict abnormal trading activities in stocks with the highest and the lowest sustainability ratings.

Finally, we relate our sentiment index to the in- and outflows of mutual funds. We asses the predictive power of sustainability sentiment for the net flows of US mutual funds that received the highest or lowest sustainability rating by Morningstar. Fixed-effects panel regression results show that higher sustainability sentiment significantly predicts larger net fund flows for sustainable mutual funds, and net outflows for mutual funds with the lowest sustainability rating.

Related work and contributions. Our paper contributes to three main strands of literature. First, our paper contributes to an emerging literature studying preferences for sustainability in the financial market. From a behavioral perspective, much of the focus has been on investor motives, where evidence is pointing towards nonpecuniary motives being a principal driver. ${ }^{1}$ Setting motives aside, the fact that investors collectively view sustainability as a positive attribute has been addressed recently, both empirically and experimentally. Hartzmark and Sussman (2019) present causal evidence suggesting that a large portion of the market views sustainability as a positive company attribute. Using a natural experiment setting where Morningstar first

\footnotetext{
${ }^{1}$ Earlier laboratory experiments have suggested that moral benefits are of primary concern to investors (Beal, Goyen, and Phillips, 2005; Glac, 2009; Webley, Lewis, and Mackenzie, 2001), whereas more recently, Doeskeland and Pedersen (2016) show that wealth framing is more effective than moral framing in making investors engage in responsible investment. The notion of social preferences, used very broadly, has been the subject of a relatively veteran literature strand investigating the motives of socially responsible investing Anand and Cowton (1993); Buzby and Falk (1978,7); Lewis and Cullis (1990); Moskowitz (1972); Rosen, Sandler, and Shani (1991); Statman (2000); Webley, Lewis, and Mackenzie (2001). More recent experimental studies, surveys, and empirical analyses supporting the hypothesis that socially responsible investors are motivated by non-financial social, ethical, and moral value characteristics of their portfolios include research by McLachlan and Gardner (2004), Beal, Goyen, and Phillips (2005), Bollen (2007), Williams (2007), Renneboog, Ter Horst, and Zhang (2008), Nilsson (2009), Barreda-Tarrazona, Matallin-Saez, and Balaguer-Franch (2011), and Dorfleitner and Utz (2014), amongst others.
} 
published mutual fund sustainability ratings, being categorized as low sustainability resulted in net outflows of more than $\$ 12$ billion while being categorized as high sustainability led to net inflows of more than $\$ 24$ billion. In a field experimental setting, with a pension fund that grants its members a real vote on its sustainable-investment policy, Bauer, Ruof, and Smeets (2021) find that two-thirds of participants are willing to expand the fund's engagement with companies based on selected sustainable development goals, even when they expect engagement to hurt financial performance. While in both cases the evidence clearly points towards strong preferences for sustainability qualities, these studies only provide a snapshot of these preferences. Moreover, the setting of both studies largely depends on a certain event occurring, namely the publishing of sustainability ratings in one case, and the survey sent out by the pension fund for the sake of their strategic decision. In general, however, it remains unclear how the market collectively views sustainability at any given point in time, an insight provided by our index.

Second, our paper is an empirical contribution to the theoretical literature investigating investor preferences for sustainability and their market impact. Several prominent theoretical models have integrated such general tastes for sustainable assets into models of asset pricing. Heinkel, Kraus, and Zechner (2001) build an equilibrium model in which ethical investors exclude polluting firms, resulting in an increase of the cost of capital of polluting firms. Fama and French (2007) provide a framework for studying how disagreement and tastes for holding assets as consumption goods, such as green assets, can affect asset prices. More recent models, such as those of Baker, Bergstrasser, Serafaim, and Wurgler (2020), Pedersen, Fitzgibbons, and Pomorski (2020), and Pástor, Stambaugh, and Taylor (2020), consider several types of investors with differing tastes for or knowledge of sustainability and derive the return predictions (Baker, Bergstrasser, Serafaim, and Wurgler, 2020), the ESG-efficient frontier (Pedersen, Fitzgibbons, and Pomorski, 2020), and the equilibrium (Pástor, Stambaugh, and Taylor, 2020). Our paper is a direct empirical test for these models in the universe of general sentiment for sustainability of equity and mutual funds. In particular, our results confirm the prediction of the model of Pástor, Stambaugh, and Taylor (2020) showing that changes in investors' taste for sustainability predict at least in the short run higher returns for sustainable stocks. Our evidence is thus in line with the recent empirical analyses of Ardia, Bluteau, Boudt, and Inghelbrecht (2021) and Pástor, Stambaugh, and Taylor (2021), who argue that shifts in climate concerns contribute to the outperformance of sustainable stocks. Moreover, our finding that higher sustainability sentiment predicts larger flows into sustainable mutual funds is in line with the prediction of the 
model of Pedersen, Fitzgibbons, and Pomorski (2020).

Third, our paper contributes to the strand of the sentiment literature that proposes novel, high-frequency measures that do not rely on market outcomes such as return and volume. Several studies have proposed measures to capture investor sentiment based on social media textual data (Antweiler and Frank, 2004; Cookson and Niessner, 2020; Renault, 2017). These studies generally focus on the construction of stock-specific sentiment measures and identify relevant content through a stock's ticker or name. Baker, Bloom, Davis, and Renault (2021) extend this approach to construct social media-based sentiment measure about the whole economy. They define a set of keywords to identify social media content about the economic uncertainty. We contribute to this literature by providing a simple approach to construct keyword lists about specific topics, in our case sustainability of stocks, which can be then used to identify relevant social media messages. Perhaps most closely related to our approach are the recent works of Engle, Giglio, Kelly, Lee, and Stroebel (2020) and Ardia, Bluteau, Boudt, and Inghelbrecht (2021). These papers use news media articles to capture attention to climate change and the level of risk and uncertainty related to climate change, respectively. There are, however, two important distinctions to our index. First, we focus on capturing taste regarding sustainability issues more broadly beyond the environment. Indeed, as we will show in the next section, social and governance related issues are equally as important to investors when considering the sustainability profile of firms. Second, our index is a direct measure of investor sentiment with respect to the sustainability profile of firms rather than a general measure of climate change sentiment, which incorporates the sentiment of the population beyond the investment universe.

The remainder of the paper is organized as follows. Section 2 introduces the data and describes the construction of our measure of investor sentiment for sustainability. We provide a detailed analysis of our sentiment index in Section 3. In Section 4 we analyze the relation between sustainability sentiment, asset prices, and trading volume. We investigate in- and outflows of mutual funds in Section 5. Section 6 concludes.

\section{Data and Methodology}

\subsection{StockTwits data}

We capture investor sentiment for sustainability using messages shared on the social media platform StockTwits. Founded in 2008, StockTwits is specifically designed for investors and 


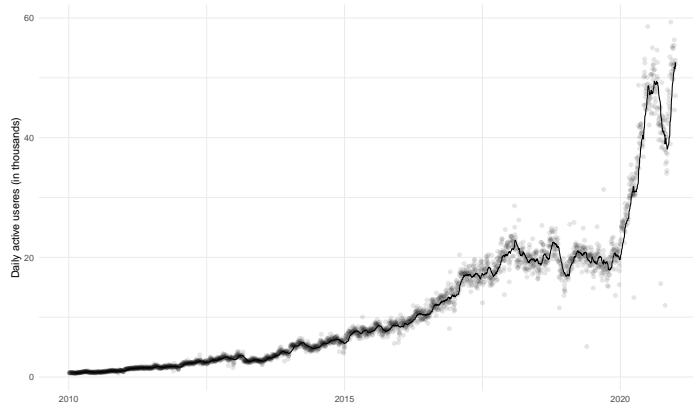

(a) Daily number of active users

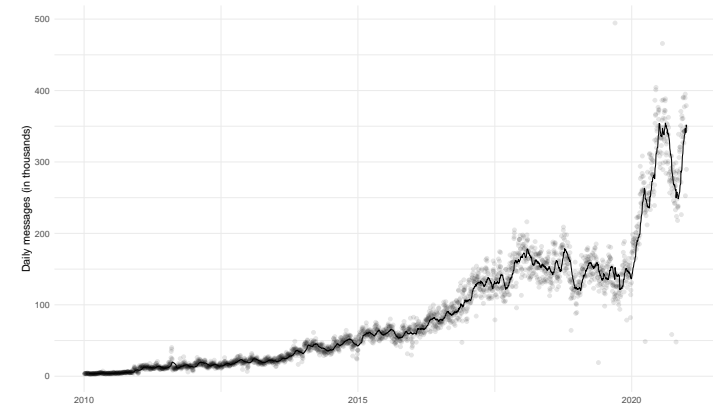

(b) Daily volume of messages posted

Figure 1: Number of active users and volume of messages posted on StockTwits

NotE: The figure depicts in the left panel the time series of the daily number of active users on StockTwits (users that shared at least one message). The right panel depicts the volume of messages posted on StockTwits. The dots represent the time series values and the solid line its one-month moving average.

traders and as of May 2019 allows its users to share short messages of 1'000 characters (prior to May 2019 the number of characters was limited to 140). The number of active users constantly increased over the past decade, as depicted in Figure 1. The figure shows in panel (a) the time series of the daily number of active users on StockTwits (users that shared at least one message), and in panel (b) depicts the volume of messages posted on StockTwits. In particular over the year 2020, the number of users and the volume of messages shared on the social media increased drastically. As of 2020, there are roughly three million users that regularly use the platform.

Users of this platform share investment ideas and opinions about financial markets. When sharing a short message, users can also express their feelings by labeling the message as either "bullish" or "bearish." This way users also share their opinions and reveal their sentiment about ESG-related topics. Figure 2 shows two examples of messages shared on StockTwits about ESG. Whereas the author of the first message is clearly optimistic about ESG-related investments, the author of the second message is more critical about sustainable investing. Our goal is to identify all messages that are related to ESG, similar to the two examples shown in Figure 2, and summarize in a daily sentiment index the opinions of investors about this topic.

We obtain all messages shared on StockTwits between 2010 and 2020. This amounts to approximately 250 millions messages. For each message, we have information about the publication time, the bullish-bearish label assigned by the user (if any), and user-specific information. This includes the self-reported trading experience ("novice," "intermediate," or "professional"), trading approach (e.g. "value"), and the holding period (e.g. "long term investor"). Cookson and Niessner (2020) find that these self-reported characteristics reliably categorize users.

The construction of our sentiment measures based on data obtained from StockTwits involves 
Kornie7 Bullish 11/28/20,08:12 PM

\$ENPH \$FSR \$RIDE \$SBE \$NBAC

Excited for 2021. ESG wave will continue. Will it be a tsunami? 8

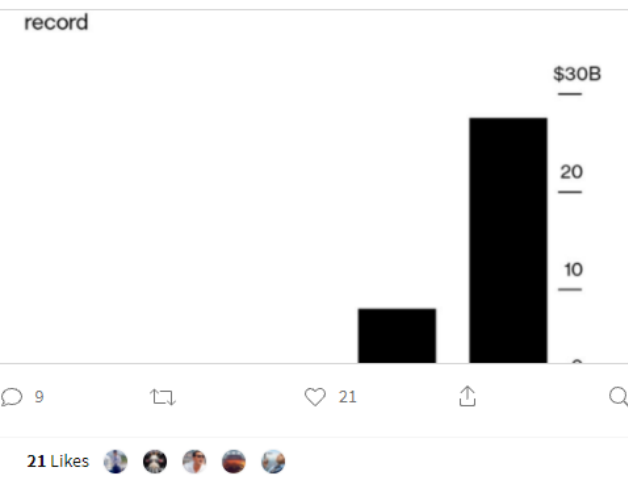

(a) Example of a bullish message about ESG
VoxGeorge Bearish 5/13/19, 10:11 PM

\$TSLA Hello Tesla cultists - this IS a scientific truth - every time Mt Edna burps, or any other volcano burps, it puts more than 10,000 times more $\mathrm{CO} 2$ into our atmosphere than mankind's entire history. So, manmade global warming or climate change or whatever moniker U wanna call it..is 'fake'. F-A-K-E !! Even in France, the people have had enough of the lies- starting the Yellow Jacket movement, they are being TAXED to death for every little 'greenie' nonsense!! The 'green' movement is nothing more than an illusion created to make a new market and the sheeple are supposed to follow. No thanks to bullshit, I say. Wake up and have a great week ahead.

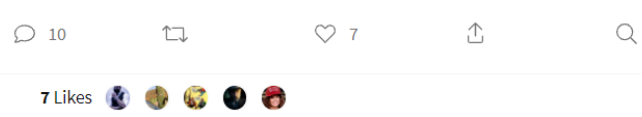

(b) Example of a bearish message about ESG

Figure 2: Example of messages shared on StockTwits about ESG investing

two major steps. First, we identify all messages with relevant sustainability-related content. To this end, we generate a list of keywords that are likely used when discussing environmental, social, or governance topics on the social media platform. Second, we construct the sustainability sentiment index by selecting all StockTwits messages that contain an uni- or bi-gram from the environmental, social, or governance keyword lists and aggregate the data to construct a daily sentiment index.

\subsection{Content identification}

The most straightforward and reliable approach to collecting social media messages about a specific topic is to use hashtags. These are metadata tags preceded by the hash symbol ("\#"), which are widely used on microblogging and social media platforms, including Twitter. However, the use of hashtags has not been widely adopted on StockTwits. We therefore expand our approach for collecting relevant social media messages as follows. Based on an initial corpus of microblogging messages identified by sustainability-specific hashtags, we construct a list of keywords that can be used to identify the relevant StockTwits messages. More precisely, we construct three keyword lists consisting of so-called uni-grams (one word) and bi-grams (two words) that are used in environmental-, social-, or governance-related messages. We identify these keywords by comparing the language used in a corpus of messages about either environ- 
mental, social, or governance aspects with that used in a corpus of random messages. Words or expressions used more often in the former corpus than in the latter are likely to be specific to sustainability topics.

The corpus of messages about the environment is constructed by collecting all messages shared on StockTwits that mention the hashtag "\#environment" or "\#climatechange." Similarly, all messages that mention the hashtags "\#socialresponsability," "\#csr," "\#socimp," or "\#socialimpact" define the dataset of social-related messages, and those that mention the hashtags "\#corpgov" or "\#governance" define the corpus of governance-related messages. Because of the limited use of hashtags on StockTwits, we enhance these corpora by additionally collecting all messages shared on Twitter that mention one of the above hashtags. ${ }^{2}$ In total, the environmental corpus consists of $12,508,172$ messages, the social corpus of $2,017,588$ messages, and the governance corpus $1,360,769$ messages.

We next compare the uni- and bi-grams used in our collected sustainability-related corpora with those used in a randomly selected corpus of $10 \%$ of all messages shared on StockTwits between January 2010 and December 2020, which amounts to a random corpus of 27,055,764 messages. For each of the three corpora, we define an initial keyword list by selecting the 2,000 uni- and bi-grams that are used most frequently, relative to the sample of random messages. We then refine these keyword lists by manually evaluating each item. In particular, we remove keywords that may be often used in different contexts. For example, the word "electric" is removed from the environmental keyword list since it is often used to refer to the company General Electric Co. We allow for keywords to be part of more than one of the three lists, such as the keyword "esg", which is part of all three keyword lists.

Appendix A offers a detailed description of our approach to construct the keyword lists. The three keyword lists used to identify environmental-, social-, and governance-related social media messages are reported in Table A1. The environmental, social, and governance keyword lists consist of respectively 149, 130, and 165 items, of which 336 are uni- and 108 are bi-grams. The top 30 most used keywords in each category are displayed in bold in Table A1, and Figure 3 displays the proportional use of all keywords graphically. To the best of our knowledge, these are the first social media specific sustainability keyword lists that have been proposed in the literature. We thus contribute to the work of Baier, Berninger, and Kiesel (2020) who

\footnotetext{
${ }^{2}$ Note that data from Twitter is only used for the construction of the keyword list and not for the final sentiment measures presented later in this paper.
} 
recently introduced an ESG-dictionary of uni-grams constructed from 10-k filings. While there are common aspects between their keyword list and ours (the intersection between the two amounts to 123 keywords or $28 \%$ of our list), there are some important differences. First, the language used on social media platforms often differs from that used in corporate reports. For example, while the social keyword list of Baier, Berninger, and Kiesel (2020) includes the word "social," it does not include the expressions "socialgood" (our list excludes the word "social" since it is mostly used to refer to social media platforms). Moreover, social media users tend to use abbreviations which are not found in corporate reports (for example "exec" is short for "executives"). Second, while Baier, Berninger, and Kiesel (2020) consider only uni-grams, we also include bi-grams in our keyword lists. This enables us to better capture the meaning of words according to their context. For example, the word "power" is not only used to describe a source of energy, but also to describe the power of certain people and companies. We therefore exclude the word "power" from our keyword lists, but include, for example, the bi-gram "solar power." Similarly, the word "green" is mostly used in the context of profits and investment returns, and we therefore exclude it from the environmental keyword list. We instead include the bi-grams "green energy" and "green living."
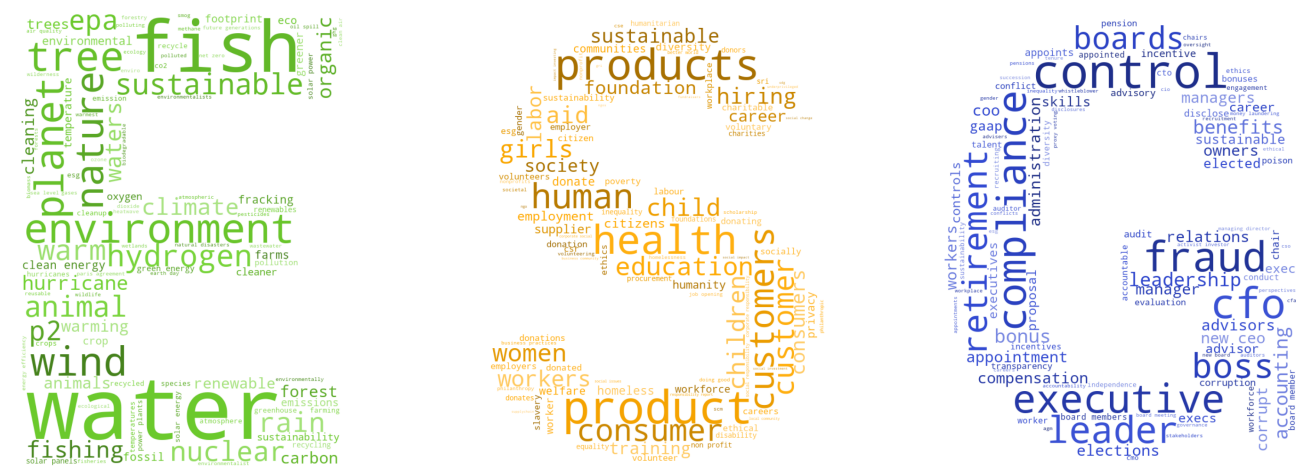

Figure 3: Graphical representation of the ESG-related keyword lists

\subsection{Index construction}

We construct three sentiment indices by selecting all StockTwits messages that contain an unior bi-gram from each of the environmental, social, and governance keyword lists. The message 
data is initially cleaned by removing URLs, cashtags, references to other users, un-escape HTML escape codes, punctuation and stop-words. We then select all messages that mention at least one of the keywords reported in Table A1. For example, we define the corpus of environmental messages by collecting all posts that mention one of the keywords in Panel A of Table A1. We obtain three corpora of environmental, social, and governance messages. These may intersect, since one message can be assigned to more than one component. In total we collect $8,266,391$ ESG-related messages, of which 469,908 messages belong to two components and 83,998 to three components. 1,743,576 messages mention one of the environmental keywords, 3,191,357 mention social keywords, and 3,969,362 mention a governance keyword.

Note that the volume of messages in each category is not necessarily reflective of the underlying interest in each topic. Indeed, in our process of developing the keyword list using Twitter and StockTwits, we observed that on Twitter people discuss environmental issues far more often than social or governance topics, whereas on StockTwits we observe the opposite. Intuitively this may be explained by environmental issues being a more global phenomenon, not always related to specific firms, whereas social and governance issues, such as having a corrupt CEO or mis-treating employees, are directly related to companies. Figure 4 displays a proxy for the "relevance" of each of the E, S, and G topics. Our measure of topic relevance is defined as the share of $\mathrm{E} / \mathrm{S} / \mathrm{G}$ messages, where each component is weighted by how much it is discussed on StockTwits, relative to its sample average. The figure indicates a comparable level of interest amongst the individual ESG components. Note for example that social issues were discussed more intensely during the initial stages of the COVID-19 pandemic (Spring 2020) compared to environmental or governance topics. Moreover, clear spikes in environmental relevance are visible throughout, most prominently around the oil spill of Deepwater Horizon (2010) and around hurricane Irma (2017).

Next, we classify all selected messages as having either a positive or negative sentimental connotation. We use a StockTwits feature that allows users to label their messages (and replies to other messages) as being either "bullish" or "bearish." Because not all messages have been labeled by users, we train a penalized logistic regression using all labeled messages. Appendix $\mathrm{B}$ offers a detailed description of the data preparation and the estimation of the classification model. ${ }^{3}$ Using the trained model, we classify all unlabeled messages as being either "bullish" or

\footnotetext{
${ }^{3}$ The classification accuracy of our model over a test set is $79.05 \%$, which is in line with that of other related studies (e.g. Cookson and Niessner, 2020; Renault, 2017). Moreover, we obtain a similar classification accuracy when using support vector machines and a naive Bayes classifier.
} 


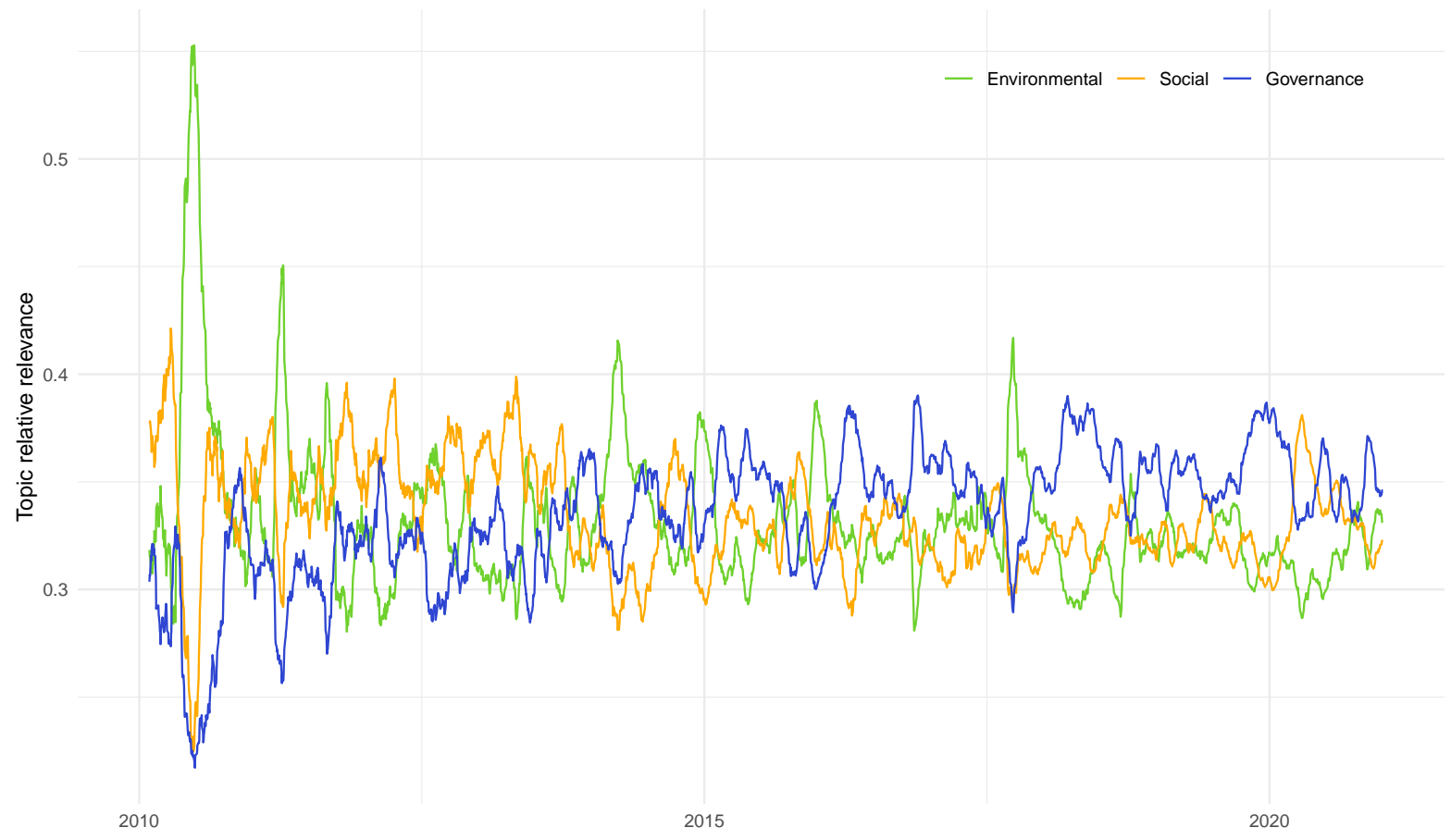

Figure 4: Relevance of environmental, social, and governance topics over time.

"bearish." We define the sentiment score of the $i$ th message shared on day $t$ as $S_{i, t} \in\{-1,1\}$, where 1 stands for "bullish" and -1 for "bearish."

Finally, for each of the three ESG components, we aggregate the identified messages to a daily sentiment score, denoted by $\operatorname{ISS}_{t}^{\mathrm{E}}, \mathrm{ISS}_{t}^{\mathrm{G}}, \mathrm{ISS}_{t}^{\mathrm{S}}$. Following, among others, Antweiler and Frank (2004), we aggregate the classified messages belonging to the environmental corpus to a daily sentiment score as follows:

$$
\mathrm{ISS}_{t}^{\mathrm{E}}=\frac{\mathrm{NumE}_{t}^{\text {Bull }}-\mathrm{NumE}_{t}^{\text {Bear }}}{\mathrm{NumE}_{t}^{\text {Bull }}+\mathrm{NumE}_{t}^{\text {Bear }}}
$$

where $\mathrm{NumE}_{t}{ }^{\mathrm{Bull}}$ and $\mathrm{NumE}_{t}{ }^{\mathrm{Bear}}$ are, respectively, the total number of bullish and bearish messages shared on day $t$ about environmental issues. The daily sentiment score $\operatorname{ISS}_{t}^{\mathrm{E}}$ can be interpreted as the difference between the share of bullish and bearish messages shared about environmental issues. For example, when $60 \%$ of the environmental-related messages have a positive sentiment connotation and $40 \%$ a negative one, the sentiment score is $0.2\left(\operatorname{ISS}_{t}^{\mathrm{E}}=\right.$ $0.6-0.4)$. The sentiment scores for the social and governance components, that is $\operatorname{ISS}_{t}^{S}$ and $\mathrm{ISS}_{t}^{\mathrm{G}}$, are defined analogously to Equation (1). Finally, we define the overall Investor Sentiment 
for Sustainability $\left(\mathrm{ISS}_{t}\right)$ index as the average of the three indices defined above, that is:

$$
\mathrm{ISS}_{t}=\frac{\mathrm{ISS}_{t}^{\mathrm{E}}+\mathrm{ISS}_{t}^{\mathrm{S}}+\mathrm{ISS}_{t}^{\mathrm{G}}}{3}
$$

Note that, one could define $\operatorname{ISS}_{t}$ directly analogous to Equation (1) by using all classified messages. However, this could be problematic since the total number of collected messages varies greatly between the three components. For example, we collect roughly 3.9 million messages that mention a governance-related keyword, but only 1.7 million messages about environmental issues. These differences are not necessarily related to the fact that investors care more or less about specific topics. It might be related, for instance, to the fact that the list of governance keywords is longer than that of environmental keywords. Nevertheless, in our main empirical analysis in Section 4 we also consider an alternative weighting scheme that assigns more weight to the components that are intensively discussed on StockTwits. Our main findings are not affected by the choice of the aggregation approach used to define $\operatorname{ISS}_{t}$.

Besides measuring sustainability specific sentiment, we also define a market-wide global social media sentiment index. To this end, we use the random corpus of StockTwits messages introduced in Section 2.2 and follow the same approach as for the Investor Sentiment for Sustainability indices by aggregating the random messages to a daily sentiment index, hereafter referred to as SentGlob.

\subsection{Other data}

Firm data. Our sample of selected StockTwits messages goes from January 1, 2010 to December 31, 2020. For traded US companies, we obtain information about daily stock prices and trading volume from CRSP, and balance sheet data from Compustat. We obtain the three Fama-French factors (Fama and French, 1993) and the momentum factor of Carhart (1997) from Kenneth French's website. ${ }^{4}$ We include in our dataset the daily log CBOE Volatility index (VIX for short). The following variables calculated for each stock will be used throughout the paper. The return (in percent) is the daily log return in excess of the risk-free rate (one-month Treasury bill rate). The log market capitalization is computed as the daily market value of outstanding shares. The book-to-market value is computed following Fama and French (2008). A stock's "beta" is obtained by regressing each month its excess daily return on the excess market return.

\footnotetext{
${ }^{4}$ http://mba.tuck.dartmouth.edu/pages/faculty/ken.french/data_library.html
} 
Following Ang, Hodrick, Xing, and Zhang (2006), the idiosyncratic volatility is defined as the monthly standard deviation of the residuals of the aforementioned regression. Following Amihud (2002), we define the illiquidity of a stock as the monthly average of the ratio between daily absolute returns and the dollar trading volume. For better readability, we multiply the illiquidity measure by $10^{7}$. Finally, we define a stock's turnover (in percent) as the trading volume divided by the total number of outstanding shares.

Sustainability ratings. Sustainability ratings are evaluations of a company based on a comparative assessment of their quality and performance with respect to environmental, social or governance issues. With the use of these ratings in investment practice considerably increasing, so has the number of ESG rating providers. Given the complexity of developing an objective measure of a firm's non-financial sustainability related performance, the validity of and disagreement among these ratings has been documented critically in the recent literature (Berg, Koelbel, and Rigobon, 2020; Brandon, Krueger, and Schmidt, 2021; Christensen, Serafaim, and Sikochi, 2021). We use ESG ratings from MSCI to capture the market view of sustainability of individual firms. Our primary reason for this choice of ratings provider is that MSCI ratings are one of the most widely used by the investment community and are often considered an "industry standard" for sustainability ratings. Indeed, according to documentation provided by MSCI, $90 \%$ of the largest asset managers as well as over 12'000 investment companies use MSCI ESG ratings. Moreover, our purpose in this paper is to understand investor sentiment towards sustainability, captured in terms of ratings, rather than the quality of a given rating. MSCI being widely known, accessible, and used in the investment community is therefore of importance in our context.

MSCI defines 37 key issues covering themes related to sustainability and then aggregates the key issue data into an overall score in which each issue is weighted according to its assessed materiality in each industry. Because ESG issues tend to vary systematically among industries, scores are adjusted with respect to industry. For each company, we have an industry-adjusted ESG score that ranges from 0 to 10 , with 0 being the lowest possible overall sustainability performance. We match the ratings with the CRSP dataset as follows. First, we select from the CRSP dataset all stocks traded on the NYSE, NASDAQ, or AMEX with security code 10 or 11. We then match the CRSP dataset with the ESG ratings using CUSIP codes. Finally, we match the CRSP dataset with the Compustat dataset. The ESG ratings at our disposal 
cover the time period from January 2008 to December 2020. Nevertheless, to match these data with our sentiment indices, we consider stocks with a MSCI ESG rating from January 2010 to December 2020. For this time period we match 2,970 companies from the CRSP dataset.

Mutual fund data. We obtain sustainability ratings for US mutual funds from Morningstar. Our reason for this choice is motivated by the study of Hartzmark and Sussman (2019), which documents a causal relation between Morningstar's sustainability rating and mutual fund flows. The sample covers the time period from August 2018 to December 2020. Morningstar categorizes mutual funds based on the sustainability of their investments int low, below average, average, above average, and high. We obtain monthly market data for US mutual funds from the CRSP Mutual Fund Database. We match the sustainability ratings and the CRSP Mutual Fund Database using ISIN codes. We then remove all mutual funds which are not open-ended. Our final sample covers 2,428 US mutual funds.

Investor attention. We measure investor attention using Google Trends data. Google provides relative search volumes for a keyword or specific topic. Following the pioneering work of Da, Engelberg, and Gao (2011), several studies have used this data to proxy for investor attention. In a recent study tangentially related to our paper, Choi, Gao, and Jiang (2020) proxy for investor attention to global warming by using Google Trends data for the topic "global warming." We follow their approach and construct measures of investor attention to environmental, social, and governance topics using the relative search volume for the topics "climate change," "social responsibility," and "corporate governance." Following Da, Engelberg, and Gao (2011), we define the attention measures as the natural logarithm of the ratio of the daily relative search volume and its average over the previous year. We denote these daily measures as AttE, AttS, and AttG. We define the attention to ESG topics in general (hereafter AttESG) as the average of these three attention measures.

News analytics. We measure ESG news sentiment using the RavenPack News Analytics database and follow the approach outlined in a white paper of RavenPack's research team. ${ }^{5}$ We collect all news articles published by Dow Jones Newswires, regional editions of the Wall Street Journal, Barron's, and MarketWatch that cover a topic related to environmental, social, or

\footnotetext{
${ }^{5}$ https ://www.ravenpack.com/research/msci-esg-ratings-sentiment/
} 
governance issues. ${ }^{6}$ The data covers the period from January 2010 to November 2020. For each article, RavenPack News Analytics provides an Event Sentiment Score (ESS) that ranges between 0 (negative news) and 100 (positive). We rescale ESS to range between -1 and +1 and define the daily ESG news sentiment as the average ESS of all ESG-related news articles published on that day. We also include the Media Climate Change Concern index introduced by Ardia, Bluteau, Boudt, and Inghelbrecht (2021), hereafter referred to as MCCC. Using articles about climate change published in eight major U.S. newspapers, Ardia, Bluteau, Boudt, and Inghelbrecht (2021) compute a daily score that captures the level of negativity, risk, and uncertainty discussed in each article. We follow their approach and include in our analysis the unexpected changes in climate change concerns by computing the residuals of an AR(1) estimated on MCCC, hereafter referred to as UMC. The index is available at the daily frequency from 2003 to mid-2018. ${ }^{7}$

Table 1 provides a summary and brief description of the main variables used in this paper.

\section{Properties of investor sentiment for sustainability}

In this section, we analyze our measure of investor sentiment for sustainability. First we, provide descriptive statistics that motivate our choice of orthogonalizing the sustainability sentiment indices with respect to the global market-wide sentiment index. Second, to understand what drives daily variations in sustainability sentiment, we analyze the social media activity of users in our sample. Second, we provide statistics about the type of investors discussing ESG-related topics on social media. Third, we investigate the relation of our index with market regimes. Finally, we examine potential drivers of sentiment for sustainability.

\subsection{Descriptive statistics}

We present some simple contemporaneous correlations among all of our sentiment indices. Table 2 reports in Panel A the Pearson correlation coefficients between ISS, ISS $^{\mathrm{E}}$, ISS ${ }^{\mathrm{S}}$, ISS ${ }^{\mathrm{G}}$, and SentGlob. The correlation coefficients between the sentiment measures of the three ESG components range between 0.50 and 0.62 . Each of the ESG sentiment indices are also highly correlated with the global sentiment index. This makes intuitive sense, as we expect the sustainability specific sentiment measures to be partially associated with general sentiment. For example, dur-

\footnotetext{
${ }^{6}$ The list of ESG-related topics was provided by RavenPack News Analytics and is available from the authors upon request.

${ }^{7}$ The data is available from the Sentometrics Research webpage (https://sentometrics-research.com/ download/mccc/).
} 
Table 1: Summary of the main variables

\begin{tabular}{|c|c|c|}
\hline Variable & Description & Availability \\
\hline ISS & $\begin{array}{l}\text { Investors' ESG sentiment computed using the sentiment of } \\
\text { ESG-related messages shared on StockTwits. ESG sentiment } \\
\text { is defined as the average of } \operatorname{ISS}^{\mathrm{E}}, \mathrm{ISS}^{\mathrm{S}} \text {, and ISS }{ }^{\mathrm{G}} \text {. }\end{array}$ & $2010-2020$ \\
\hline $\mathrm{ISS}^{\mathrm{E}}$ & $\begin{array}{l}\text { Investors' environmental sentiment computed using the senti- } \\
\text { ment of environmental-related messages shared on StockTwits. }\end{array}$ & $2010-2020$ \\
\hline ISS $^{\mathrm{S}}$ & $\begin{array}{l}\text { Investors' social sentiment computed using the sentiment of } \\
\text { social-related messages shared on StockTwits. }\end{array}$ & $2010-2020$ \\
\hline $\mathrm{ISS}^{\mathrm{G}}$ & $\begin{array}{l}\text { Investors' governance sentiment computed using the sentiment } \\
\text { of governance-related messages shared on StockTwits. }\end{array}$ & $2010-2020$ \\
\hline SentGlob & $\begin{array}{l}\text { Global market-wide investors' sentiment computed using the } \\
\text { sentiment of user-labeled messages shared on StockTwits. }\end{array}$ & $2010-2020$ \\
\hline AttE & $\begin{array}{l}\text { The log of the ratio between the daily relative Google search } \\
\text { volume about the topic "climate change" and its average over } \\
\text { the previous year. }\end{array}$ & $2010-2020$ \\
\hline AttS & $\begin{array}{l}\text { The log of the ratio between the daily relative Google search } \\
\text { volume about the topic "social responsibility" and its average } \\
\text { over the previous year. }\end{array}$ & $2010-2020$ \\
\hline AttG & $\begin{array}{l}\text { The log of the ratio between the daily relative Google search } \\
\text { volume about the topic "corporate governance" and its average } \\
\text { over the previous year. }\end{array}$ & $2010-2020$ \\
\hline AttESG & The daily average of AttE, AttS, and AttG. & $2010-2020$ \\
\hline ESG news sentiment & $\begin{array}{l}\text { Daily sentiment of ESG-related news articles constructed us- } \\
\text { ing data and sentiment scores provided by RavenPack News } \\
\text { Anaylitcs. }\end{array}$ & 2010 - Nov. 2020 \\
\hline $\mathrm{UMC}$ & $\begin{array}{l}\text { Residuals of an AR(1) estimated on the Media Climate Change } \\
\text { Concern Index introduced by Ardia, Bluteau, Boudt, and In- } \\
\text { ghelbrecht (2021). }\end{array}$ & 2010 - June 2018 \\
\hline Market return & The CRSP value-weighted daily market return. & $2010-2020$ \\
\hline Log VIX & The natural logarithm of the daily CBOE Volatility Index. & $2010-2020$ \\
\hline
\end{tabular}

Note: The table provides a summary and descriptions of the main variables used in this study.

ing market upturns we expect investors to feel generally more bullish (Kumar and Lee, 2006). More importantly, even though we carefully selected the ESG-specific keywords, we most likely include messages that are not related to environmental, social, or governance topics. To address this effect, we disentangle investor sustainability sentiment from other sentiment confounders by orthogonalizing ISS, ISS ${ }^{\mathrm{E}}$, ISS $^{\mathrm{S}}$, and ISS $^{\mathrm{G}}$ with respect to the general sentiment index SentGlob. More precisely, we regress each of the sustainability sentiment indices on SentGlob and define their orthogonalized versions as the residuals of this regression. For the remainder of this paper, all reported results are obtained using the orthogonalized sentiment indices. For the sake of simplicity, we will refer to the orthogonalized indices with the same variable names, i.e. ISS, ISS $^{\mathrm{E}}, \mathrm{ISS}^{\mathrm{S}}$, ISS ${ }^{\mathrm{G}}$, and SentGlob. The correlations between the orthogonalized sentiment indices are reported in Panel B of Table 2. The correlation coefficients between the orthogonalized sentiment measures of the three ESG components are smaller but still positive and range between 0.18 and 0.34 . 
Table 2: Correlation between the sentiment indices

\begin{tabular}{lccccc}
\hline \multicolumn{2}{l}{ Panel A: Correlation between the raw sentiment indices } & & & \\
\hline & $(1)$ & $(2)$ & $(3)$ & $(4)$ & $(5)$ \\
\cline { 2 - 6 } & 1.00 & 0.82 & 0.87 & 0.83 & 0.77 \\
$\operatorname{ISS}_{t}(1)$ & & 1.00 & 0.56 & 0.50 & 0.63 \\
$\operatorname{ISS}_{t}^{\mathrm{E}}(2)$ & & 1.00 & 0.62 & 0.68 \\
$\operatorname{ISS}_{t}^{\mathrm{S}}(3)$ & & & 1.00 & 0.63 \\
$\operatorname{ISS}_{t}^{\mathrm{G}}(4)$ & & & & 1.00 \\
SentGlob $_{t}(5)$ & & & & \\
\hline
\end{tabular}

Panel B: Correlation between the orthogonalized sentiment indices

\begin{tabular}{lccccc}
\hline & $(1)$ & $(2)$ & $(3)$ & $(4)$ & $(5)$ \\
\cline { 2 - 6 } & 1.00 & 0.67 & 0.74 & 0.70 & 0.00 \\
$\operatorname{ISS}_{t}(1)$ & & 1.00 & 0.23 & 0.18 & 0.00 \\
$\operatorname{ISS}_{t}^{\mathrm{E}}(2)$ & & 1.00 & 0.34 & 0.00 \\
$\operatorname{ISS}_{t}^{\mathrm{S}}(3)$ & & & 1.00 & 0.00 \\
$\operatorname{ISS}_{t}^{\mathrm{G}}(4)$ & & & & 1.00 \\
SentGlob $_{t}(5)$ & & & & &
\end{tabular}

Note: The table reports the Pearson correlation coefficients between the ESG, environmental, social, and governance sentiment indices and the market-wide sentiment measure SentGlob. Panel A reports the correlations for the raw, and Panel B for the orthogonalized ESG, environmental, social, and governance sentiment indices.

Table 3 reports detailed summary statistics for $\operatorname{ISS}_{t}, \operatorname{ISS}_{t}^{\mathrm{E}}, \operatorname{ISS}_{t}^{\mathrm{S}}$, and $\operatorname{ISS}_{t}^{\mathrm{G}}$ (recall that from now onwards we consider only the orthogonalized sentiment indices). Panel A shows the three quartiles, the mean, standard deviation, skewness, and kurtosis. Due to the orthogonalization, all four sentiment indices have mean zero. Moreover, they are all left-skewed. Panel B reports for $\mathrm{ISS}_{t}, \mathrm{ISS}_{t}^{\mathrm{E}}, \mathrm{ISS}_{t}^{\mathrm{S}}$, and $\mathrm{ISS}_{t}^{\mathrm{G}}$ the first six autocorrelations and the test statistic of an augmented Dickey-Fuller $(1979 ; 1981)$ test. $^{8}$ The four sentiment time series are persistent. For example, the autocorrelation at the sixth lag ranges between 0.12 and 0.26 . However, we can reject the null hypothesis of a unit-root at the $1 \%$ significance level for all four sentiment indices.

Figure 5 plots the main sentiment indices analyzed in this study. The time series of ISS $_{t}$, $\mathrm{ISS}_{t}^{\mathrm{E}}, \mathrm{ISS}_{t}^{\mathrm{S}}$, and $\mathrm{ISS}_{t}^{\mathrm{G}}$ are depicted in the upper panel of Figure 5. The lower panel of Figure 5 depicts the global sentiment index SentGlob ${ }_{t}$. For better readability, we plot the one-month moving average of each sentiment measure. The figure also highlights four events that have had an effect on the sentiment indices. For example, most recently the sentiment of all three ESG components decreased significantly at the beginning of the COVID-19 pandemic, but quickly recovered during the second half of 2020. While during the UN Climate Change Conference of $2010 \mathrm{ISS}_{t}^{\mathrm{E}}$ peaked, we observe a negative environmental sentiment during the UN Climate Change Conference of 2013. During the former, the states' parties agreed upon the establishment

\footnotetext{
${ }^{8}$ The augmented Dickey-Fuller test includes a drift and the number of augmentations is determined by the Bayesian information criterion.
} 


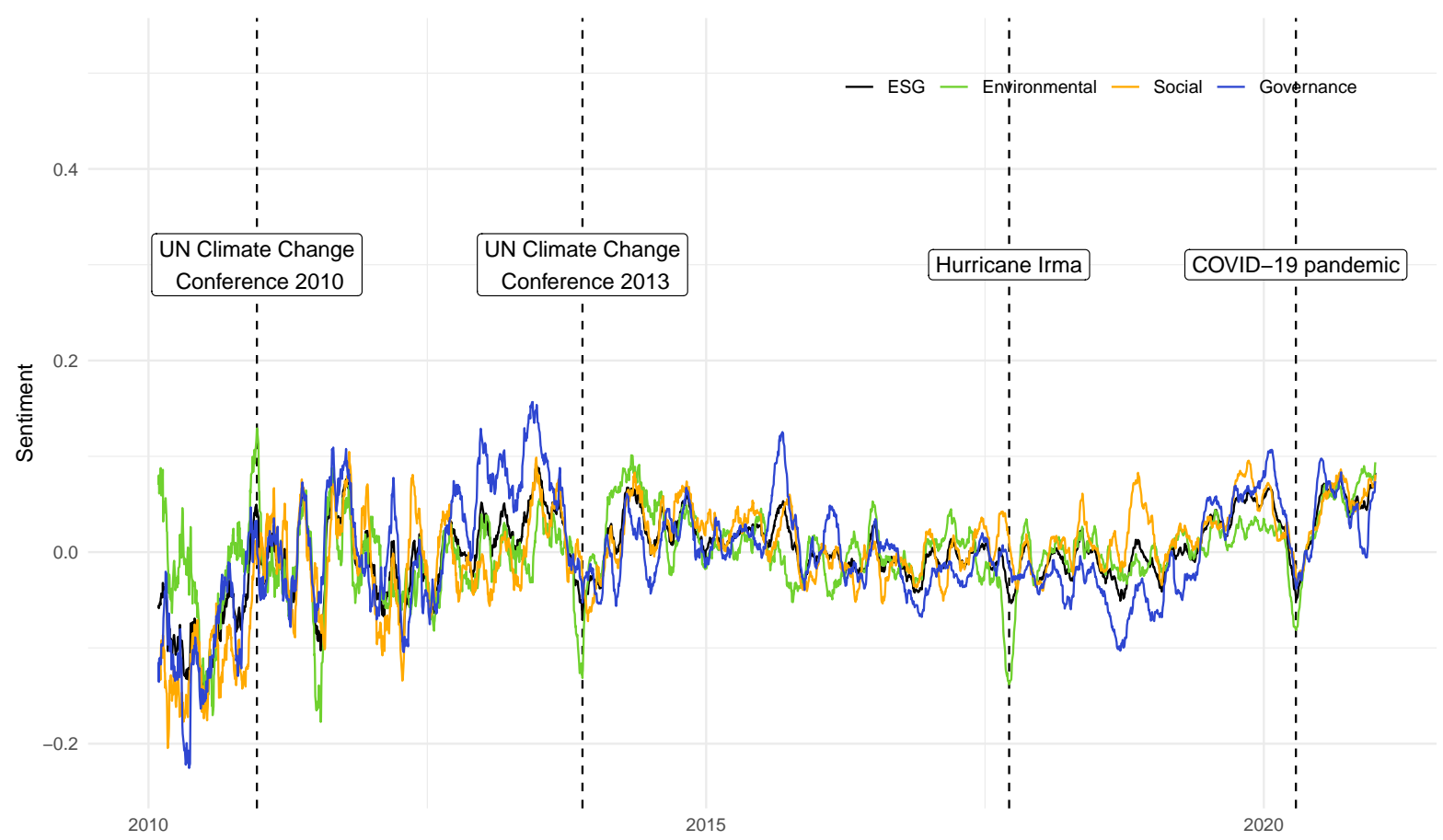

(a) Environmental, social, governance, and ESG sentiment indices

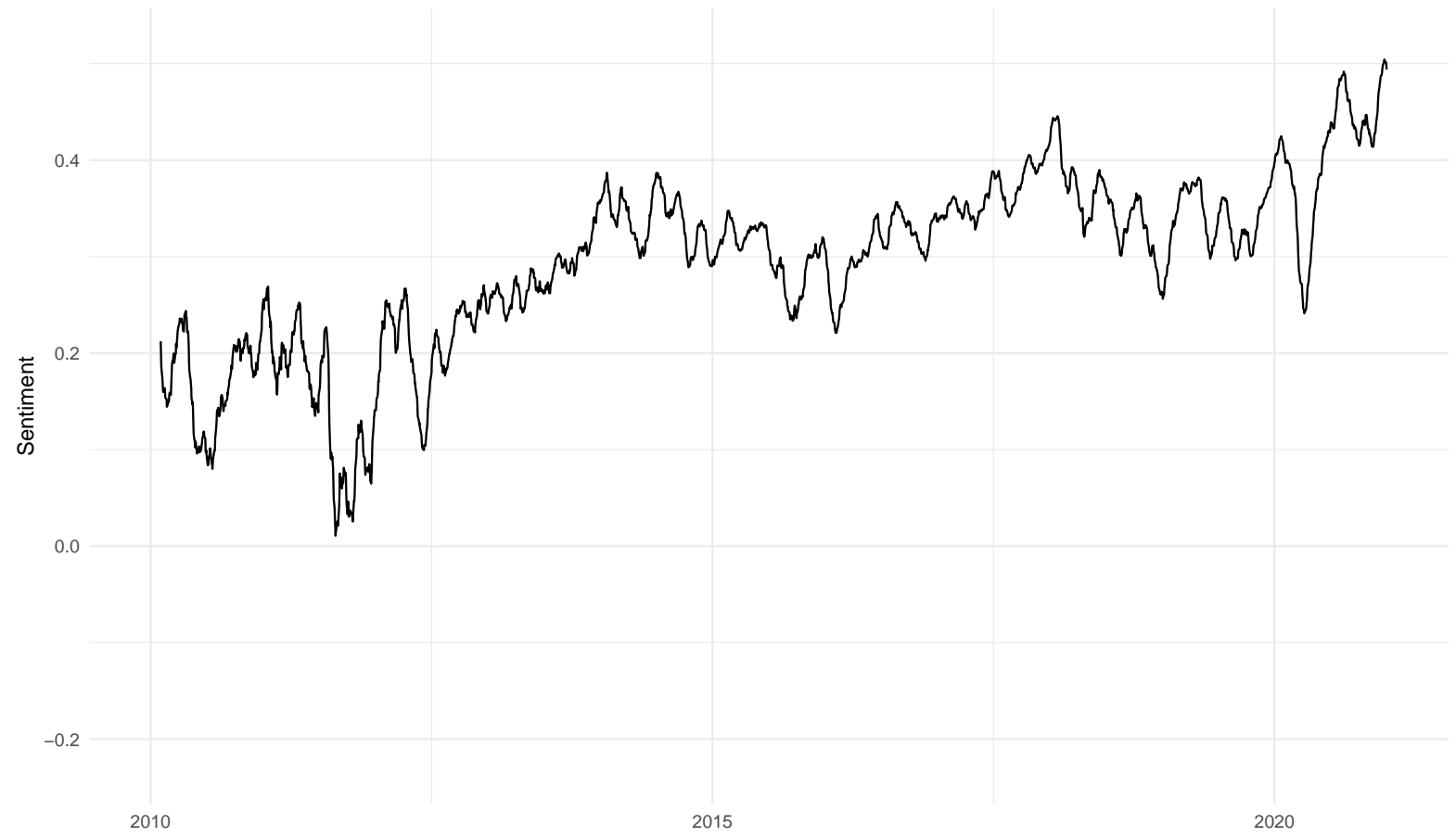

(b) Global market-wide sentiment index

Figure 5: Moving average of environmental, social, governance, ESG, and global sentiment indices

Note: The figure depicts in the upper panel the time series of $\operatorname{ISS}_{t}, \operatorname{ISS}_{t}^{\mathrm{E}}, \operatorname{ISS}_{t}^{\mathrm{S}}$, and $\operatorname{ISS}_{t}^{\mathrm{G}}$ (orthogonalized). The lower panel depicts the global social media sentiment measure SentGlob ${ }_{t}$. For better readability, we plot the one-month moving average of each sentiment measure. 
Table 3: Summary statistics of the sustainability sentiment indices

\begin{tabular}{|c|c|c|c|c|c|c|c|}
\hline \multicolumn{8}{|c|}{ Panel A: Distribution of the sentiment indexes } \\
\hline & $Q_{25 \%}$ & $Q_{50 \%}$ & $Q_{75 \%}$ & Mean & Std. & Skewness & Kurtosis \\
\hline $\mathrm{ISS}_{t}$ & -0.03 & 0.00 & 0.05 & 0.00 & 0.08 & -0.91 & 6.87 \\
\hline $\mathrm{ISS}_{t}^{\mathrm{E}}$ & -0.05 & 0.01 & 0.06 & 0.00 & 0.11 & -0.82 & 8.27 \\
\hline $\mathrm{ISS}_{t}^{\mathrm{S}}$ & -0.04 & 0.01 & 0.06 & 0.00 & 0.11 & -1.05 & 8.07 \\
\hline $\mathrm{ISS}_{t}^{\mathrm{G}}$ & -0.05 & 0.00 & 0.06 & 0.00 & 0.11 & -0.79 & 7.56 \\
\hline \multicolumn{8}{|c|}{ Panel B: Time dependence in the sentiment indexes } \\
\hline & $\mathrm{ACF}(1)$ & $\mathrm{ACF}(2)$ & $\mathrm{ACF}(3)$ & $\mathrm{ACF}(4)$ & $\mathrm{ACF}(5)$ & $\operatorname{ACF}(6)$ & ADF-Test \\
\hline $\mathrm{ISS}_{t}$ & 0.34 & 0.30 & 0.28 & 0.28 & 0.26 & 0.24 & $-24.37^{c}$ \\
\hline $\mathrm{ISS}_{t}^{\mathrm{E}}$ & 0.15 & 0.16 & 0.13 & 0.13 & 0.09 & 0.12 & $-29.81^{c}$ \\
\hline $\mathrm{ISS}_{t}^{\mathrm{S}}$ & 0.28 & 0.23 & 0.20 & 0.23 & 0.19 & 0.14 & $-26.87^{c}$ \\
\hline $\mathrm{ISS}_{t}^{\mathrm{G}}$ & 0.37 & 0.28 & 0.28 & 0.26 & 0.27 & 0.26 & $-24.83^{c}$ \\
\hline \multicolumn{8}{|c|}{$\begin{array}{l}\text { Note: The table reports summary statistics for } \operatorname{ISS}_{t}, \mathrm{ISS}_{t}^{\mathrm{E}}, \mathrm{ISS}_{t}^{\mathrm{S}} \text {, and } \mathrm{ISS}_{t}^{\mathrm{G}} \text {. Panel A depicts the } 25 \%, 50 \% \text {, and } \\
75 \% \text { quantiles, the mean, standard deviation, skewness, and kurtosis of the sentiment indexes. Panel B reports the } \\
\text { autocorrelation functions for lags } 1, \ldots, 6 \text {, and the augmented Dickey-Fuller test statistic (ADF-Test). The ADF-Test } \\
\text { includes a constant and the number of augmentations is determined with the Bayesian Information Criterion. Test statistics } \\
\text { for which we can reject the null-hypothesis of a unit root at the } 1 \%, 5 \% \text {, and } 10 \% \text { level are indicated respectively by the } \\
\text { superscripts } c, b \text {, and } a \text {. }\end{array}$} \\
\hline
\end{tabular}

of the Green Climate Fund. Developed countries advocated for a found that uses a wide range of financial instruments. Investors might have interpreted this as good news for the stock market and felt more bullish about environmental-friendly investments. Finally, we observe a decrease in investors environmental sentiment in September 2017 when hurricane Irma developed and moved towards the Caribbean Sea. Note that the highlighted events focus on the environmental ESG component as it is easier to draw connections between environmental-events and $\operatorname{ISS}_{t}^{\mathrm{E}}$. By manually analyzing messages about governance and social issues on days where $\operatorname{ISS}_{t}^{\mathrm{G}}$ and $\operatorname{ISS}_{t}^{\mathrm{S}}$ peaked, we find that shifts in these sentiment indices are generally related to firm-specific events rather than more general news.

\subsubsection{User activity}

The reader might be wondering if the daily variation in our sentiment index stems primarily from tweets of new users, rather than investors updating their opinion about ESG. This is, however, only partially the case. In fact, roughly $70 \%$ of the authors of the ESG-related messages in our sample shared at least two sustainability tweets. In Table 4, we further analyze the social media activity of users that discuss ESG-related topics on StockTwits. More precisely, the first row reports summary statistics for the number of ESG-related messages shared by each users. The second line reports summary statistics for the number of days between two ESG-related 
messages shared by the same user, and the last row reports instead summary statistics for the share of sustainability tweets with a different sentimental connotation compared to the previous ESG-related message shared by the same user. The statistics reported in the second and third row are computed only for users that shared at least two messages about ESG-related topics on StockTwits.

Table 4: User activity, change in sentiment and time between ESG tweets

\begin{tabular}{lrrrrr}
\hline & $Q_{25 \%}$ & $Q_{50 \%}$ & $Q_{75 \%}$ & Mean & Std. \\
\cline { 2 - 6 } Number of tweets & 3.00 & 7.00 & 20.00 & 33.62 & 623.32 \\
Days between tweets & 3.91 & 14.77 & 49.00 & 56.62 & 138.76 \\
Sentiment change (in \%) & 0.00 & 27.08 & 48.61 & 29.97 & 29.47 \\
\hline
\end{tabular}

Note: The table reports summary statistics for StockTwits users that shared ESG-related messages on StockTwits. More precisely, the first row reports summary statistics for the number of ESG-related messages shared by each users. The second line reports summary statistics for the number of days between two ESG-related messages shared by the same user. The last row reports instead summary statistics for the share of ESG tweets with a different sentimental connotation compared to the previous ESG message shared by a user. The statistics reported in the second and third row are computed only for users that shared at least two messages about ESG-related topics on StockTwits.

Table 4 shows that $75 \%$ of the users that shared ESG-related messages posted at least three tweets about sustainability. On average, a user shares a message about sustainability every two months. Moreover, on average $30 \%$ of the times a user shares an ESG-related tweet, he/she changes his/her opinion, i.e. the message has a different sentiment. As an additional robustness check, we create a measure of investor sentiment for sustainability based on a fixed sample of users. More precisely, we consider only messages published by users that shared at least one ESGrelated message before 2016. We compare this index with our ISS $_{t}$ index (both orthogonalized with respect to the global market-wide sentiment measure). Over the time period 2016-2020 the correlation between the two indices is 0.65 . In other words, most of the variation in sustainability sentiment comes from existing users "updating" their opinion about sustainability. In Section 4, we carry out further robustness tests of our asset pricing application with respect to the sentiment index constructed from a fixed sample of users.

\subsection{Investor profiles}

In Table 5, we analyze the profile of investors that tend to discuss sustainability-related topics on StockTwits. Recall that StockTwits users classify themselves on the platform according to their trading experience, trading approach, and holding period. We consider all users that shared at least one message from the random sample of StockTwits messages introduced in Section 2. For 
each of the 1,065,161 users, we collect all messages they posted on StockTwits between 2010 and 2020. When at least $10 \%$ of a user's messages mention one of the ESG-related keywords listed in Table A1, we define her/him as an ESG user. ${ }^{9}$ The first three rows of Table 5 report the proportion of ESG users as well as the proportion of users from the random sample that classify themselves as being novice, intermediate, or professional traders. Similarly, the remainder of the table reports the proportion of ESG users and proportion of users from the random sample that follow a certain trading strategy and have a certain holding period for their investments. The last column of Table 5 reports the test statistic of a two-sample proportion test for the null hypothesis that the proportion of ESG users with a specific characteristic equals that in the random sample of users. The results indicate that among the ESG users, we find proportionally more (self-reported) professional investors, investors that follow a fundamental, value, or growth strategy, and investors with a long-term investment horizon. The differences in the proportions are all highly significant (at $1 \%$ level). The proportion of technical and momentum investors with a short-term horizon is instead significantly lower in the sample of ESG-users.

Table 5: Characteristics of StockTwits users

\begin{tabular}{|c|c|c|c|c|}
\hline & & $\begin{array}{c}\text { Proportion ESG } \\
\text { users }\end{array}$ & $\begin{array}{l}\text { Proportion } \\
\text { random users }\end{array}$ & Test statistic \\
\hline \multirow[t]{4}{*}{ Trading experience } & Novice & $28.24 \%$ & $33.41 \%$ & $-9.17^{c}$ \\
\hline & Intermediate & $38.68 \%$ & $41.76 \%$ & $-5.22^{c}$ \\
\hline & Professional & $33.08 \%$ & $24.82 \%$ & $15.85^{c}$ \\
\hline & Total number of users & 7,368 & 126,059 & \\
\hline \multirow[t]{7}{*}{ Trading approach } & Fundamental & $16.33 \%$ & $12.37 \%$ & $9.81^{c}$ \\
\hline & Value & $13.27 \%$ & $9.97 \%$ & $8.98^{c}$ \\
\hline & Growth & $21.34 \%$ & $18.06 \%$ & $6.97^{c}$ \\
\hline & Momentum & $13.66 \%$ & $18.05 \%$ & $-9.41^{c}$ \\
\hline & Technical & $28.83 \%$ & $37.29 \%$ & $-14.39^{c}$ \\
\hline & Global Macro & $6.57 \%$ & $4.27 \%$ & $9.18^{c}$ \\
\hline & Total number of users & 7,128 & 123,440 & \\
\hline \multirow[t]{5}{*}{ Holding period } & Day Trader & $20.38 \%$ & $23.71 \%$ & $-6.48^{c}$ \\
\hline & Swing Trader & $26.95 \%$ & $37.49 \%$ & $-18.01^{c}$ \\
\hline & Position Trader & $19.78 \%$ & $17.81 \%$ & $4.22^{c}$ \\
\hline & Long Term Investor & $32.90 \%$ & $20.99 \%$ & $23.85^{c}$ \\
\hline & Total number of users & 7,180 & 126,833 & \\
\hline
\end{tabular}

Note: The table depicts the proportion of StockTwits users with a specific characteristic. The table compares the proportions between users messaging about ESG topics and a random sample of users. The sample users is created by selecting all users that shared a message in a $10 \%$ random sample of messages posted on StockTwits between 2010 and 2020. When $10 \%$ of a user's posted messages are related to ESG topics, we define her or him as being an ESG user. The last column reports test statistics of a two-sample proportion test for the null hypothesis that the proportion of ESG users with a specific characteristic equals that in the random sample of users. The superscripts $a, b$, and $c$ indicate respectively significance at the $10 \%, 5 \%$, and $1 \%$ level.

\footnotetext{
${ }^{9}$ The minimum threshold of $10 \%$ is arbitrary. However, unreported robustness checks show that when we increase the $10 \%$ threshold, the difference between ESG users and random StockTwits users reported in Table 5 become even larger.
} 


\subsection{Market regimes}

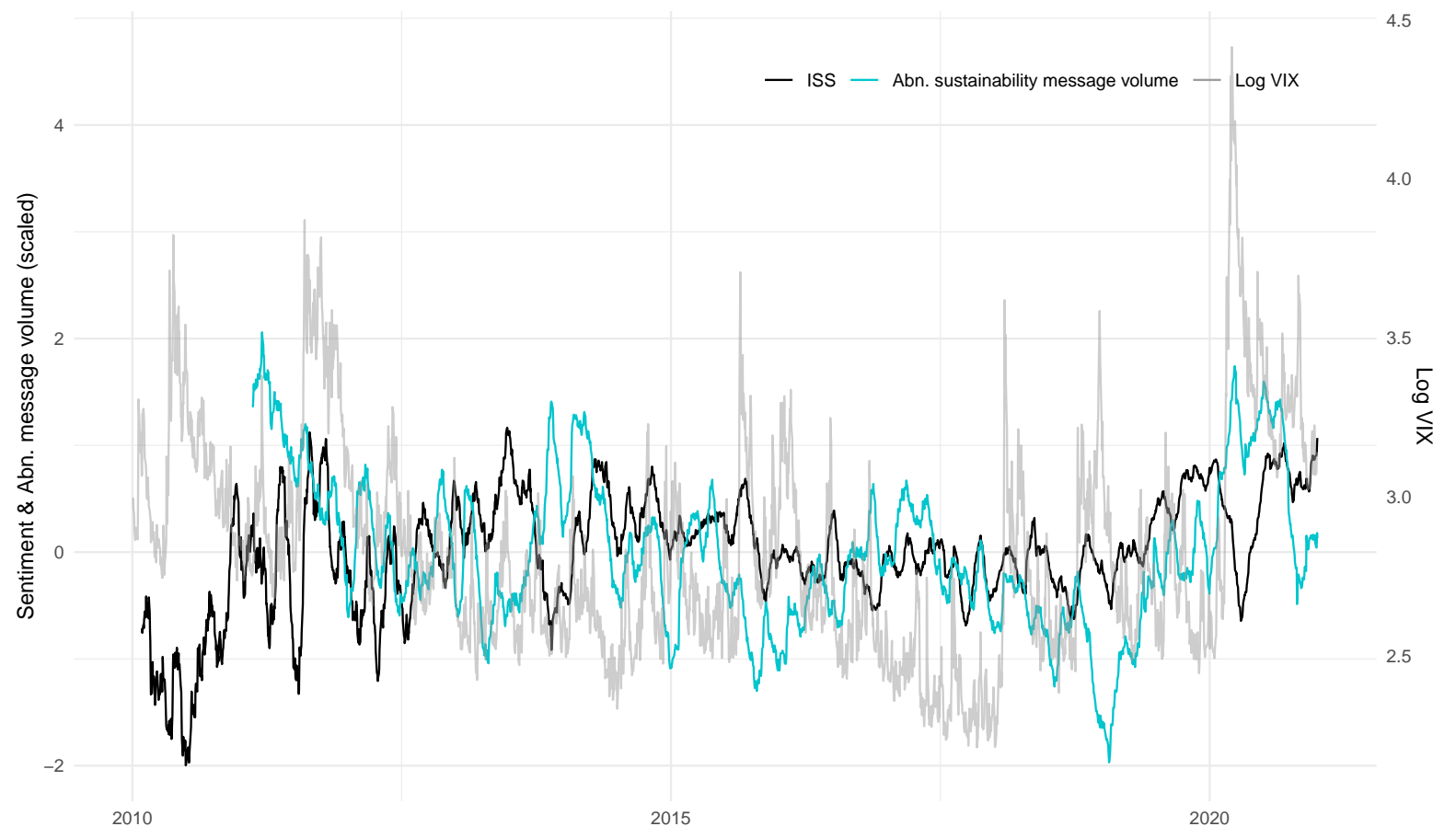

Figure 6: Sustainability sentiment, social media message volume, and the VIX index

Noте: The figure depicts in investor sentiment for sustainability, the abnormal message volume about sustainability on StockTwits, and the log VIX index. We define the abnormal message volume as the natural logarithm of the ratio between the daily volume of messages shared on StockTwits about sustainability and its average over the previous year. The sentiment and abnormal message volume are scaled to have zero mean and unit standard deviation.

We next examine the relationship between investor sentiment for sustainability and volatility regimes. General market sentiment is known to be negatively associated with high volatility regimes (Baker and Wurgler, 2007; Barberis, Shleifer, and Vishny, 1998), and we ask whether sentiment for sustainability follows the same pattern. That said there is mounting evidence of a positive association between measures of risk and measures of sustainability, which may influence investor sentiment for sustainability in periods of high volatility. Indeed, a growing body of work suggests that sustainability information is linked to risk measures. In a theoretical setting, Heinkel, Kraus, and Zechner (2001) discuss that polluting firms carry greater systematic risk. Albuquerque, Koskinen, and Zhang (2018) show both theoretically and empirically that firms with high ESG ratings are less exposed to systemic risks. Goldberg and Mouti (2019) focus on downside risk and ESG ratings and find mixed evidence, while controlling for multiple stock characteristics, such as realized historical volatility. Dunn, Fitzgibbons, and Pomorski (2017) empirically assess total and stock-specific risk indicators of different ESG profiles and conclude that ESG ratings are negatively linked to levels of risk. Moreover, the relationship 
between sustainability and risk has been shown to be more pronounced during during crises (Albuquerque, Koskinen, and Zhang, 2018; Ding, Levine, Lin, and Xie, 2020; Dunn, Fitzgibbons, and Pomorski, 2017; Goldberg and Mouti, 2019). More specifically, recent studies have revealed that both financial and non-financial companies with high ESG ratings have been more resilient in times of crises. For example, Cornett, Erhemjamts, and Tehranian (2016) show that U.S. banks' financial performance during the Great Recession is positively related to their ESG score, and Lins, Servaes, and Tamayo (2017) report that U.S. non-financial firms with high ESG ratings had better financial performance than other firms during the same time. For the most recent 2020 market crash induced by the COVID pandemic, evidence on the link between ESG ratings and stock market performance is mixed. For example, Pástor and Vorsatz (2020) provide evidence that equity mutual funds with high sustainability ratings perform well, as do funds with high star ratings. While Serafeim (2020), Albuquerque, Koskinen, Yang, and Zhang (2020) and Ding, Levine, Lin, and Xie (2020) also report a positive link between sustainability ratings and stock market performance, Demers, Hendriske, Joss, and Lev (2021) do not find a significant correlation between sustainability and stock prices during the crash after controlling for various factors.

For a first diagnostic insight into the relationship between sustainability sentiment and volatility regimes, Figure 6 displays the time series of the 22-day moving averages of the overall sustainability sentiment index, the abnormal sustainability message volume posted on StockTwits, together with the logarithmic VIX index over the period 2010-2021. Following among others Da, Engelberg, and Gao (2011), we define the abnormal message volume as the natural logarithm of the ratio between the daily volume of messages shared on StockTwits about sustainability and its average over the previous year. We make the following anecdotal observations. First, between 2010 and 2020, both ISS and the abnormal message volume about sustainability seem to be positively correlated with the VIX. This indicates that, contrary to the general market sentiment, investor sentiment for sustainability increases in times of high volatility. Second, this relationship seems to temporarily reverse during the COVID induced market crisis in early 2020. Intuitively, this may be due to the fact that sentiment has arguably been influenced by other socioeconomic uncertainty factors during the pandemic.

In order to underpin this potential regime dependency statistically, we regress both the sustainability sentiment index and the volume of sustainability related messages against measures of market uncertainty. We consider the CRSP market return, the logarithmic VIX index, the 
Table 6: Correlation analysis between investor sentiment for sustainability and uncertainty

\begin{tabular}{|c|c|c|c|c|c|c|}
\hline \multirow[b]{2}{*}{ Market return } & \multicolumn{6}{|c|}{ Dependent variable: ISS $_{t}$} \\
\hline & $\begin{array}{r}-0.110^{c} \\
(-3.266)\end{array}$ & & & & & $\begin{array}{l}-0.021 \\
(-1.262)\end{array}$ \\
\hline Log VIX & & $\begin{array}{c}0.002 \\
(0.036)\end{array}$ & & & & $\begin{array}{r}0.090 \\
(1.213)\end{array}$ \\
\hline $\begin{array}{ll}\text { Realized } & \text { volatility } \\
\text { S\&P } 500 & \end{array}$ & & & 0.041 & & & 0.037 \\
\hline FEARS Index & & & $(0.879)$ & $\begin{array}{c}0.051^{b} \\
(2.440)\end{array}$ & & $\begin{array}{r}(0.749) \\
-0.016 \\
(-1.085)\end{array}$ \\
\hline Twitter Eco. Uncer. & & & & & $\begin{array}{l}-0.083^{b} \\
(-2.262)\end{array}$ & $\begin{array}{l}-0.132^{c} \\
(-3.008)\end{array}$ \\
\hline Intercept & $\begin{array}{c}0.001 \\
(0.024)\end{array}$ & $\begin{array}{c}0.000 \\
(-0.008)\end{array}$ & $\begin{array}{c}0.045 \\
(0.764)\end{array}$ & $\begin{array}{c}-0.004 \\
(-0.147)\end{array}$ & $\begin{array}{r}0.123^{c} \\
(2.747)\end{array}$ & $\begin{array}{r}0.183^{c} \\
(3.894)\end{array}$ \\
\hline$R^{2}$ & $0.931 \%$ & $-0.036 \%$ & $0.125 \%$ & $0.180 \%$ & $1.130 \%$ & $3.690 \%$ \\
\hline Observations & 2,769 & 2,768 & 2,426 & 2,769 & 2,235 & 1,953 \\
\hline
\end{tabular}

Note: The table reports the estimated coefficients from regressing $\mathrm{ISS}_{t}$ on several uncertainty measures. The uncertainty measures are the CRSP market return, the $\log$ VIX, the daily $\log$ realized volatility of the S\&P 500 (constructed from 5-minute intraday returns), the FEARS Index, and the Twitter Economy uncertainty Index. The t-statistics reported in parentheses are computed using Newey-West standard errors. The superscripts $a, b$, and $c$ indicate respectively significance at the $10 \%, 5 \%$, and $1 \%$ level.

daily $\log$ realized volatility of the S\&P 500, as well as two indices capturing market-level uncertainty sentiment. The first is the Financial and Economic Attitudes Revealed by Search (FEARS) index of Da, Engelberg, and Gao (2015), which captures internet search behaviour of households based on search queries related to economic uncertainty (such as "recession" or "unemployment"). The second is the Twitter Economic Uncertainty (TEU) index ${ }^{10}$ of Baker, Bloom, Davis, and Renault (2021), which is based on counts of tweets about the "economy" and "uncertainty."

Tables 6 and 7 contain the results of the correlation analyses. We find that investor sentiment for sustainability is negatively correlated with the market return, positively associated with the FEARS index, but negatively associated with the Twitter Economic Uncertainty index. Because of our earlier anecdotal observation of the reverse effect the COVID pandemic may have had on sustainability sentiment, we rerun the same regressions until the end of 2019 (thereby excluding the pandemic) and find that the association with market return and the FEARS index is more magnified and more significant, whereas the association with the Twitter Economic Uncertainty index disappears. This may be due to the fact that the initial phase of the COVID pandemic may have introduced socioeconomic uncertainty issues that were largely captured by

\footnotetext{
${ }^{10}$ The Twitter Economic Uncertainty index is available from https://www.policyuncertainty.com/twitter -uncert.html.
} 
Table 7: Correlation analysis between the social media posting volume about sustainability and uncertainty

\begin{tabular}{|c|c|c|c|c|c|c|}
\hline \multirow[b]{2}{*}{ Market return } & \multicolumn{6}{|c|}{ Dependent variable: abnormal social media posting volume about ESG } \\
\hline & $\begin{array}{l}-0.008 \\
(-0.606)\end{array}$ & & & & & $\begin{array}{c}0.005 \\
(0.577)\end{array}$ \\
\hline Log VIX & & $\begin{array}{r}0.098^{c} \\
(3.573)\end{array}$ & & & & $\begin{array}{r}0.078^{b} \\
(2.252)\end{array}$ \\
\hline $\begin{array}{ll}\text { Realized } & \text { volatility } \\
\text { S\&P } 500 & \end{array}$ & & & $0.091^{c}$ & & & 0.031 \\
\hline FEARS Index & & & $(2.885)$ & $\begin{array}{c}-0.031^{b} \\
(-2.007)\end{array}$ & & $\begin{array}{c}(0.871) \\
-0.019 \\
(-1.338)\end{array}$ \\
\hline Twitter Eco. Uncer. & & & & & $\begin{array}{c}0.017 \\
(0.540)\end{array}$ & $\begin{array}{l}-0.025 \\
(-0.891)\end{array}$ \\
\hline Intercept & $\begin{array}{c}0.000 \\
(0.002)\end{array}$ & $\begin{array}{c}0.008 \\
(0.218)\end{array}$ & $\begin{array}{c}0.039 \\
(0.993)\end{array}$ & $\begin{array}{c}0.003 \\
(0.070)\end{array}$ & $\begin{array}{c}0.004 \\
(0.117)\end{array}$ & $\begin{array}{c}0.046 \\
(1.270)\end{array}$ \\
\hline$R^{2}$ & $67.733 \%$ & $68.670 \%$ & $69.092 \%$ & $67.804 \%$ & $69.440 \%$ & $70.502 \%$ \\
\hline Observations & 2,510 & 2,509 & 2,198 & 2,510 & 2,235 & 1,953 \\
\hline
\end{tabular}

Noте: The table reports the estimated coefficients from regressing the abnormal social media posting volume of ESGrelated messages on several uncertainty measures. The uncertainty measures are the CRSP market return, the log VIX, the daily $\log$ realized volatility of the S\&P 500 (constructed from 5-minute intraday returns), the FEARS Index, and the Twitter Economy uncertainty Index. We control for the abnormal global StockTwits posting volume. The abnormal posting volumes are defined as the natural logarithm of the ratio between the daily volume of messages shared on StockTwits and its average over the previous year. The t-statistics reported in parentheses are computed using Newey-West standard errors. The superscripts $a, b$, and $c$ indicate respectively significance at the $10 \%, 5 \%$, and $1 \%$ level.

the Twitter uncertainty index, and which affected global market sentiment, including sentiment for sustainability. The results of Table 7 on the association between the social media posting volume on sustainability issues and proxies for market uncertainty support the hypothesis that sentiment for sustainable investments increases in periods of high market uncertainty. We find that periods of higher uncertainty are associated with higher abnormal volume of messages about ESG shared on StockTwits. In particular, people tend to discuss on social media about sustainability more intensively during periods of high market volatility.

\subsection{Drivers of sustainability sentiment}

We next analyze the association between our measure of investor sentiment for sustainability and other variables that may be used as proxies for investor sentiment for sustainability. Three main variables we consider are: (i) attention measures based on Google search volume; (ii) ESG news sentiment based on RavenPack News Analytics and the media climate change concern index of Ardia, Bluteau, Boudt, and Inghelbrecht (2021) ${ }^{11}$; and (iii) ESG news volume based

\footnotetext{
${ }^{11}$ Note that in principle, and since they are closely related, we could also use the climate change news index of Engle, Giglio, Kelly, Lee, and Stroebel (2020). However, since this index is only available at the monthly frequency, we chose the daily index of Ardia, Bluteau, Boudt, and Inghelbrecht (2021).
} 
on RavenPack News Analytics.

The most prominent variable that may be closely related to investor sentiment is attention. Whereas financial theory traditionally assumes that investors have unconstrained cognitive resources, a large body of psychological literature establishes that attention is a scarce cognitive resource (Kahneman, 1973), and individual investors can devote only limited attention to their portfolios. Recent studies support the idea that news releases (Barber and Odean, 2008; Yuan, 2015) and online search frequency (Da, Engelberg, and Gao, 2011) are associated with increases in investor attention to asset markets, which in turn impacts the cross-section of stock prices (Barber and Odean, 2008). The relationship between investor attention and general market sentiment has been discussed in the literature. For example, Da, Engelberg, and Gao (2011) argue that retail investor attention and retail investor sentiment are positively related, since on one hand attention is a necessary condition to generate sentiment, and on the other hand retail investors are more likely to be sentiment traders suffering from various behavioral biases.

While media content provides fundamental information about a company, news articles may also play a significant role in the formation of investors' beliefs. In fact, articles about the stock market's performance have been found to influence investors' sentiment, which in turn has an effect on asset prices (Tetlock, 2007), in particular during periods of high uncertainty (García, 2013). It might thus be that news about ESG-related topics influences investors' sentiment for sustainability.

We regress the orthogonalized investor sentiment for sustainability measure on attention to ESG, ESG news sentiment obtained from RavenPack News Analytics, and the abnormal volume of news published about ESG. Additionally, we run the same regression for the environmental, social, and governance sentiment indices and control for the respective attention measures. For $\operatorname{ISS}_{t}$ and the environmental sentiment index, $\operatorname{ISS}_{t}^{\mathrm{E}}$, we also consider unexpected changes in climate change concerns ${ }^{12}$ (UMC). Given the regime dependency of sustainability sentiment (Section 3.3) together with the documented positive association between market volatility and investor interest in sustainability (Albuquerque, Koskinen, Yang, and Zhang (2020); Ding, Levine, Lin, and Xie (2020); Dunn, Fitzgibbons, and Pomorski (2017); Goldberg and Mouti (2019)), we also consider the market return and the logarithm of the VIX index. In all regressions, we include a dummy variable being equal to one on days where the UN Climate Change Conference

\footnotetext{
${ }^{12}$ Note that the media climate change concern index of Ardia, Bluteau, Boudt, and Inghelbrecht (2021) is only available from 2010 to mid-2018.
} 
is held (COP dummy).

The estimation results of the various linear regressions are reported in the first four columns of Table 8. All variables are standardized and the t-statistics reported in parentheses are computed using Newey-West standard errors. Overall, the correlations between our measures of sustainability sentiment and ESG news sentiment are positive but small in magnitude. The regression coefficient of ESG news sentiment is statistically significant at the $5 \%$ level for $\mathrm{ISS}_{t}$, borderline significant for $\operatorname{ISS}_{t}^{S}$, and insignificant for $\operatorname{ISS}_{t}^{\mathrm{E}}$ and $\operatorname{ISS}_{t}^{\mathrm{G}}$. Unexpected changes in media climate change concerns (UMC) are not significantly correlated with sustainability sentiment. Note that the sentiment measures appear to be higher during market downturns: $\mathrm{ISS}_{t}$, $\mathrm{ISS}_{t}^{\mathrm{E}}, \mathrm{ISS}_{t}^{\mathrm{S}}$, and $\mathrm{ISS}_{t}^{\mathrm{G}}$ are significantly negatively correlated with the market return and/or positively with the log VIX index, which corroborates our findings from Section 3.3. During the UN Climate Change Conferences, we find investor sentiment for sustainability to be significantly lower.

In the last three columns of Table 8 , we analyze potential non-linearities in the correlation between $\mathrm{ISS}_{t}$ and our variables of interest. We divide investor sentiment for sustainability into its positive and negative components, that is $\operatorname{ISS}_{t}^{+}=\max \left(\operatorname{ISS}_{t}, 0\right)$ and $\operatorname{ISS}_{t}{ }^{-}=\min \left(\operatorname{ISS}_{t}, 0\right)$. We regress these sentiment measures on the same set of variables used for the regressions in the first column of Table 8. The most striking difference between the results for $\mathrm{ISS}_{t}^{+}$and $\mathrm{ISS}_{t}{ }^{-}$ concerns their correlation with the news sentiment. ESG news sentiment positively and significantly correlates with the negative component of ESG investor sentiment, but is not significantly correlated with $\mathrm{ISS}_{t}{ }^{-}$. We find a similar result for UMC: unexpected changes in media climate change concerns are significantly related with less negative sustainability sentiment. In the last column of Table 8 we regress investors disagreement about ESG topics on the variables of interest. We follow Cookson and Niessner (2020) and define investors' sentiment disagreement as $\operatorname{DisISS}_{t}=\sqrt{1-\mathrm{ISS}_{t}^{2}}$. When all investors have the same sentiment about ESG-related topics, this measure is close to zero, whereas it is close to one when investors disagree. We find that investors' disagreement about ESG topics correlates positively and significantly with investors' attention, ESG news sentiment, and unexpected changes in media climate change concerns. That said, it is important to bear in mind that all correlations are relatively low.

Finally, we analyze lead-lag relations between $\mathrm{ISS}_{t}, \mathrm{AttESG}_{t}$, the sentiment of ESG news articles, and UMC. We estimate a vector autoregressive (VAR) model of these variables. The order of the VAR model is determined with the Bayesian information criterion. All variables 
Table 8: Correlation analysis of the sustainability sentiment measures

\begin{tabular}{|c|c|c|c|c|c|c|c|}
\hline & ISS $_{t}$ & $\operatorname{ISS}_{t}^{\mathrm{E}}$ & $\operatorname{ISS}_{t}^{S}$ & $\mathrm{ISS}_{t}^{\mathrm{G}}$ & $\mathrm{ISS}_{t}^{+}$ & $\mathrm{ISS}_{t}^{-}$ & DisISS $_{t}$ \\
\hline $\operatorname{AttESG}_{t}$ & $\begin{array}{c}0.010 \\
(0.331)\end{array}$ & & & & $\begin{array}{l}-0.018 \\
(-1.065)\end{array}$ & $\begin{array}{c}0.028 \\
(1.639)\end{array}$ & $\begin{array}{r}0.054^{b} \\
(2.294)\end{array}$ \\
\hline $\operatorname{AttE}_{t}$ & & $\begin{array}{l}-0.011 \\
(-0.285)\end{array}$ & & & & & \\
\hline $\mathrm{AttS}_{t}$ & & & $\begin{array}{c}0.020 \\
(0.910)\end{array}$ & & & & \\
\hline $\operatorname{AttG}_{t}$ & & & & $\begin{array}{l}-0.010 \\
(-0.455)\end{array}$ & & & \\
\hline ESG news sentiment & $\begin{array}{r}0.065^{b} \\
(2.206)\end{array}$ & $\begin{array}{c}0.035 \\
(1.313)\end{array}$ & $\begin{array}{r}0.041^{a} \\
(1.658)\end{array}$ & $\begin{array}{c}0.030 \\
(0.948)\end{array}$ & $\begin{array}{l}-0.022 \\
(-1.440)\end{array}$ & $\begin{array}{r}0.087^{c} \\
(4.362)\end{array}$ & $\begin{array}{r}0.115^{c} \\
(4.480)\end{array}$ \\
\hline ESG news volume & $\begin{array}{c}0.020 \\
(0.811)\end{array}$ & $\begin{array}{c}0.030 \\
(1.071)\end{array}$ & $\begin{array}{c}0.022 \\
(1.131)\end{array}$ & $\begin{array}{l}-0.010 \\
(-0.377)\end{array}$ & $\begin{array}{c}0.014 \\
(0.855)\end{array}$ & $\begin{array}{c}0.007 \\
(0.502)\end{array}$ & $\begin{array}{c}-0.011 \\
(-0.638)\end{array}$ \\
\hline UMC & $\begin{array}{c}0.022 \\
(1.177)\end{array}$ & $\begin{array}{c}0.017 \\
(0.874)\end{array}$ & & & $\begin{array}{l}-0.005 \\
(-0.505)\end{array}$ & $\begin{array}{r}0.028^{b} \\
(2.341)\end{array}$ & $\begin{array}{r}0.038^{c} \\
(2.801)\end{array}$ \\
\hline Market return & $\begin{array}{l}-0.165^{c} \\
(-3.468)\end{array}$ & $\begin{array}{l}-0.129^{c} \\
(-2.660)\end{array}$ & $\begin{array}{l}-0.098^{c} \\
(-3.474)\end{array}$ & $\begin{array}{l}-0.024 \\
(-1.144)\end{array}$ & $\begin{array}{l}-0.090^{b} \\
(-2.358)\end{array}$ & $\begin{array}{r}-0.075^{c} \\
(-3.809)\end{array}$ & $\begin{array}{c}0.043 \\
(0.689)\end{array}$ \\
\hline Log VIX & $\begin{array}{r}0.099^{b} \\
(2.180)\end{array}$ & $\begin{array}{l}-0.005 \\
(-0.108)\end{array}$ & $\begin{array}{r}0.071^{b} \\
(2.373)\end{array}$ & $\begin{array}{r}0.085^{b} \\
(2.018)\end{array}$ & $\begin{array}{r}0.131^{c} \\
(4.419)\end{array}$ & $\begin{array}{l}-0.032 \\
(-1.558)\end{array}$ & $\begin{array}{l}-0.170^{c} \\
(-5.543)\end{array}$ \\
\hline COP dummy & $\begin{array}{l}-0.284^{b} \\
(-2.164)\end{array}$ & $\begin{array}{l}-0.219^{b} \\
(-2.383)\end{array}$ & $\begin{array}{l}-0.166^{a} \\
(-1.695)\end{array}$ & $\begin{array}{l}-0.092 \\
(-0.470)\end{array}$ & $\begin{array}{l}-0.146^{b} \\
(-2.492)\end{array}$ & $\begin{array}{l}-0.138 \\
(-1.586)\end{array}$ & $\begin{array}{c}0.014 \\
(0.244)\end{array}$ \\
\hline Intercept & $\begin{array}{c}0.069 \\
(1.538)\end{array}$ & $\begin{array}{c}-0.017 \\
(-0.443)\end{array}$ & $\begin{array}{c}0.101^{c} \\
(3.078)\end{array}$ & $\begin{array}{r}0.089^{a} \\
(1.933)\end{array}$ & $\begin{array}{r}0.381^{c} \\
(13.808)\end{array}$ & $\begin{array}{r}-0.312^{c} \\
(-13.509)\end{array}$ & $\begin{array}{c}0.028 \\
(0.974)\end{array}$ \\
\hline $\begin{array}{l}R^{2} \\
\text { Observations }\end{array}$ & $\begin{array}{c}3.748 \% \\
1,879\end{array}$ & $\begin{array}{c}1.231 \% \\
1,879\end{array}$ & $\begin{array}{c}2.506 \% \\
2,468\end{array}$ & $\begin{array}{c}1.017 \% \\
2,468\end{array}$ & $\begin{array}{c}7.569 \% \\
1,879\end{array}$ & $\begin{array}{c}4.743 \% \\
1,879\end{array}$ & $\begin{array}{c}8.615 \% \\
1,879\end{array}$ \\
\hline
\end{tabular}

NoтE: The table reports the estimated coefficients from regressing the ESG sentiment measures on several explanatory variables. The regressors are the attention measures AttESG, AttE, AttS, and AttG, the ESG news articles sentiment and abnormal publication volume, the CRSP market return, the log VIX index, and a dummy being equal to one on days where the Conference of the Parties' (COP) UN Climate Change Conference is held. For the regression of ISS $t$ and ISS $t_{t}^{\mathrm{E}}$ we additionally include unexpected changes in media climate change concerns (UMC). In the first four columns the dependent variables are $\operatorname{ISS}_{t}, \operatorname{ISS}_{t}^{\mathrm{E}}, \operatorname{ISS}_{t}^{\mathrm{S}}$, and $\operatorname{ISS}_{t}^{\mathrm{G}}$. In the fifth and sixth column we regress ISS $t^{+}=\max \left(\mathrm{ISS}_{t}, 0\right)$ and ISS ${ }_{t}^{-}=\min \left(\mathrm{ISS}_{t}, 0\right)$ on the aforementioned explanatory variables. The last column reports the estimated coefficients from regressing DisISS $S_{t}=\sqrt{1-\text { ISS }_{t}^{2}}$ on the same explanatory variables used in the first column of this table. The t-statistics reported in parentheses are computed using Newey-West standard errors. The superscripts $a, b$, and $c$ indicate respectively significance at the $10 \%$,

$5 \%$, and $1 \%$ level. 
Table 9: Vector autoregressive (VAR) model of ESG-related sentiment, attention and news

\begin{tabular}{|c|c|c|c|c|}
\hline \multicolumn{5}{|l|}{ Panel A: Linear sentiment } \\
\hline & ISS $_{t}$ & $\operatorname{AttESG}_{t}$ & $\begin{array}{c}\text { ESG news sent. } \\
\text { in } t\end{array}$ & $\mathrm{UMC}$ in $t$ \\
\hline \multirow[t]{2}{*}{$\mathrm{ISS}_{t-1}$} & $0.184^{c}$ & -0.010 & 0.022 & $0.041^{a}$ \\
\hline & $(8.507)$ & $(-0.502)$ & $(1.208)$ & $(1.935)$ \\
\hline \multirow{2}{*}{$\mathrm{ISS}_{t-2}$} & $0.132^{c}$ & -0.029 & -0.024 & $-0.036^{a}$ \\
\hline & $(6.040)$ & $(-1.417)$ & $(-1.292)$ & $(-1.667)$ \\
\hline \multirow[t]{2}{*}{$\mathrm{ISS}_{t-3}$} & $0.104^{c}$ & 0.027 & 0.006 & -0.004 \\
\hline & $(4.745)$ & $(1.338)$ & $(0.320)$ & $(-0.163)$ \\
\hline \multirow{2}{*}{$\mathrm{ISS}_{t-4}$} & $0.120^{c}$ & 0.015 & $0.043^{b}$ & 0.003 \\
\hline & $(5.601)$ & $(0.737)$ & $(2.320)$ & $(0.156)$ \\
\hline \multirow[t]{2}{*}{$\operatorname{AttESG}_{t-1}$} & 0.023 & $0.217^{c}$ & 0.032 & $0.072^{c}$ \\
\hline & $(0.995)$ & $(10.009)$ & $(1.605)$ & $(3.062)$ \\
\hline \multirow[t]{2}{*}{$\operatorname{AttESG}_{t-2}$} & -0.018 & $0.159^{c}$ & 0.000 & -0.024 \\
\hline & $(-0.756)$ & $(7.225)$ & $(-0.022)$ & $(-1.007)$ \\
\hline \multirow[t]{2}{*}{$\operatorname{AttESG}_{t-3}$} & 0.024 & $0.137^{c}$ & -0.007 & -0.028 \\
\hline & $(1.008)$ & $(6.209)$ & $(-0.329)$ & $(-1.200)$ \\
\hline \multirow[t]{2}{*}{$\operatorname{AttESG}_{t-4}$} & 0.013 & $0.107^{c}$ & -0.012 & 0.008 \\
\hline & $(0.535)$ & $(4.950)$ & $(-0.604)$ & $(0.356)$ \\
\hline \multirow[t]{2}{*}{ ESG news sent. in $t-1$} & $0.084^{c}$ & $0.039^{a}$ & $0.232^{c}$ & $0.059^{b}$ \\
\hline & $(3.369)$ & $(1.706)$ & $(10.753)$ & $(2.388)$ \\
\hline \multirow[t]{2}{*}{ ESG news sent. in $t-2$} & 0.008 & -0.023 & $0.155^{c}$ & 0.017 \\
\hline & $(0.307)$ & $(-0.958)$ & $(7.070)$ & $(0.657)$ \\
\hline \multirow{2}{*}{ ESG news sent. in $t-3$} & -0.017 & 0.035 & $0.172^{c}$ & 0.012 \\
\hline & $(-0.680)$ & $(1.488)$ & $(7.841)$ & $(0.460)$ \\
\hline \multirow[t]{2}{*}{ ESG news sent. in $t-4$} & 0.023 & -0.020 & $0.153^{c}$ & $0.048^{a}$ \\
\hline & $(0.901)$ & $(-0.851)$ & $(7.099)$ & $(1.940)$ \\
\hline \multirow[t]{2}{*}{$\mathrm{UMC}$ in $t-1$} & -0.009 & $0.060^{c}$ & 0.028 & $-0.046^{b}$ \\
\hline & $(-0.419)$ & $(2.958)$ & $(1.481)$ & $(-2.100)$ \\
\hline \multirow[t]{2}{*}{$\mathrm{UMC}$ in $t-2$} & -0.017 & 0.016 & $0.052^{c}$ & $0.088^{c}$ \\
\hline & $(-0.793)$ & $(0.778)$ & $(2.783)$ & $(4.051)$ \\
\hline \multirow[t]{2}{*}{$\mathrm{UMC}$ in $t-3$} & -0.029 & 0.002 & 0.007 & $0.079^{c}$ \\
\hline & $(-1.346)$ & $(0.077)$ & $(0.374)$ & $(3.620)$ \\
\hline \multirow[t]{2}{*}{$\mathrm{UMC}$ in $t-4$} & -0.005 & 0.000 & $0.049^{c}$ & $0.069^{c}$ \\
\hline & $(-0.223)$ & $(0.015)$ & $(2.602)$ & $(3.170)$ \\
\hline \multirow[t]{2}{*}{ Intercept } & -0.026 & -0.010 & -0.015 & 0.011 \\
\hline & $(-1.206)$ & $(-0.496)$ & $(-0.802)$ & $(0.511)$ \\
\hline$R^{2}$ & $15.115 \%$ & $21.358 \%$ & $33.171 \%$ & $4.083 \%$ \\
\hline Observations & 2,134 & 2,134 & 2,134 & 2,134 \\
\hline
\end{tabular}

(continued)

are standardized and have zero mean and unit standard deviation. The estimation results are reported in Panel A of Table 9. All four variables of interest are strongly autocorrelated. Moreover, sentiment from ESG news articles significantly predicts higher sustainability sentiment, ESG attention, and UMC. A one standard deviation increase in the news sentiment predicts an increase of 0.084, 0.039, and 0.059 standard deviations for the next day's ISS $_{t}$, AttESG , and UMC, respectively. We do not find any significant lead-lag relation between investors' sentiment and attention to ESG topics. Interestingly, while UMC leads attention to ESG, unexpected changes in media climate change concerns lag ISS $_{t}$ and ESG news sentiment. In Panel B of 9 we 
Table 9 continued: Vector autoregressive (VAR) model of ESG-related sentiment, attention and news

\begin{tabular}{|c|c|c|c|c|c|}
\hline & $\mathrm{ISS}_{t}{ }^{+}$ & $\mathrm{ISS}_{t}^{-}$ & $\operatorname{AttESG}_{t}$ & $\begin{array}{c}\text { ESG news } \\
\text { sent. in } t\end{array}$ & $\mathrm{UMC}$ in $t$ \\
\hline $\mathrm{ISS}_{t-1}+$ & $\begin{array}{r}0.208^{c} \\
(8.999)\end{array}$ & $\begin{array}{c}-0.001 \\
(-0.049)\end{array}$ & $\begin{array}{l}-0.046 \\
(-1.131)\end{array}$ & $\begin{array}{l}-0.005 \\
(-0.137)\end{array}$ & $\begin{array}{l}-0.032 \\
(-0.745)\end{array}$ \\
\hline $\mathrm{ISS}_{t-2}+$ & $\begin{array}{r}0.143^{c} \\
(6.123)\end{array}$ & $\begin{array}{c}0.011 \\
(0.372)\end{array}$ & $\begin{array}{l}-0.049 \\
(-1.184)\end{array}$ & $\begin{array}{l}-0.140^{c} \\
(-3.661)\end{array}$ & $\begin{array}{l}-0.057 \\
(-1.288)\end{array}$ \\
\hline $\mathrm{ISS}_{t-3}+$ & $\begin{array}{c}0.082^{c} \\
(3.525)\end{array}$ & $\begin{array}{c}0.013 \\
(0.442)\end{array}$ & $\begin{array}{c}0.056 \\
(1.372)\end{array}$ & $\begin{array}{r}-0.093^{b} \\
(-2.452)\end{array}$ & $\begin{array}{c}-0.011 \\
(-0.257)\end{array}$ \\
\hline $\mathrm{ISS}_{t-1}{ }^{-}$ & $\begin{array}{c}0.013 \\
(0.721)\end{array}$ & $\begin{array}{r}0.182^{c} \\
(7.862)\end{array}$ & $\begin{array}{c}0.023 \\
(0.753)\end{array}$ & $\begin{array}{r}0.048^{a} \\
(1.663)\end{array}$ & $\begin{array}{r}0.090^{c} \\
(2.714)\end{array}$ \\
\hline $\mathrm{ISS}_{t-2}{ }^{-}$ & $\begin{array}{c}0.013 \\
(0.756)\end{array}$ & $\begin{array}{r}0.134^{c} \\
(5.746)\end{array}$ & $\begin{array}{c}-0.010 \\
(-0.325)\end{array}$ & $\begin{array}{c}0.067^{b} \\
(2.320)\end{array}$ & $\begin{array}{c}-0.020 \\
(-0.595)\end{array}$ \\
\hline ISS $_{t-3}{ }^{-}$ & $\begin{array}{c}0.023 \\
(1.293)\end{array}$ & $\begin{array}{r}0.132^{c} \\
(5.742)\end{array}$ & $\begin{array}{c}0.016 \\
(0.517)\end{array}$ & $\begin{array}{r}0.108^{c} \\
(3.764)\end{array}$ & $\begin{array}{c}0.010 \\
(0.293)\end{array}$ \\
\hline $\operatorname{AttESG}_{t-1}$ & $\begin{array}{c}0.001 \\
(0.061)\end{array}$ & $\begin{array}{r}0.030^{a} \\
(1.867)\end{array}$ & $\begin{array}{r}0.233^{c} \\
(10.781)\end{array}$ & $\begin{array}{r}0.033^{a} \\
(1.661)\end{array}$ & $\begin{array}{l}0.071^{c} \\
(3.087)\end{array}$ \\
\hline $\operatorname{AttESG}_{t-2}$ & $\begin{array}{c}0.002 \\
(0.154)\end{array}$ & $\begin{array}{l}-0.021 \\
(-1.312)\end{array}$ & $\begin{array}{r}0.176^{c} \\
(8.089)\end{array}$ & $\begin{array}{l}-0.013 \\
(-0.634)\end{array}$ & $\begin{array}{l}-0.025 \\
(-1.065)\end{array}$ \\
\hline $\operatorname{AttESG}_{t-3}$ & $\begin{array}{c}0.010 \\
(0.787)\end{array}$ & $\begin{array}{c}0.015 \\
(0.937)\end{array}$ & $\begin{array}{r}0.165^{c} \\
(7.639)\end{array}$ & $\begin{array}{l}-0.010 \\
(-0.482)\end{array}$ & $\begin{array}{l}-0.021 \\
(-0.897)\end{array}$ \\
\hline ESG news sent. in $t-1$ & $\begin{array}{c}0.009 \\
(0.707)\end{array}$ & $\begin{array}{r}0.082^{c} \\
(4.768)\end{array}$ & $\begin{array}{c}0.035 \\
(1.507)\end{array}$ & $\begin{array}{r}0.248^{c} \\
(11.585)\end{array}$ & $\begin{array}{r}0.064^{c} \\
(2.607)\end{array}$ \\
\hline ESG news sent. in $t-2$ & $\begin{array}{l}-0.018 \\
(-1.366)\end{array}$ & $\begin{array}{c}0.028 \\
(1.580)\end{array}$ & $\begin{array}{l}-0.031 \\
(-1.311)\end{array}$ & $\begin{array}{r}0.172^{c} \\
(7.914)\end{array}$ & $\begin{array}{c}0.024 \\
(0.976)\end{array}$ \\
\hline ESG news sent. in $t-3$ & $\begin{array}{l}-0.028^{b} \\
(-2.169)\end{array}$ & $\begin{array}{c}0.022 \\
(1.277)\end{array}$ & $\begin{array}{c}0.034 \\
(1.456)\end{array}$ & $\begin{array}{r}0.196^{c} \\
(9.126)\end{array}$ & $\begin{array}{c}0.020 \\
(0.796)\end{array}$ \\
\hline $\mathrm{UMC}$ in $t-1$ & $\begin{array}{l}-0.012 \\
(-1.064)\end{array}$ & $\begin{array}{c}0.003 \\
(0.186)\end{array}$ & $\begin{array}{r}0.055^{c} \\
(2.725)\end{array}$ & $\begin{array}{c}0.027 \\
(1.452)\end{array}$ & $\begin{array}{l}-0.044^{b} \\
(-2.004)\end{array}$ \\
\hline $\mathrm{UMC}$ in $t-2$ & $\begin{array}{l}-0.016 \\
(-1.347)\end{array}$ & $\begin{array}{l}-0.007 \\
(-0.483)\end{array}$ & $\begin{array}{c}0.010 \\
(0.471)\end{array}$ & $\begin{array}{c}0.049^{c} \\
(2.578)\end{array}$ & $\begin{array}{r}0.091^{c} \\
(4.211)\end{array}$ \\
\hline $\mathrm{UMC}$ in $t-3$ & $\begin{array}{l}-0.025^{b} \\
(-2.149)\end{array}$ & $\begin{array}{c}0.001 \\
(0.060)\end{array}$ & $\begin{array}{c}0.005 \\
(0.262)\end{array}$ & $\begin{array}{c}0.006 \\
(0.308)\end{array}$ & $\begin{array}{r}0.076^{c} \\
(3.515)\end{array}$ \\
\hline Intercept & $\begin{array}{r}0.209^{c} \\
(10.284)\end{array}$ & $\begin{array}{r}-0.225^{c} \\
(-8.456)\end{array}$ & $\begin{array}{c}0.013 \\
(0.367)\end{array}$ & $\begin{array}{c}0.148^{c} \\
(4.439)\end{array}$ & $\begin{array}{c}0.075^{b} \\
(1.968)\end{array}$ \\
\hline $\begin{array}{l}R^{2} \\
\text { Observations }\end{array}$ & $\begin{array}{c}12.060 \% \\
2,135\end{array}$ & $\begin{array}{c}16.901 \% \\
2,135\end{array}$ & $\begin{array}{c}20.534 \% \\
2,135\end{array}$ & $\begin{array}{c}32.472 \% \\
2,135\end{array}$ & $\begin{array}{c}3.728 \% \\
2,135\end{array}$ \\
\hline
\end{tabular}

Note: The table reports in Panel A the estimates of a VAR(4) model of investor sentiment for sustainability, investors' attention to ESG topics, ESG news sentiment, and unexpected changes in climate change concerns (UMC). In Panel B, in the VAR(3) we distinguish between positive and negative sustainability sentiment. The order of the VAR models is determined with the Bayesian information criterion. The t-statistics are reported in parentheses and the superscripts $a, b$, and $c$ indicate respectively significance at the $10 \%, 5 \%$, and $1 \%$ level. 
investigate if the lead-lag relations between investor sentiment for sustainability and the other variables are non-linear. To this end, we estimate the same VAR model replacing $\mathrm{ISS}_{t}$ with $\mathrm{ISS}_{t}{ }^{+}$ and $\mathrm{ISS}_{t}{ }^{-}$. Both $\mathrm{ISS}_{t}{ }^{+}$are $\mathrm{ISS}_{t}^{-}$strongly autocorrelated. Interestingly, ESG news sentiment does not predict $\mathrm{ISS}_{t}{ }^{+}$(except for the three-day lagged value which has a negative coefficient significant at the $5 \%$ level). We find instead predictive power of negative ESG news for the one-day ahead value of $\mathrm{ISS}_{t}{ }^{-}$(significant at the $1 \%$ ). Moreover, we find that attention to ESG predicts next day's negative sustainability sentiment, but the coefficient is small in magnitude and only significant at the $10 \%$ level.

Overall, the correlation analysis corroborates our findings from Section 3.3 showing that sustainability sentiment positively correlates with market uncertainty. We find that pessimism about sustainability correlates with news about ESG in general and climate change. Moreover, the lead-lag analysis indicates that ESG news sentiment predicts negative sustainability sentiment, but not positive $\mathrm{ISS}_{t}$. Our findings also suggest that when investors pay attention to ESG, they tend to disagree in terms of their sustainability sentiment. Fianlly, the relatively low coefficients across all of our regressions indicate that $\mathrm{ISS}_{t}$ is capturing novel components related to market sentiment for sustainability that go beyond general uncertainty or environemntal news.

\section{Sustainability sentiment and asset prices}

In this section, we analyze the extent to which our sentiment indices have an influence on stock prices. We address the hypothesis that higher ESG sentiment leads to a shift in investors' demand creating upward price pressures. Following the theory of Pástor, Stambaugh, and Taylor (2020), we expect that an increase sustainability sentiment predicts high returns for above average sustainable firms and lower returns for below average sustainable firms.

\subsection{Constructing sustainable portfolios}

We construct ten different portfolios classified according to their sustainability profiles as follows. Each trading day, we sort all stocks according to their MSCI ESG rating. The sorted stocks are then grouped in ten decile portfolios. We consider both value-weighted and equal-weighted portfolios. ${ }^{13}$ Table 10 reports time series averages for a range of characteristics for the ESG portfolios. We observe that compared to High ESG stocks, Low ESG stocks have on average

\footnotetext{
${ }^{13}$ For value-weighted portfolios we define the weights as the stocks' market capitalization at the end of the previous month.
} 
higher excess returns, a smaller market capitalization, smaller book-to-market ratios, higher idiosyncratic volatility, and are more illiquid.

In the remainder of this section we focus on the lowest (Low ESG) and highest (High $E S G)$ ESG portfolios. We denote the daily returns of these two portfolios as Return $n_{\text {Low }, t}$ and Return $_{\mathrm{High}, t}$, respectively. Furthermore, we construct for each portfolio a sentiment measure by collecting all messages shared on StockTwits that mention a stock that is part of the respective portfolio. Messages are classified using the logistic regression model described in Appendix B and aggregated to a daily sentiment index analogous to Equation (1). The sentiment measures

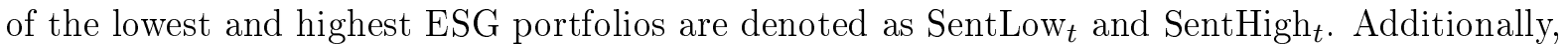
we consider a zero-cost investment strategy that goes long in the last decile portfolio and short in the first decile portfolio. We denote the daily return of this high-minus-low ESG portfolio as $\operatorname{Return}_{\mathrm{HmL}, t}$. The daily sentiment measure of the high-minus-low portfolio is defined as $\operatorname{SentHmL}_{t}=\left(\right.$ SentHigh $_{t}-$ SentLow $\left._{t}\right) / 2$.

We start by carrying out two diagnostic analyses of the relationship between sentiment and return. First, we look at correlations between sentiment and returns. Table 11 reports the Pearson correlation coefficients between $\mathrm{ISS}_{t}$, SentGlob $_{t}$, and the returns and sentiment measures of the value-weighted ESG portfolios. Note that now investors' sustainability sentiment and the global social media sentiment are uncorrelated since we orthogonalize ISS $_{t}$ with respect to SentGlob $_{t}$. We observe that the sentiment measures of the three portfolios correlated positively with the respective returns. In particular, the contemporaneous correlation between $\mathrm{SentHmL}_{t}$ and the return of the long-short strategy is 0.19 . Moreover, ISS $_{t}$ is positively correlated with SentHmL $L_{t}$. However, the correlation between $\operatorname{ISS}_{t}$ and the portfolio returns is close to zero.

Second, we implement a simple trading strategy that showcases the relation between investors' sustainability sentiment and future realized stock returns. Each day, if ISS $_{t}$ is positive we go long in the high ESG portfolio and short in the low ESG portfolio. If $\mathrm{ISS}_{t}$ is instead negative, we do the opposite and open a long position in the low ESG portfolio and a short position in the high ESG portfolio. This position is held for the next 30 trading days. The average cumulative returns of the simple trading strategy for equally-weighted and value-weighted portfolios are depicted in the upper panel of Figure 7. The vertical lines represent $95 \%$ confidence intervals for the average cumulative returns. The cumulative returns increase over the first 20 trading days and are significantly positive. Afterwards the returns do only marginally increase and the average return of the strategy which invests in value-weighted portfolios is no 
Table 10: Characteristics of ESG-sorted portfolios based on the MSCI ratings

\begin{tabular}{|c|c|c|c|c|c|c|c|c|c|c|}
\hline \multicolumn{11}{|l|}{ Panel A: Value-weighted } \\
\hline & Low ESG & 2 & 3 & 4 & 5 & 6 & 7 & 8 & 9 & High ESG \\
\hline ESG Score & 0.922 & 1.993 & 2.667 & 3.248 & 3.736 & 4.216 & 4.843 & 5.521 & 6.409 & 8.082 \\
\hline Return & 0.060 & 0.047 & 0.039 & 0.048 & 0.046 & 0.058 & 0.046 & 0.057 & 0.060 & 0.045 \\
\hline Log market capitalization & 10.508 & 10.252 & 10.593 & 10.483 & 10.252 & 10.505 & 10.328 & 10.517 & 11.166 & 11.066 \\
\hline Book-to-market & 0.463 & 0.477 & 0.557 & 0.462 & 0.506 & 0.546 & 0.485 & 0.410 & 0.368 & 0.389 \\
\hline Beta & 1.019 & 1.033 & 1.031 & 1.059 & 1.029 & 1.023 & 0.940 & 0.997 & 0.974 & 0.946 \\
\hline Idiosyncratic volatility & 0.013 & 0.013 & 0.013 & 0.013 & 0.013 & 0.012 & 0.013 & 0.013 & 0.011 & 0.011 \\
\hline Illiquidity & 0.003 & 0.004 & 0.003 & 0.003 & 0.004 & 0.003 & 0.003 & 0.004 & 0.002 & 0.001 \\
\hline Turnover & 0.825 & 0.988 & 0.881 & 0.888 & 0.856 & 0.863 & 0.869 & 0.908 & 0.817 & 0.751 \\
\hline Share inst. inv. (13F) & 68.366 & 75.003 & 74.396 & 73.121 & 76.871 & 74.576 & 76.508 & 77.079 & 73.681 & 74.263 \\
\hline \multicolumn{11}{|l|}{ Panel B: Equal-weighted } \\
\hline & Low ESG & 2 & 3 & 4 & 5 & 6 & 7 & 8 & 9 & High ESG \\
\hline ESG Score & 1.049 & 1.995 & 2.651 & 3.242 & 3.721 & 4.227 & 4.843 & 5.520 & 6.409 & 7.937 \\
\hline Return & 0.053 & 0.049 & 0.038 & 0.044 & 0.044 & 0.050 & 0.053 & 0.052 & 0.055 & 0.048 \\
\hline Log market capitalization & 8.040 & 7.977 & 7.951 & 8.013 & 7.987 & 8.096 & 8.088 & 8.213 & 8.350 & 8.772 \\
\hline Book-to-market & 0.576 & 0.549 & 0.537 & 0.508 & 0.556 & 0.530 & 0.517 & 0.484 & 0.469 & 0.460 \\
\hline Beta & 1.177 & 1.198 & 1.198 & 1.233 & 1.210 & 1.168 & 1.174 & 1.162 & 1.127 & 1.058 \\
\hline Idiosyncratic volatility & 0.019 & 0.019 & 0.020 & 0.020 & 0.019 & 0.018 & 0.018 & 0.018 & 0.017 & 0.016 \\
\hline Illiquidity & 0.052 & 0.109 & 0.042 & 0.041 & 0.037 & 0.034 & 0.045 & 0.190 & 0.030 & 0.033 \\
\hline Turnover & 1.171 & 1.129 & 1.202 & 1.144 & 1.079 & 1.104 & 1.072 & 1.116 & 1.012 & 1.011 \\
\hline Share inst. inv. (13F) & 79.101 & 81.285 & 81.137 & 78.964 & 80.031 & 79.778 & 81.907 & 83.639 & 82.437 & 81.977 \\
\hline
\end{tabular}

Note: The table reports time series averages of value-weighted (Panel A) and equal-weighted (Panel B) stock-specific characteristics for the ten ESG-sorted portfolios. The stock-specific characteristics are the MSCI ESG score, the daily log excess return (in \%), the log market capitalization, the book-to-market ratio computed following Fama and French (2008), the beta computed each month by regressing its daily log excess return on the market excess return, the idiosyncratic volatility defined as the standard deviation of the aforementioned regression (Ang, Hodrick, Xing, and Zhang, 2006), the illiquidity defined as the monthly average of the ratio between daily absolute returns and the dollar trading volume (Amihud, 2002), and the turnover ratio defined as the trading volume divided by the total number of shares outstanding. The return and turnover ratio are reported in percent, and the illiquidity measure is multiplied by $10^{7}$. The ten portfolios are formed by sorting each day all stocks in our dataset based on their ESG rating, as provided by MSCI. 
Table 11: Correlation between the sentiment indexes and portfolio returns

\begin{tabular}{|c|c|c|c|c|c|c|c|c|}
\hline & (1) & $(2)$ & (3) & (4) & $(5)$ & (6) & (7) & (8) \\
\hline $\mathrm{ISS}_{t}(1)$ & 1.00 & 0.00 & -0.01 & 0.09 & 0.09 & -0.08 & -0.07 & 0.02 \\
\hline SentGlob $_{t}(2)$ & & 1.00 & 0.53 & 0.54 & -0.06 & 0.21 & 0.25 & 0.06 \\
\hline SentLow $_{t}(3)$ & & & 1.00 & 0.40 & -0.63 & 0.20 & 0.17 & -0.09 \\
\hline SentHigh $_{t}(4)$ & & & & 1.00 & 0.47 & 0.17 & 0.24 & 0.13 \\
\hline $\mathrm{SentHmL}_{t}(5)$ & & & & & 1.00 & -0.04 & 0.05 & 0.19 \\
\hline $\operatorname{Return}_{\mathrm{Low}, t}(6)$ & & & & & & 1.00 & 0.90 & -0.36 \\
\hline Return $_{\mathrm{High}, t}(7)$ & & & & & & & 1.00 & 0.09 \\
\hline Return $_{\mathrm{HmL}, t}$ (8) & & & & & & & & 1.00 \\
\hline
\end{tabular}

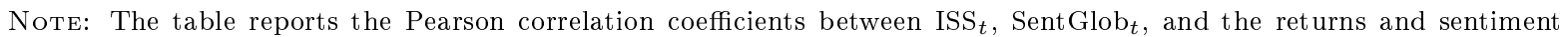
measures of the value-weighted ESG portfolios.

longer significantly different from zero. On average, the return after 30 trading days amounts to roughly 35 basis points. The results suggest that investors demand more sustainable stocks when $\mathrm{ISS}_{t}$ is positive, and in turn the higher demand pushes prices up increasing the returns of these stocks. The lower panel of Figure 7 depicts the risk-adjusted returns of the simple trading strategy, which correspond to the intercept ("alphas") from regressing the cumulative return on the three Fama and French (1993) factors and the momentum factor of Carhart (1997). ${ }^{14}$ Even after controlling for well-known risk factors, the trading strategy returns remain significantly positive. These results are particularly interesting when considering the fact that over the entire sample, the high ESG portfolio has on average a lower return than the low ESG portfolio.

The two diagnostic analyses presented in this section show that (i) $\mathrm{ISS}_{t}$ is contemporaneously uncorrelated with the return of a strategy long in high ESG portfolio and short in the low ESG portfolio, but (ii) ISS $_{t}$ appears to predict investors' demand for sustainable stocks. The results of the simple trading strategy might however be driven by other factors. For example, $\operatorname{ISS}_{t}$ could simply be a proxy of investors' sentiment for the stocks in the high and low ESG portfolios. Alternatively, $\mathrm{ISS}_{t}$ could simply capture the information of ESG related news articles. In the remainder of this section, we will test more formally the hypothesis that ISS $_{t}$ predicts investors' demand for sustainable stocks and hence their returns using multivariate regressions, whilst controlling for other potential predictors.

\footnotetext{
${ }^{14}$ The three Fama and French (1993) factors and the momentum factor are aggregated to the same frequency as the cumulative returns, i.e. we regress the cumulative return from $t$ to $t+h$ on the factor returns from $t$ to $t+h$.
} 


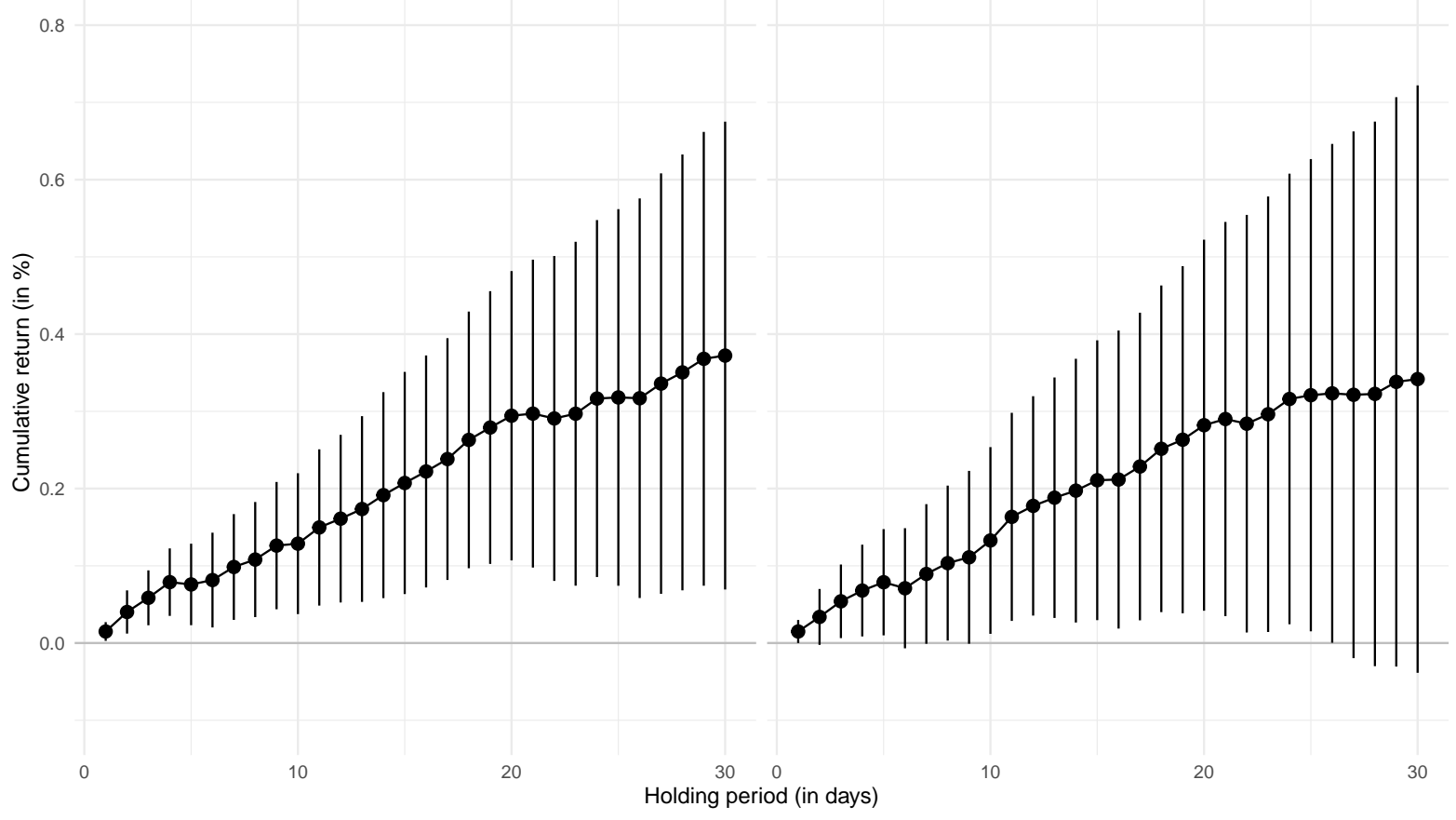

(a) Average cumulative raw returns

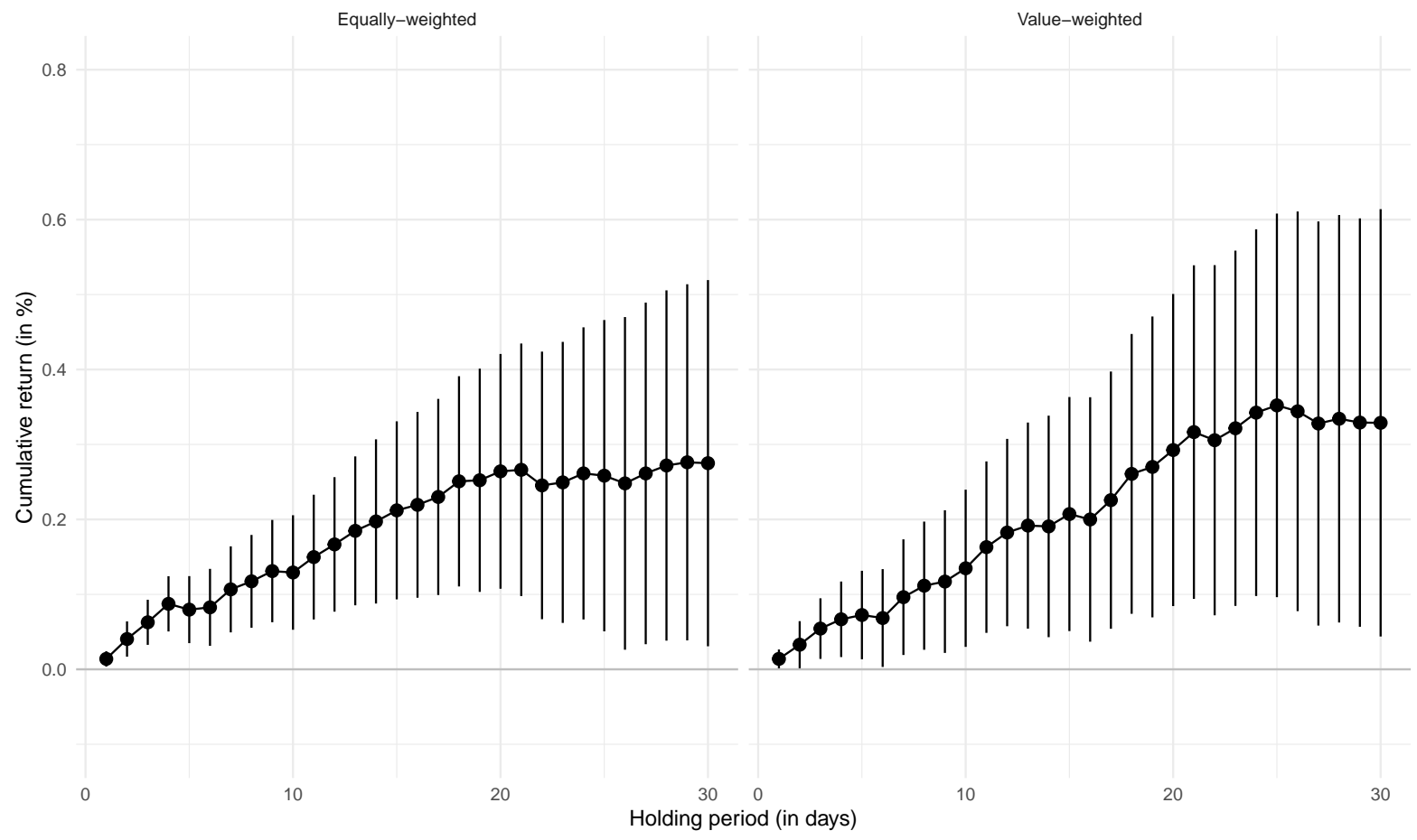

(b) Average cumulative risk-adjusted returns

Figure 7: Trading strategy returns based on $\operatorname{ISS}_{t}$

Note: The figure depicts the average cumulative returns of a trading strategy that goes long (short) in the high ESG portfolio and short (long) in the low ESG portfolio when $\mathrm{ISS}_{t}$ is positive (negative). The dots represent the average cumulative returns and the vertical lines the respective $95 \%$ confidence intervals. The confidence intervals are heteroskedastic robust and take into account the correlation induced by the overlapping nature of the cumulative returns. The upper panel depicts the average raw returns and the lower panel the average risk-adjusted returns. 


\subsection{Return predictability}

Our null hypothesis is that when investors feel more bullish (respectively bearish) about sustainability, the demand for stocks with an above (respectively below) average sustainability profile is unaffected. This hypothesis is motivated by the efficient market hypothesis in that asset prices fully reflect all available information. The alternative hypothesis builds on the theory of sustainable investing in equilibrium (Pástor, Stambaugh, and Taylor, 2020), in which sustainable assets outperform when there is a shift in investor taste for sustainability. Under this hypothesis, when investors feel more bullish (respectively bearish) about sustainability, the demand for stocks with above (respectively below) average sustainability profile increases. We would thus expect high sustainability sentiment, as captured by $\mathrm{ISS}_{t}$, to predict high future returns for stocks with high ESG scores. On the other hand, we expect low ESG sentiment to predict high future returns of stocks with low ESG scores. We test this hypothesis by running the following predictive regression:

$$
\operatorname{Return}_{\mathrm{HmL}, t+1}^{h}=\alpha+\beta \mathrm{ISS}_{t}+\gamma^{\prime} X_{t}+\epsilon_{t+1}^{h}
$$

where $\operatorname{Return}_{\mathrm{HmL}, t}^{h}=\sum_{i=0}^{h-1} \operatorname{Return}_{\mathrm{HmL}, t+i}$ is the continuously compounded excess return from $t$ to $t+h$ of the long-short strategy that goes long in the high ESG portfolio and short in the low ESG portfolio. For better interpretability of our results, we annualize the returns and standardize the predictors to have zero mean and unit standard deviation. Furthermore, we run the same predictive regression for risk-adjusted returns defined as the intercept plus the residuals from regressing the daily continuously compounded excess return on the three Fama and French (1993) factors and the momentum factor of Carhart (1997).

The vector $X_{t}$ contains several control variables. A concern that arises is that portfolios classified by their sustainability profiles implicitly carry a categorization along other related dimensions. Indeed, the summary statistics of the ten ESG portfolios presented in Table 10 showed that the stocks in the highest and lowest deciles differ in dimensions other than their ESG rating. In particular, stocks in the first decile have a smaller market capitalization, smaller bookto-market ratios, and higher idiosyncratic volatility compared to stocks in the last decile. These observations are consistent with a large body of research on sustainability ratings of individual stocks (Artiach, Lee, Nelson, and Walker, 2010; Drempetic, Klein, and Zwergel, 2019; Dunn, Fitzgibbons, and Pomorski, 2017). The risk-adjusted returns already account to some extent for these differences. Nevertheless, we want to ensure that $\mathrm{ISS}_{t}$ does not simply capture investors' 
taste for different company characteristics. Moreover, even though we orthogonalized $\operatorname{ISS}_{t}$ with respect to $\mathrm{SentGlob}_{t}$, the reader might still wonder if our measure of investors' ESG sentiment is simply capturing the market wide sentiment of investors. Finally, investors' sustainability sentiment might simply reflect their attention to sustainability or news about ESG related topics. To address these concerns, we include in the vector $X_{t}$ the portfolio sentiment $\mathrm{SentHmL}_{t}$, the global sentiment measure SentGlob ${ }_{t}$, the ESG attention measure AttESG ${ }_{t}$, ESG news sentiment, and portfolio specific characteristics (log market capitalization, book-to-market ratio, illiquidity, idiosyncratic volatility).

We estimate the predictive regression for five prediction horizons: one day, one week, two weeks, one month, and three months. Under the alternative hypothesis, we expect $\beta$ to be significantly positive. We use heteroskedastic robust standard errors and take into account the correlation induced by the overlapping nature of the dependent variable. It is well known that, when the predictors are persistent and their innovations correlated with the innovations of the dependent variable, the estimates of a predictive regression are biased (Stambaugh, 1999). Furthermore, under the null hypothesis of no predictability, the distribution of the t-statistics is not standard normal (e.g. Torous, Valkanov, and Yan, 2004). Even though the correlations between ISS $_{t}$ and the portfolio returns are close to zero, we address these concerns and obtain critical values by bootstrapping. More precisely, we follow, among others, Welch and Goyal (2008) and obtain the distribution of t-statistics by bootstrapping under the null-hypothesis with 5,000 replications. A detailed description of the bootstrap approach can be found in Appendix C.

The estimation results for raw and risk-adjusted returns are reported in Table 12. In the first five columns of Table 12, we report the estimation results of the regression defined in Equation (3) for raw returns. The last five columns report the results for risk-adjusted returns. The portfolios are value-weighted in Panel A and equal-weighted in Panel B. The t-statistics are reported in parentheses below the respective estimate. The table reports the estimated coefficient of $\mathrm{ISS}_{t}$ and the intercept. ${ }^{15}$ The intercepts for both value-weighted and equal-weighted portfolios are negative, showing that on average the stocks in the low ESG portfolio outperform the stocks in the high ESG portfolio (in terms of raw and risk-adjusted returns). The estimated coefficients of $\mathrm{ISS}_{t}$ are positive throughout all settings and prediction horizons, meaning that higher values of $\mathrm{ISS}_{t}$ predict higher future returns. For the value-weighted raw and risk-adjusted returns

\footnotetext{
${ }^{15}$ Estimated coefficients for the control variables are available from the authors upon request.
} 
these results are all significant at least at the $5 \%$ level, except for the one-day horizon where we find only significance at the $10 \%$ level for the risk-adjusted return and no significance for the raw return. The predictive power for the equal-weighted raw returns is significant at the $5 \%$ level, except for the one-day horizon where we find no significance. For the risk-adjusted equal-weighted returns, the estimated coefficients are significant at the $5 \%$ level from the oneweek up to the one-month horizon. The predictive power of $\mathrm{ISS}_{t}$ is also economically significant: a one-standard deviation increase in investors' sustainability sentiment predicts an annualize return of roughly $4 \%$ over the next five trading days. The predictive power increases over the first five trading days, and then starts to revert: we find the smallest predictive power at the one-quarter horizon.

\subsection{Robustness}

In the following, we asses the robustness of the results presented in Table 12. The tables summarizing the robustness checks are relegated to Appendix D. We start by analyzing if all components that determine our ESG sentiment measure have predictive power for the returns of the high-minus-low ESG portfolio. Tables D1, D2, and D3 report the estimation results of the regression defined in Equation (3) separately for $\operatorname{ISS}_{t}^{\mathrm{E}}, \operatorname{ISS}_{t}^{\mathrm{S}}$, and $\operatorname{ISS}_{t}^{\mathrm{G}}$. We find that the former two have significant predictive power for the returns of the high-minus-low ESG portfolio, whereas the estimated coefficients of ISS $_{t}^{G}$ are significantly positive only for the value-weighted returns from the two-weeks up to the one-quarter horizon, and for the equal-weighted returns from the one-month up to the one-quarter horizon. While there are clear differences between the sentiment measures, overall the robustness results show that the sentiments of all three ESG components have to some extent predictive power for the high-minus-low ESG portfolio returns.

Next, we asses the robustness of the results presented in Table 12 with regard to the control variables. In Table D4 we report the coefficients of $\mathrm{ISS}_{t}$ when estimating Equation (3) without any control variables. Our results are unaffected by excluding all control variables, and are qualitatively the same when excluding all control variables: ISS $_{t}$ has significant predictive power for the long-short raw and risk-adjusted returns, in particular over the one-week horizon. Table D5 reports the regression results for Equation (3) when additionally controlling for the unexpected changes in media climate change concerns (UMC), as defined by Ardia, Bluteau, Boudt, and Inghelbrecht (2021). Note that this index ends mid-2018, and hence the predictive regression uses only data from 2010 to the end of June 2018. The estimated coefficients of 
Table 12: Predictive regression for high-minus-low ESG portfolio returns

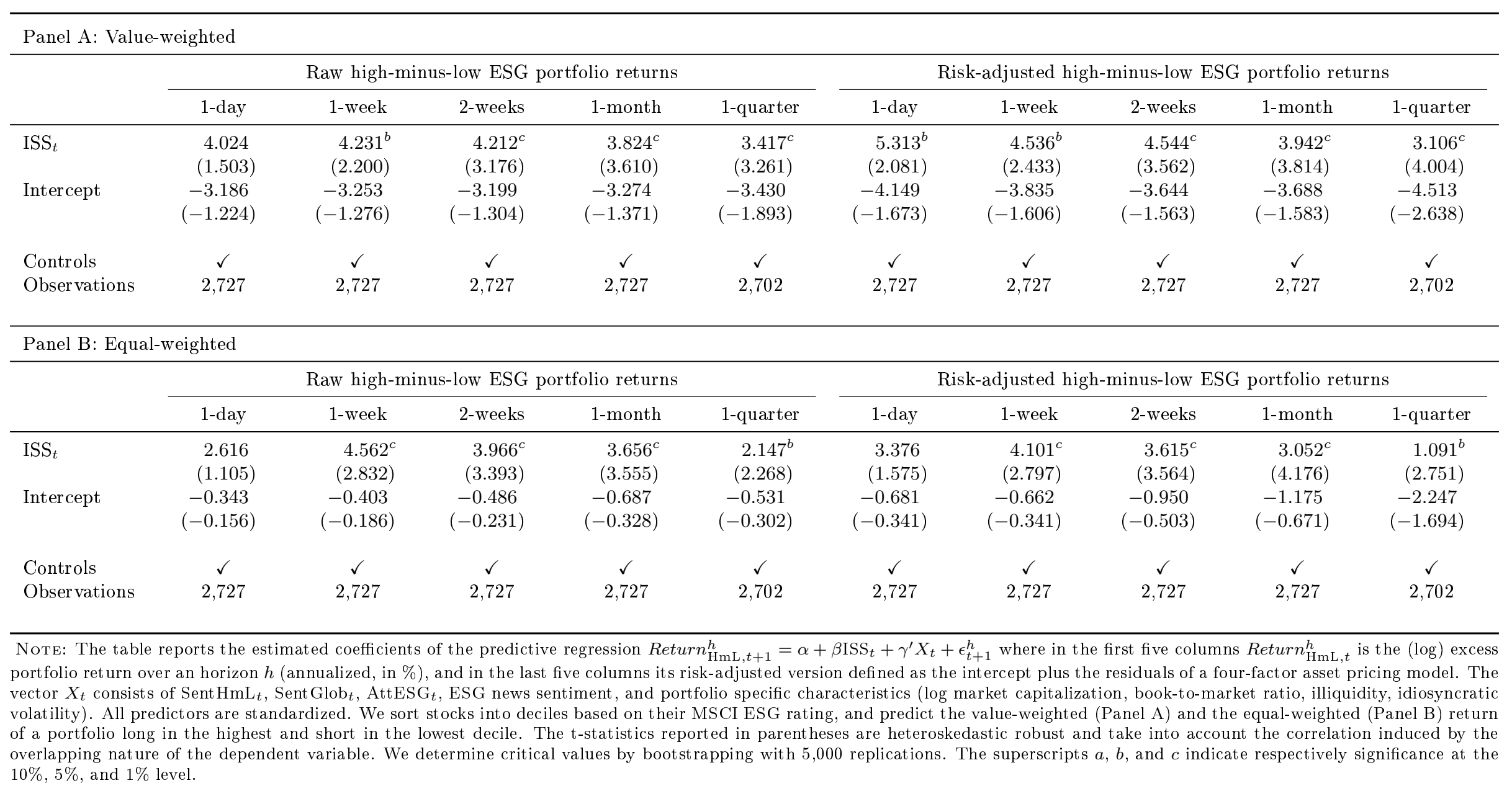


ISS $_{t}$ are slightly smaller, but, except for the equal-weighted returns at one-day and one-quarter horizon, statistically significant.

Furthermore, we analyze the robustness of our results with respect to the composition of social media users that discuss ESG-related topics. More precisely, we investigate if the predictive power of $\operatorname{ISS}_{t}$ is solely driven by new users discussing sustainability on social media. To this end, we define ISS $_{t}$ using only tweets of users that shared at least one ESG-related message before 2016 (see Section 3.1.1). The regression results are reported in Table D6. The results are qualitatively unaffected when defining sustainability sentiment using a fixed pool of social media users.

Finally, we asses the robustness of the aggregation scheme used to define ISS $_{t}$. In Equation (2) each sentiment component is assigned the same weight, i.e. $\operatorname{ISS}_{t}=\left(\operatorname{ISS}_{t}^{\mathrm{E}}+\operatorname{ISS}_{t}^{S}+\operatorname{ISS}_{t}^{\mathrm{G}}\right) / 3$. An alternative aggregation scheme, for instance, could assigns more weight to the ESG component that is most discussed on the social media platform StockTwits. Let $w_{t}^{\mathrm{E}}$ be the share of messages about the environment among all ESG-related messages published on day $t$, and define $\widetilde{w}_{t}^{\mathrm{E}}=$ $w_{t}^{\mathrm{E}} / \bar{w}^{\mathrm{E}}$ where $\bar{w}^{\mathrm{E}}$ is the sample average of $w_{t}^{\mathrm{E}}$. Intuitively, $\widetilde{w}_{t}^{\mathrm{E}}$ captures the abnormal share of messages about the environment published on a given day. We can then define the aggregated investor sentiment for sustainability as $\operatorname{ISS}_{t}=\left(\widetilde{w}_{t}^{\mathrm{E}} \operatorname{ISS}_{t}^{\mathrm{E}}+\widetilde{w}_{t}^{\mathrm{S}} \operatorname{ISS}_{t}^{\mathrm{S}}+\widetilde{w}_{t}^{\mathrm{G}} \operatorname{ISS}_{t}^{\mathrm{G}}\right) /\left(\widetilde{w}_{t}^{\mathrm{E}}+\widetilde{w}_{t}^{\mathrm{S}}+\widetilde{w}_{t}^{\mathrm{G}}\right)$. The estimation results using this alternative weighting scheme (see Table D7) are in line with our baseline findings report in Table 12. The estimated coefficients are all significantly positive and of the same magnitude as with the simpler aggregation scheme described in Equation (2).

\subsection{Non-linearities in the predictability}

The analysis of the investor sustainability sentiment index presented in Section 3 showed that the relation between $\mathrm{ISS}_{t}$ and the sentiment of ESG news is non-linear. More precisely, news about ESG leads negative investor sentiment for sustainability, but is not significantly related to positive $\mathrm{ISS}_{t}$. Moreover, news sentiment generally increases the disagreement between investors' sentiment for sustainability. In the following, we analyze whether there are differences in the predictive power of positive and negative $\mathrm{ISS}_{t}$ for stock returns. To this end, we estimate the following predictive regression:

$$
\operatorname{Return}_{\mathrm{HmL}, t+1}^{h}=\alpha+\beta_{1} \mathrm{ISS}_{t}^{+}+\beta_{2} \mathrm{ISS}_{t}^{-}+\gamma^{\prime} X_{t}+\epsilon_{t+1}^{h}
$$


where Return $n_{\mathrm{HmL}, t+1}^{h}$ is the risk-adjusted return of the high-minus-low ESG portfolio, $\mathrm{ISS}_{t}{ }^{+}=$ $\max \left(\mathrm{ISS}_{t}, 0\right), \mathrm{ISS}_{t}{ }^{-}=\min \left(\mathrm{ISS}_{t}, 0\right)$, and $X_{t}$ is the same vector of control variables as in Equation (3). Table 13 reports the estimated coefficients for the value-weighted (Panel A) and equalweighted (Panel B) returns of the high-minus-low ESG portfolio. For the one-day return, the coefficient of $\mathrm{ISS}_{t}{ }^{+}$is positive and larger in magnitude compared to the results depicted in Table 12, but decrease quickly afterwards and for the equal-weighted portfolio becomes even negative at the one-quarter prediction horizon. For example, a one-standard deviation increase in $\mathrm{ISS}_{t}{ }^{+}$ predicts an annualized increase in next day's return of 9 percentage points, but over the next 22 trading days it predicts an annualized increase of only 1.76 percentage points. Moreover, the estimated coefficients of $\mathrm{ISS}_{t}{ }^{+}$are only significant at the one-day horizon. The estimated coefficients of $\mathrm{ISS}_{t}{ }^{-}$are instead significantly positive at longer horizons. For the value-weighted portfolio, for instance, $\mathrm{ISS}_{t}{ }^{-}$has significant predictive power for the two-weeks, one-month, and one-quarter forecasting horizon. This result suggests that positive shocks in investors' taste for sustainability revert quickly, whereas negative shocks tend to be more persistent over time, especially for the value-weighted portfolio.

The reversion in the prediction of $\mathrm{ISS}_{t}{ }^{+}$is both consistent with the model of Pástor, Stambaugh, and Taylor (2020), as well as with the behavioral interpretation of investor sentiment. Theoretical models along the lines of De Long, Shleifer, Summers, and Waldmann (1990), for instance, define sentiment as the noise traders' subjective beliefs about future cash flows and investment risks. Baker and Wurgler (2006), among others, find that higher investor sentiment predicts lower future monthly returns, since prices revert to their fundamental value. The behavioral interpretation of $\mathrm{ISS}_{t}+$ is also in line with the results presented in Section 3 where we did not find any relation between the positive sustainability sentiment and ESG news sentiment. The return predictions of $\mathrm{ISS}_{t}{ }^{-}$are instead not or at least only slowly reverting. Together with our finding that ESG news sentiment leads negative sustainability sentiment, we argue that the information in $\mathrm{ISS}_{t}{ }^{-}$is (at least in part) of fundamental nature.

If this conjecture holds true, we expect an increase in $\mathrm{ISS}_{t}{ }^{+}$to predict higher short-term returns and the subsequent reversion in the returns to take longer for stocks that are more difficult to arbitrage. In contrast, we expect the predictive power of $\mathrm{ISS}_{t}{ }^{-}$to be larger throughout all horizons for stocks that are easier to arbitrage. We proxy the difficulty to arbitrage a stock by the share of institutional investors. The supply of lendable stocks in the short-selling market is generally lower for stocks with low institutional ownership, limiting the arbitrage possibilities 
Table 13: Non-linear predictive power of ESG sentiment

\begin{tabular}{|c|c|c|c|c|c|}
\hline \multicolumn{6}{|c|}{ Panel A: Value-weighted } \\
\hline & 1-day & 1-week & 2-weeks & 1-month & 1-quarter \\
\hline $\mathrm{ISS}_{t}+$ & $\begin{array}{r}9.199^{a} \\
(1.728)\end{array}$ & $\begin{array}{c}5.066 \\
(1.378)\end{array}$ & $\begin{array}{c}2.701 \\
(1.040)\end{array}$ & $\begin{array}{c}1.759 \\
(0.891)\end{array}$ & $\begin{array}{c}0.383 \\
(0.232)\end{array}$ \\
\hline $\mathrm{ISS}_{t}^{-}$ & $\begin{array}{c}2.564 \\
(0.614)\end{array}$ & $\begin{array}{c}4.160 \\
(1.537)\end{array}$ & $\begin{array}{r}5.847^{c} \\
(3.226)\end{array}$ & $\begin{array}{c}5.486^{c} \\
(3.222)\end{array}$ & $\begin{array}{r}5.013^{c} \\
(5.662)\end{array}$ \\
\hline Intercept & $\begin{array}{r}-6.458^{a} \\
(-1.735)\end{array}$ & $\begin{array}{c}-4.150 \\
(-1.495)\end{array}$ & $\begin{array}{c}-2.549 \\
(-0.991)\end{array}$ & $\begin{array}{c}-2.392 \\
(-0.904)\end{array}$ & $\begin{array}{c}-2.914 \\
(-1.779)\end{array}$ \\
\hline Controls & $\checkmark$ & $\checkmark$ & $\checkmark$ & $\checkmark$ & $\checkmark$ \\
\hline Observations & 2,727 & 2,727 & 2,727 & 2,727 & 2,702 \\
\hline \multicolumn{6}{|c|}{ Panel B: Equal-weighted } \\
\hline & 1-day & 1-week & 2-weeks & 1-month & 1-quarter \\
\hline $\mathrm{ISS}_{t}^{+}$ & $\begin{array}{r}8.261^{a} \\
(1.930)\end{array}$ & $\begin{array}{c}2.887 \\
(0.971)\end{array}$ & $\begin{array}{c}2.486 \\
(1.109)\end{array}$ & $\begin{array}{c}1.946 \\
(1.047)\end{array}$ & $\begin{array}{c}-0.351 \\
(-0.391)\end{array}$ \\
\hline $\mathrm{ISS}_{t}^{-}$ & $\begin{array}{l}-0.198 \\
(-0.057)\end{array}$ & $\begin{array}{r}4.990^{b} \\
(2.559)\end{array}$ & $\begin{array}{r}4.442^{b} \\
(2.728)\end{array}$ & $\begin{array}{c}3.861^{c} \\
(3.313)\end{array}$ & $\begin{array}{r}2.138^{b} \\
(3.226)\end{array}$ \\
\hline Intercept & $\begin{array}{c}-3.634 \\
(-1.211)\end{array}$ & $\begin{array}{c}0.072 \\
(0.031)\end{array}$ & $\begin{array}{c}-0.267 \\
(-0.129)\end{array}$ & $\begin{array}{c}-0.506 \\
(-0.287)\end{array}$ & $\begin{array}{c}-1.384 \\
(-0.987)\end{array}$ \\
\hline Controls & $\begin{array}{c}\checkmark \\
2707\end{array}$ & $\begin{array}{c}\checkmark \\
2727\end{array}$ & $\begin{array}{c}\checkmark \\
2797\end{array}$ & $\begin{array}{c}\checkmark \\
2797\end{array}$ & $\begin{array}{l}\checkmark \\
2702\end{array}$ \\
\hline
\end{tabular}

Note: The table reports the estimated coefficients of the predictive regression $\operatorname{Return}_{\mathrm{HmL}, t+1}^{h}=\alpha+\beta_{1} \mathrm{ISS}_{t}^{+}+\beta_{2} \mathrm{ISS}_{t}^{-}+$ $\gamma^{\prime} X_{t}+\epsilon_{t+1}^{h}$ where Return $n_{\mathrm{HmL}, t}^{h}$ is the risk-adjusted (log) return of the high-minus-low ESG portfolio over an horizon $h$ (annualized, in \%). Risk-adjusted returns are the intercept plus the residuals of a four-factor asset pricing model. The non-linear investor sustainability sentiment measures are defined as $\operatorname{ISS}_{t}{ }^{+}=\max \left(\operatorname{ISS}_{t}, 0\right)$ and $\operatorname{ISS}_{t}{ }^{-}=\min \left(\operatorname{ISS}_{t}, 0\right)$. The vector $X_{t}$ consists of SentHmL ${ }_{t}$, SentGlob, AttESG $_{t}$, ESG news sentiment, and portfolio specific characteristics (log market capitalization, book-to-market ratio, illiquidity, idiosyncratic volatility). All predictors are standardized. We sort stocks into deciles based on their MSCI ESG rating, and predict the value-weighted (Panel A) and the equal-weighted (Panel B) return of a portfolio long in the highest and short in the lowest decile. The t-statistics reported in parentheses are heteroskedastic robust and take into account the correlation induced by the overlapping nature of the dependent variable. We determine critical values by bootstrapping with 5,000 replications. The superscripts $a, b$, and $c$ indicate respectively significance at the $10 \%, 5 \%$, and $1 \%$ level.

(see, among others, Nagel, 2005). We use data from the Thomson Reuters Institutional Holdings (13F) database and collect for each company in our sample the fraction of shares outstanding held by institutional investors. Within each of the decile portfolios introduced in Section 4.1, we divide stocks into three groups based on their share of institutional investors. We then consider a high-minus-low portfolio which goes long in the portfolio of stocks with the highest institutional ownership within the last ESG decile, and short in the portfolio of stocks with the highest institutional ownership within the first ESG decile. Similarly, we define a high-minus-low portfolio that considers only the stocks with the lowest institutional ownership within the first and last ESG deciles.

Table 14 reports the estimation results of the regression defined in Equation (4) separately for stocks with a low (first five columns) and for those with a high (last five columns) share 
Table 14: Non-linear predictive power of ISS for ESG portfolios with low and high share of institutional holdings

\begin{tabular}{|c|c|c|c|c|c|c|c|c|c|c|}
\hline \multicolumn{11}{|c|}{ Panel A: Value-weighted } \\
\hline & \multicolumn{5}{|c|}{ Low institutional holdings } & \multicolumn{5}{|c|}{ High institutional holdings } \\
\hline & 1-day & 1-week & 2-weeks & 1-month & 1-quarter & 1-day & 1-week & 2-weeks & 1-month & 1-quarter \\
\hline $\mathrm{ISS}_{t}^{+}$ & $\begin{array}{l}11.575 \\
(1.332)\end{array}$ & $\begin{array}{l}10.385^{a} \\
(2.009)\end{array}$ & $\begin{array}{c}5.467 \\
(1.329)\end{array}$ & $\begin{array}{c}3.710 \\
(1.275)\end{array}$ & $\begin{array}{c}2.258 \\
(1.551)\end{array}$ & $\begin{array}{c}5.914 \\
(0.823)\end{array}$ & $\begin{array}{c}-0.649 \\
(-0.173)\end{array}$ & $\begin{array}{c}0.494 \\
(0.163)\end{array}$ & $\begin{array}{c}1.403 \\
(0.545)\end{array}$ & $\begin{array}{l}-2.853^{a} \\
(-2.191)\end{array}$ \\
\hline $\mathrm{ISS}_{t}^{-}$ & $\begin{array}{c}-0.398 \\
(-0.059)\end{array}$ & $\begin{array}{c}1.972 \\
(0.516)\end{array}$ & $\begin{array}{c}2.616 \\
(0.920)\end{array}$ & $\begin{array}{c}5.204^{b} \\
(2.391)\end{array}$ & $\begin{array}{r}4.065^{c} \\
(3.662)\end{array}$ & $\begin{array}{c}0.181 \\
(0.031)\end{array}$ & $\begin{array}{r}9.715^{c} \\
(2.933)\end{array}$ & $\begin{array}{r}9.915^{c} \\
(3.328)\end{array}$ & $\begin{array}{r}7.839^{c} \\
(3.862)\end{array}$ & $\begin{array}{c}3.374^{b} \\
(2.611)\end{array}$ \\
\hline Intercept & $\begin{array}{c}-8.216 \\
(-1.359)\end{array}$ & $\begin{array}{c}-7.406 \\
(-1.590)\end{array}$ & $\begin{array}{c}-5.331 \\
(-1.193)\end{array}$ & $\begin{array}{c}-3.261 \\
(-0.746)\end{array}$ & $\begin{array}{l}-5.221 \\
(-1.915)\end{array}$ & $\begin{array}{l}-4.049 \\
(-0.800)\end{array}$ & $\begin{array}{c}2.131 \\
(0.595)\end{array}$ & $\begin{array}{c}1.249 \\
(0.394)\end{array}$ & $\begin{array}{c}-1.044 \\
(-0.357)\end{array}$ & $\begin{array}{c}-4.441 \\
(-1.842)\end{array}$ \\
\hline Controls & $\checkmark$ & $\checkmark$ & $\checkmark$ & $\checkmark$ & $\checkmark$ & $\checkmark$ & $\checkmark$ & $\checkmark$ & $\checkmark$ & $\checkmark$ \\
\hline Observations & 2,727 & 2,727 & 2,727 & 2,727 & 2,702 & 2,727 & 2,727 & 2,727 & 2,727 & 2,702 \\
\hline \multicolumn{11}{|c|}{ Panel B: Equal-weighted } \\
\hline & \multicolumn{5}{|c|}{ Low institutional holdings } & \multicolumn{5}{|c|}{ High institutional holdings } \\
\hline & 1-day & 1-week & 2-weeks & 1-month & 1-quarter & 1-day & 1-week & 2-weeks & 1-month & 1-quarter \\
\hline $\mathrm{ISS}_{t}^{+}$ & $\begin{array}{l}18.558^{c} \\
(2.488)\end{array}$ & $\begin{array}{l}13.413^{c} \\
(3.088)\end{array}$ & $\begin{array}{r}7.879^{b} \\
(2.449)\end{array}$ & $\begin{array}{c}5.381 \\
(1.648)\end{array}$ & $\begin{array}{c}3.146^{a} \\
(1.876)\end{array}$ & $\begin{array}{c}3.447 \\
(0.534)\end{array}$ & $\begin{array}{c}3.229 \\
(0.833)\end{array}$ & $\begin{array}{c}4.362 \\
(1.429)\end{array}$ & $\begin{array}{c}4.101 \\
(1.723)\end{array}$ & $\begin{array}{c}0.285 \\
(0.209)\end{array}$ \\
\hline $\mathrm{ISS}_{t}^{-}$ & $\begin{array}{c}-2.595 \\
(-0.459)\end{array}$ & $\begin{array}{c}-0.654 \\
(-0.165)\end{array}$ & $\begin{array}{c}-0.523 \\
(-0.148)\end{array}$ & $\begin{array}{c}0.214 \\
(0.083)\end{array}$ & $\begin{array}{c}-1.182 \\
(-0.712)\end{array}$ & $\begin{array}{c}-0.078 \\
(-0.015)\end{array}$ & $\begin{array}{r}6.342^{b} \\
(2.166)\end{array}$ & $\begin{array}{r}7.078^{c} \\
(2.807)\end{array}$ & $\begin{array}{c}6.548^{c} \\
(3.932)\end{array}$ & $\begin{array}{c}3.473^{b} \\
(2.462)\end{array}$ \\
\hline Intercept & $\begin{array}{l}-10.898^{b} \\
(-2.105)\end{array}$ & $\begin{array}{c}-8.919^{a} \\
(-2.205)\end{array}$ & $\begin{array}{c}-6.762 \\
(-1.950)\end{array}$ & $\begin{array}{c}-4.270 \\
(-1.172)\end{array}$ & $\begin{array}{c}-3.270 \\
(-1.452)\end{array}$ & $\begin{array}{c}-2.971 \\
(-0.658)\end{array}$ & $\begin{array}{c}-0.441 \\
(-0.125)\end{array}$ & $\begin{array}{c}-0.917 \\
(-0.289)\end{array}$ & $\begin{array}{c}-1.459 \\
(-0.536)\end{array}$ & $\begin{array}{c}-4.488 \\
(-1.740)\end{array}$ \\
\hline Controls & $\checkmark$ & $\checkmark$ & $\checkmark$ & $\checkmark$ & $\checkmark$ & $\checkmark$ & $\checkmark$ & $\checkmark$ & $\checkmark$ & $\checkmark$ \\
\hline Observations & 2,727 & 2,727 & 2,727 & 2,727 & 2,702 & 2,727 & 2,727 & 2,727 & 2,727 & 2,702 \\
\hline
\end{tabular}

NoтE: The table reports the estimated coefficients of the predictive regression $\operatorname{Return}_{\mathrm{HmL}, t+1}^{h}=\alpha+\beta_{1} \mathrm{ISS}_{t}^{+}+\beta_{2} \mathrm{ISS}_{t}^{-}+\gamma^{\prime} X_{t}+\epsilon_{t+1}^{h}$ where $\operatorname{Return}_{\mathrm{HmL}, t}^{h}$ is the risk-adjusted $(\log )$ return of the high-minus-low ESG portfolio over an horizon $h$ (annualized, in \%). Risk-adjusted returns are the intercept plus the residuals of a four-factor asset pricing model. The non-linear investor sustainability sentiment measures are defined as $\mathrm{ISS}_{t}{ }^{+}=\max \left(\mathrm{ISS}_{t}, 0\right)$ and $\mathrm{ISS}_{t}{ }^{-}=\min \left(\mathrm{ISS}_{t}, 0\right)$. The vector $X_{t}$ consists of SentHmL $t$, SentGlob ${ }_{t}, \mathrm{AttESG}_{t}, \mathrm{ESG}$ news sentiment, and portfolio specific characteristics (log market capitalization, book-to-market ratio, illiquidity, idiosyncratic volatility). All predictors are standardized. We sort stocks into quintiles based on their MSCI ESG rating and within each quintile we split stocks according to their institutional holdings as reported in the quarterly $13 \mathrm{~F}$ filings. We predict the value-weighted (Panel A) and the equal-weighted (Panel B) return of a portfolio long in the highest and short in the lowest quintile separately for stocks with low (first five columns) and value-weighted (Panel A) and the equal-weighted (Panel B) return of a portfolio long in the highest and short in the lowest quintile separately for stocks with low (first five columns) and
high (last five columns) institutional holdings. The t-statistics reported in parentheses are heteroskedastic robust and take into account the correlation induced by the overlapping nature high (last five columns) institutional holdings. The t-statistics reported in parentheses are heteroskedastic robust and take into account the correlation induced by the overlapping nature
of the dependent variable. We determine critical values by bootstrapping with 5,000 replications. The superscripts $a, b$, and $c$ indicate respectively significance at the $10 \%, 5 \%$, and $1 \%$ level. 
of institutional investors. Over the short-term horizon (one-day and one-week), $\mathrm{ISS}_{t}{ }^{+}$has economically and statistically stronger predictive power for stocks with a low share of institutional investors. For the equal-weighted high-minus-low portfolio with a low institutional ownership, for instance, a one-standard deviation increase in $\mathrm{ISS}_{t}{ }^{+}$predicts an annualized increase in next day's risk-adjusted return of 18.56 percentage points (significant at the $5 \%$ level). In contrast, for stocks with a high institutional ownership, the increase amounts to only 3.45 percentage points and is not significant. The reversion of the short-term positive return is instead quicker for stocks with high institutional ownership. For example, for the value-weighted portfolio with high institutional ownership, the estimated coefficient of $\mathrm{ISS}_{t}{ }^{+}$is already negative for the one-week return and significantly negative for the quarterly return. The coefficients of $\mathrm{ISS}_{t}{ }^{-}$are economically larger for stocks with the highest institutional ownership. For example, for the value-weighted and equal-weighted two-week return, the coefficients are 9.92 and 7.01 (both significant at the $1 \%$ level) for stocks with the highest institutional ownership. The respective coefficients for the portfolio with low institutional ownership are 2.62 and -0.523 (both not significant).

Positive shocks in investor sentiment for sustainability thus appear to be a predominately behavioural phenomenon: bullish investors drive prices of stocks with high ESG ratings above their fundamental value. In the long run, arbitrageurs correct this deviation. On the other hand, our results suggest that bearish feelings about sustainable investments are related to fundamental news and predict permanent decreases (increases) in the prices of stocks with a high (low) ESG rating.

\subsection{Excess trading activity}

We conclude our predictive analysis in the stock universe by analyzing the relation between investors' ESG sentiment and abnormal trading volume in stocks with high/low ESG ratings. We follow Lo and Wang (2000) and study the portfolio share turnover ratio defined as the valueweighted and equal-weighted average of the stocks' turnover ratio. We define the turnover ratio of the high-minus-low ESG portfolio as the average between the turnover ratio of the first and the last decile portfolio. Since we are interested in the predictive power of sentiment for the abnormal trading activity, we follow García (2013) and remove low frequency components and calendar-effects from the portfolio share turnover ratio. More precisely, let $T O_{\mathrm{HmL}, t}$ be the daily 
$\log$ turnover ratio of high-minus-low. Consider the following regression:

$$
T O_{\mathrm{HmL}, t}=\sum_{j=1}^{5} \gamma_{j} T O_{\mathrm{HmL}, t-j}+\theta^{\prime} X_{t}+u_{t}
$$

where $X_{t}$ includes a constant, weekday dummy variables, and monthly dummies. We define the abnormal turnover ratio $\widehat{T O}_{\mathrm{HmL}, t}^{h}$ as:

$$
\widehat{T O}_{\mathrm{HmL}, t}^{h}=\sum_{i=0}^{h-1} \widehat{u}_{t+i}
$$

We standardize $\widehat{T O}_{\mathrm{HmL}, t}^{h}$ to have zero mean and unit standard deviation.

Our hypothesis is that very high and very low sentiment predicts abnormal trading in ESG stocks. When investors feel bullish or bearish about ESG topics, they will trade more intensively in stocks with high and low ESG ratings. In line with the theories of Campbell, Grossman, and Wang (1993) and De Long, Shleifer, Summers, and Waldmann (1990), for example Tetlock (2007) and García (2013) find that absolute sentiment obtained from news articles predicts trading volume. We test this hypothesis by estimating the following regression:

$$
\widehat{T O}_{\mathrm{HmL}, t+1}^{h}=\alpha+\beta_{1} \mathrm{ISS}_{t}^{+}+\beta_{2} \mathrm{ISS}_{t}^{-}+\gamma^{\prime} X_{t}+z_{t+1}^{h}
$$

where the prediction horizons are, as before, one day, one week, two weeks, one month, and one quarter. The vector $X_{t}$ consists of the same controls as in Equation (3) and additionally includes the portfolio's return and squared return on day $t$. The predictors are all standardized. The coefficients can thus be interpreted as the change in standard deviations of abnormal turnover predicted by a one-standard deviation increase in the respective predictor. We expect $\beta_{1}$ to be significantly positive and $\beta_{2}$ significantly negative.

The estimation results reported in Table 15 support our hypothesis. The estimated coefficients show that extreme high and low values of ISS $_{t}$ predict higher trading activity in stocks with high or low ESG ratings. The predictive power of $\mathrm{ISS}_{t}{ }^{+}$is short-living and decreases with the forecasting horizon, except for the one-quarter horizon. Except for the one-day abnormal turnover of the equal-weighted portfolio, the estimated coefficients of $\mathrm{ISS}_{t}{ }^{-}$are instead significantly negative throughout. These findings are consistent with the idea that the predictive power of $\mathrm{ISS}_{t}$ for stock returns is related to abnormal trading in stocks with both high and low 
Table 15: Predictive power of ESG sentiment for the abnormal share turnover

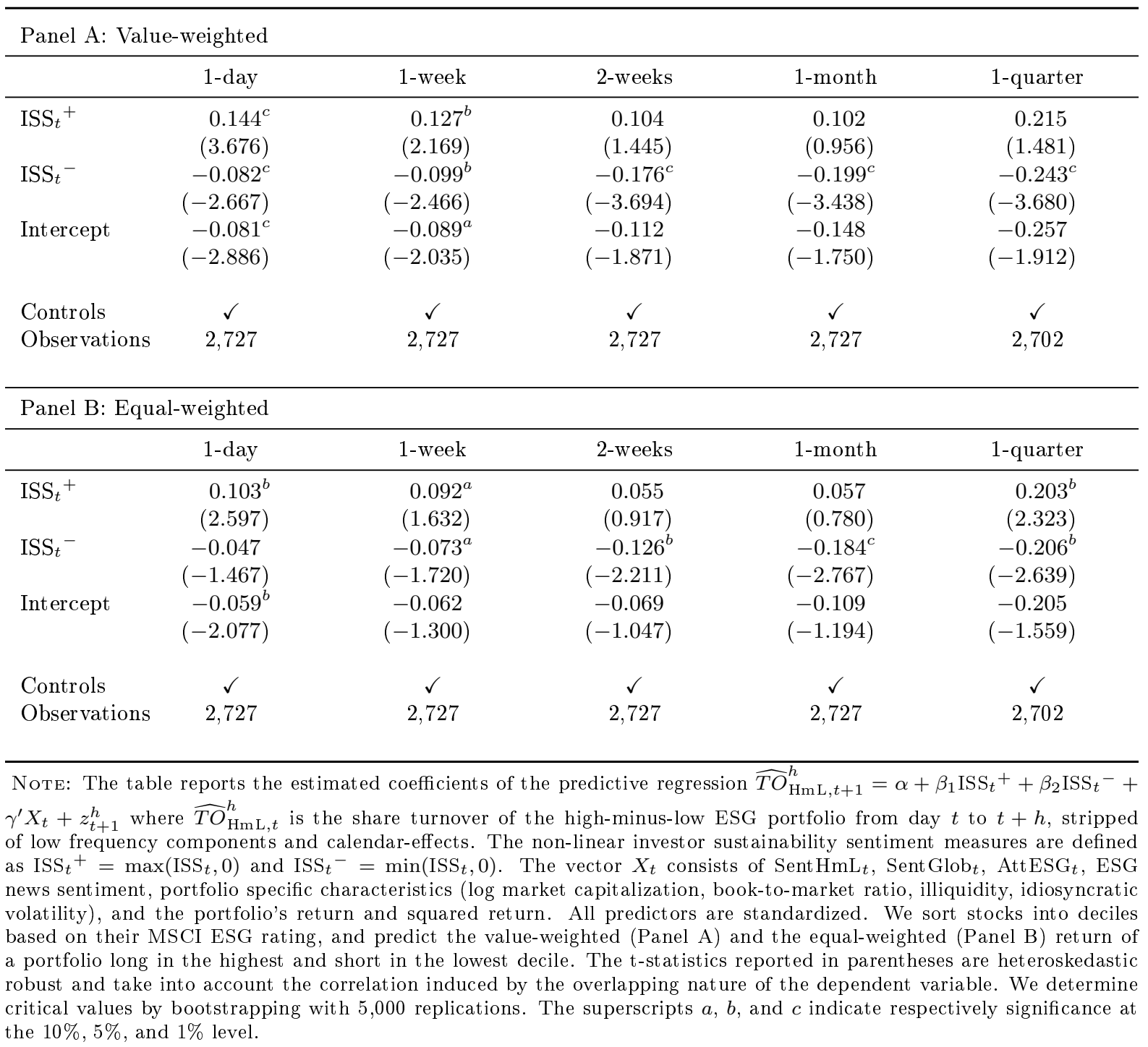

ESG ratings.

\section{$5 \quad$ Sustainability sentiment and mutual funds}

Mutual funds are a popular investment vehicle for many financial market participants. In recent years the popularity of sustainable funds increased significantly: according to Morningstar's Sustainable Funds U.S. Landscape Report for 2020, mutual funds still represent the most direct way for investors to invest sustainably (Morningstar, 2021). While in 2018 the net inflow in sustainable funds amounted to roughly USD 5 billions, in 2020 it increased to more than USD 50 billions (Morningstar, 2021). The funds' sustainability ratings published by commercial vendors play a significant role in this context. Hartzmark and Sussman (2019), for instance, provide evi- 
dence of a causal relation between Morningstar's sustainability ratings and a fund's net inflows. Not surprisingly, in a recent working paper Brière and Ramelli (2021) proxy investor sentiment for "green investments" with the monthly change in outstanding shares of environmental-friendly ETFs.

In this section we investigate the extent to which our measure of investor sentiment for sustainability can predict mutual fund flows. We define the monthly net fund flows as the percentage change in outstanding shares of open-ended US mutual funds. Our data spans from August 2018 to December 2020. In total we have 2,428 mutual funds in our dataset. Since the mutual fund data has a monthly frequency, we construct a monthly version of $\mathrm{ISS}_{t}$ : the construction still relies on Equation (1), but uses the monthly count of environmental-, social-, and governance-related social media messages.

We analyze the predictive power of $\mathrm{ISS}_{t}$ by estimating the following panel regression:

$$
\begin{aligned}
\text { FundFlow }_{i, t+1}= & \gamma_{1} \text { HighSust }_{i, t}+\gamma_{2} \text { LowSust }_{i, t}+\beta_{1} \text { HighSust }_{i, t} \cdot \mathrm{ISS}_{t}+\beta_{2} \text { LowSust }_{i, t} \cdot \text { ISS }_{t} \\
& +c_{i}+k_{t}+\gamma^{\prime} X_{i, t}+\epsilon_{i, t+1}
\end{aligned}
$$

where FundFlow $i, t+1$ is the percentage change in outstanding shares of mutual fund $i$ from month $t$ to month $t+1$, HighSust ${ }_{i, t}$ (LowSust $_{i, t}$ ) is a dummy variable being equal to one if fund $i$ obtained the highest (lowest) sustainability rating from Morningstar in month $t$ and zero otherwise, $c_{i}$ and $k_{t}$ are respectively fund and time fixed-effects, and $X_{i, t}$ is a vector of time-varying control variables (the fund flow and return in $t$ and $t-1$ and the log total dollar value of assets under management in $t$ ). The right-hand side variables are standardized to have zero mean and unit variance. In line with the results presented in Section 4, we expect higher sustainability sentiment to predict larger flows into sustainable funds and lower inflows into funds with a low sustainability rating. In other words, we expect $\beta_{1}$ to be significantly positive and $\beta_{2}$ significantly negative.

The estimated coefficients of the fixed-effects panel regression defined in Equation (6) are reported in the first column of Table 16. The t-statistics reported in parentheses below the respective coefficient are computed using standard errors clustered at the fund-level. The estimate for $\beta_{1}$ is positive and the estimate for $\beta_{2}$ negative, both significant at $5 \%$ level. In economic terms, a one-standard deviation increase in investor sentiment for sustainability is associated with a $0.24 \%$ increase in next month's outstanding shares of a sustainable mutual fund, and 
Table 16: Prediction of mutual fund flows with sustainability sentiment

\begin{tabular}{|c|c|c|}
\hline \multirow[b]{2}{*}{ Dummy high sustainability rating } & \multicolumn{2}{|c|}{ Dependent variable: Fund flow in $t+1$} \\
\hline & $\begin{array}{l}-0.143 \\
(-0.444)\end{array}$ & $\begin{array}{l}-0.487 \\
(-1.163)\end{array}$ \\
\hline Dummy low sustainability rating & $\begin{array}{c}0.101 \\
(0.671)\end{array}$ & $\begin{array}{c}0.267 \\
(1.082)\end{array}$ \\
\hline Dummy high sustainability rating $\times$ ISS $_{t}$ & $\begin{array}{r}0.244^{b} \\
(2.213)\end{array}$ & \\
\hline Dummy low sustainability rating $\times \operatorname{ISS}_{t}$ & $\begin{array}{l}-0.261^{b} \\
(-2.198)\end{array}$ & \\
\hline Dummy high sustainability rating $\times \mathrm{ISS}_{t}{ }^{+}$ & & $\begin{array}{l}0.837^{b} \\
(2.380)\end{array}$ \\
\hline Dummy low sustainability rating $\times \mathrm{ISS}_{t}{ }^{+}$ & & $\begin{array}{l}-0.521^{a} \\
(-1.657)\end{array}$ \\
\hline Dummy high sustainability rating $\times \mathrm{ISS}_{t}{ }^{-}$ & & $\begin{array}{l}-0.075 \\
(-0.474)\end{array}$ \\
\hline Dummy low sustainability rating $\times \mathrm{ISS}_{t}{ }^{-}$ & & $\begin{array}{l}-0.108 \\
(-0.703)\end{array}$ \\
\hline Fund flow in $t$ & $\begin{array}{l}-0.014 \\
(-0.227)\end{array}$ & $\begin{array}{l}-0.014 \\
(-0.227)\end{array}$ \\
\hline Fund flow in $t-1$ & $\begin{array}{l}-0.029 \\
(-0.608)\end{array}$ & $\begin{array}{l}-0.029 \\
(-0.607)\end{array}$ \\
\hline Fund return in $t$ & $\begin{array}{r}0.359^{c} \\
(4.690)\end{array}$ & $\begin{array}{r}0.364^{c} \\
(4.758)\end{array}$ \\
\hline Fund return in $t-1$ & $\begin{array}{c}0.021 \\
(0.246)\end{array}$ & $\begin{array}{c}0.018 \\
(0.210)\end{array}$ \\
\hline Log total AUM in $t$ & $\begin{array}{r}-7.209^{c} \\
(-10.759)\end{array}$ & $\begin{array}{r}-7.210^{c} \\
(-10.759)\end{array}$ \\
\hline$R^{2}$ & $5.721 \%$ & $5.723 \%$ \\
\hline Observations & 66,918 & 66,918 \\
\hline Number of funds & 2,428 & 2,428 \\
\hline Time fixed-effects & $\checkmark$ & $\checkmark$ \\
\hline Fund fixed-effects & $\checkmark$ & $\checkmark$ \\
\hline
\end{tabular}

Nоте: The table reports in the first column the estimation results of the fixed-effects panel regression FundFlow Fut $_{t+1}=$ $\gamma_{1}$ HighSust $_{i, t}+\gamma_{2}$ LowSust $_{i, t}+\beta_{1}$ HighSust $_{i, t} \cdot \operatorname{ISS}_{t}+\beta_{2}$ LowSust $_{i, t} \cdot \operatorname{ISS}_{t}+c_{i}+k_{t}+\gamma^{\prime} X_{i, t}+\epsilon_{i, t+1}$, where FundFlow Fut $_{i, 1}$ is the percentage change in outstanding shares of mutual fund $i$ from month $t$ to month $t+1$, HighSust int, $_{\text {(LowSust }}$ Lot, $_{\text {) }}$ is a dummy variable being equal to one if fund $i$ obtained the highest (lowest) sustainability rating from Morningstar in month $t$ and zero otherwise, $c_{i}$ and $k_{t}$ are respectively fund and time fixed-effects, and $X_{i, t}$ is a vector of time-varying control variables (the fund flow and return in $t$ and $t-1$ and the log total dollar value of assets under management in $t$ ). The second column reports the estimation results when distinguishing between positive and negative investor sentiment for sustainability. The right-hand side variables are standardized to have zero mean and unit variance. The t-statistics reported in parentheses below the respective coefficient are computed using standard errors clustered at the fund-level. The superscripts $a, b$, and $c$ indicate respectively significance at the $10 \%, 5 \%$, and $1 \%$ level.

a $0.26 \%$ reduction in next month's outstanding shares of a mutual fund with the lowest sustainability rating. While these effects appear to be small in absolute terms, the predictions are sizeable if compared to the average fund flows. In fact, from 2018 to 2020 funds with the highest sustainability rating experienced on average a $0.26 \%$ monthly increase in the outstanding shares, whereas the outstanding shares of mutual funds with the lowest sustainability rating shrank on average $0.38 \%$ each month. Note that in Table 16 the coefficients of the dummy variables for high and low sustainability ratings are not significant since we include mutual fund fixed-effects. 
The analysiss of ISS $t$ and its effect to asset prices suggests that the relation between sustainability sentiment and news and stock returns might be non-linear. We therefore estimate the regression defined in Equation (6) also for $\operatorname{ISS}_{t}^{+}=\max \left(\operatorname{ISS}_{t}, 0\right)$ and $\operatorname{ISS}_{t}{ }^{-}=\min \left(\operatorname{ISS}_{t}, 0\right)$. The estimation results are reported in the second column of Table 16. The results show that $\mathrm{ISS}_{t}{ }^{+}$ has significant positive (negative) predictive power for the fund flows of mutual funds with the highest (lowest) sustainability ratings. When investors are optimistic about ESG investing, a one-standard deviation increase in ISS $_{t}$ predicts a $0.84 \%$ increase in the outstanding shares of funds with the highest sustainability rating and a $0.52 \%$ decrease in those of the funds with the lowest rating. Interestingly, we do not find statistically significant evidence for the predictive power of $\mathrm{ISS}_{t}^{-}$.

In summary, we find that our measure of investor sentiment for sustainability predicts the fund flows of mutual funds. Higher sustainability sentiment predicts net inflows into funds that have a high sustainability rating and net outflows from mutual funds with a low sustainability rating. Moreover, our results suggest that investors move their money from funds with low ratings to funds with high ratings during periods of overall high sustainability sentiment (i.e. $\left.\mathrm{ISS}_{t}>0\right)$.

\section{Conclusion}

Investments in sustainable assets are on the rise, and asset pricing models incorporating sustainability are emerging as a result. This paper presents an empirical validation of the new asset pricing paradigm, in which both the sustainability profile of assets and investor sentiment towards sustainability play a role and impact asset prices. Our contribution in this space is twofold. First, we develop a novel, direct, and market-wide aggregate index of investor sentiment for sustainability using messages posted on a social media platform dedicated to investors. This is in contrast to existing measures of sustainability sentiment relying on market outcomes, such as return, volume, or mutual fund flows, which are indirect proxies for investor taste. We show that our index is related to but different from other proxies of sustainability sentiment, such as investor attention based on Google search volume or news analytics. Second, we build on the theoretical arguments as well as on the empirical accounts of the growing market share of sustainable assets by demonstrating that investor sentiment for sustainability has a significant impact on trading activity and asset prices. We find that positive shocks in investor sentiment 
for sustainability drive prices of stocks with high ESG ratings above their fundamental value, which is corrected in the long run. Our results also suggest that bearish sentiment about sustainability predict long term asset price decreases (increases) for stocks with high (low) ESG ratings. Finally, we provide evidence that increases in sustainability sentiment predict net inflows for sustainable mutual funds, and net outflows for mutual funds with low sustainability ratings.

Our index and results suggest several avenues for future work for both academics and practitioners. Further research could gauge in more detail the reaction of investors to different sustainability events, such as specific policy announcements or implementations. An interesting concrete extension of our results is the study of the relation between sustainability sentiment and other more specialized assets, such as green bonds. Our index could also be used to compare different ESG rating providers in terms of their visibility, importance, or relevance for investors. Finally, our approach towards constructing keywords for a specific topic can be adapted to measure and compare sentiment towards more specialized sustainability issues. 


\section{References}

Albuquerque, R., Y. Koskinen, S. Yang, and C. Zhang (2020): "Resiliency of Environmental and Social Stocks: An Analysis of the Exogenous COVID-19 Market Crash," The Review of Corporate Finance Studies, 9(3), 593-621.

Albuquerque, R., Y. Koskinen, and C. Zhang (2018): "Corporate Social Responsibility and Firm Risk: Theory and Social Responsibility and Firm Risk: Theory and Empirical Evidence," Management Science, 65(10), 4451-4949.

AmiHUD, Y. (2002): "Illiquidity and stock returns: cross-section and time-series effects," Journal of Financial Markets, 5(1), 31-56.

Anand, P., And C. J. Cowton (1993): "The Ethical Investor: Exploring Dimensions of Investment Behaviour," Journal of Economic Psychology, 14(2), 377-385.

Ang, A., R. J. Hodrick, Y. Xing, and X. Zhang (2006): "The cross-Section of volatility and expected returns," The Journal of Finance, 61(1), 259-299.

Antweiler, W., and M. Z. Frank (2004): "Is all that talk just noise? The information content of internet stock message boards," Journal of Finance, 59(3), 1259-1294.

Ardia, D., K. Bluteau, K. Boudt, and K. Inghelbrecht (2021): "Climate Change Concerns and Performance of Green Versus Brown Stocks," Working Paper.

Artiach, T., D. Lee, D. Nelson, and J. Walker (2010): "The determinants of corporate sustainability performance," Accounting $\&$ Finance, 50(1), 31-51.

Baier, P., M. Berninger, and F. Kiesel (2020): "Environmental, social and governance reporting in annual reports: A textual analysis," Financial Markets, Institutions 83 Instruments, 29(3), 93-118.

Baker, M., D. Bergstrasser, G. Serafaim, and J. Wurgler (2020): "Financing the Response to Climate Change: The Pricing and Ownership of U.S. Green Bonds," NBER Working Paper.

Baker, M., And J. Wurgler (2006): "Investor sentiment and the cross-section of stock returns," Journal of Finance, 61(4), 1645-1680.

(2007): "Investor Sentiment in the Stock Market," Journal of Economic Perspectives, 21(2), 129-152.

Baker, S. R., N. Bloom, S. J. Davis, and T. Renault (2021): "Twitter-Derived Measures of Economic Uncertainty," Working Paper. 
Barber, B. M., A. Morse, And A. Yasuda (2021): "Impact Investing," Journal of Financial Economics, 139, 162-185.

Barber, B. M., and T. Odean (2008): "All that Glitters: The Effect of Attention and News on the Buying Behavior of Individual and Institutional Investors," Review of Financial Studies, 21, 785-818.

Barberis, N., A. Shleifer, and R. Vishny (1998): “A Model of Investor Sentiment," Journal of Financial Economics, 49(1), 307-343.

Barreda-Tarrazona, I., J. C. Matallin-Saez, and R. Balaguer-Franch (2011): "Mesuring Investors' Socially Responsible Preferences in Mutual Funds," Journal of Business Ethics, 103(305).

Bauer, R., T. Ruof, and P. Smeets (2021): "Get Real! Individuals Prefer More Sustainable Investments," Review of Financial Studies, 34(8), 3976-4043.

Beal, D., M. Goyen, and P. J. Phillips (2005): "Why Do We Invest Ethically?" The Journal of Investing, 14(3), 66-77.

Berg, F., J. F. Koelbel, and R. Rigobon (2020): "Aggregate Confusion: The Divergence of ESG Ratings," SSRN Working Paper.

Bollen, N. P. (2007): "Mutual Fund Attributes and Investor Behavior," Journal of Financial and Quantitative Analysis, 42, 683-708.

Brandon, R. G., P. Krueger, and P. S. Schmidt (2021): "ESG Rating Disagreement and Stock Returns," Financial Analysts Journal, 77(4).

Brière, M., and S. Ramelli (2021): "Green Sentiment, Stock Returns, and Corporate Behavior," SSRN Working Paper.

Buzby, S. L., ANd H. FAlK (1978): "A Survey of the Interest in Social Responsibility Information by Mutual Funds," Accounting, Organizations and Society, 3(3/4), 191-201.

(1979): "Demand for Social Responsibility Information by University Investors," The Accounting Review, 54(1), 23-37.

Campbell, J. Y., S. J. Grossman, and J. Wang (1993): "Trading Volume and Serial Correlation in Stock Returns," The Quarterly Journal of Economics, 108(4), 905-939.

Carhart, M. M. (1997): "On Persistence in Mutual Fund Performance," The Journal of Finance, $52(1), 57-82$.

Choi, D., Z. Gao, and W. Jiang (2020): "Attention to global warming," Review of Financial Studies, 33(3), 1112-1145. 
Christensen, D., G. Serafaim, and A. Sikochi (2021): "Why is Corporate Virtue in the Eye of the Beholder? The Case of ESG Ratings.," Journal of Accounting Research.

Cookson, J. A., And M. Niessner (2020): “Why Don't We Agree? Evidence from a Social Network of Investors," Journal of Finance, 75(1), 173-228.

Cornett, M. M., O. Erhemjamts, and H. Tehranian (2016): "Greed or good deeds: An examination of the relation between corporate social responsibility and the financial performance of U.S. commercial banks around the financial crisis," Journal of Banking \& Finance, 70, 137-159.

Da, Z., J. Engelberg, and P. Gao (2011): "In Search of Attention," Journal of Finance, 66(5), 1461-1499.

(2015): "The Sum of All FEARS: Investor Sentiment and Asset Prices," Review of Financial Studies, 28(1), 1-32.

De Long, J. B., A. Shleifer, L. H. Summers, and R. J. Waldmann (1990): "Noise Trader Risk in Financial Markets," Journal of Political Economy, 98(4), 703-738.

Demers, E., J. Hendriske, P. Joss, and B. Lev (2021): "ESG Did Not Immunize Stocks During the COVID-19 Crisis, but Investments in Intangible Assets Did," Journal of Business Finance and Accounting, 48(3-4), 433-462.

Dickey, D. A., And W. A. Fuller (1979): "Distribution of the Estimators for Autoregressive Time Series With a Unit Root," Journal of the American Statistical Association, 74(366), $427-431$.

(1981): "Likelihood Ratio Statistics for Autoregressive Time Series with a Unit Root," Econometrica, 49(4), 1057-1072.

Ding, W., R. Levine, C. Lin, and W. Xie (2020): "Corporate Immunity to the COVID-19 Pandemic," Journal of Financial Economics, forthcoming.

Doeskeland, T., And L. J. T. Pedersen (2016): "Investing with Brain or Heart? A Field Experiment on Responsible Investment," Management Science, 62(6), 1632-1644.

Dorfleitner, G., and S. Utz (2014): "Profiling German-speaking Socially Responsible Investors," Qualitative Research in Financial Markets, 6(2), 118-156.

Drempetic, S., C. Klein, and B. Zwergel (2019): "The Influence of Firm Size on the ESG Score: Corporate Sustainability Ratings Under Review," Journal of Business Ethics.

Dunn, J., S. Fitzgibbons, and L. Pomorski (2017): "Assessing Risk Through Environmental, Social and Governance Exposures," Journal of Investment Management, 16, 4-17. 
Engle, R. F., S. Giglio, B. Kelly, H. Lee, and J. Stroebel (2020): "Hedging climate change news," Review of Financial Studies, 33(3), 1184-1216.

Fama, E. F., And K. R. French (1993): "Common risk factors in the returns on stocks and bonds," Journal of Financial Economics, 33(1), 3-56.

Fama, E. F., And K. R. French (2007): "Disagreement, Tastes, and Asset Prices," Journal of Financial Economics, 83, 667-689.

Fama, E. F., and K. R. French (2008): "Average Returns, B/M, and Share Issues," The Journal of Finance, 63(6), 2971-2995.

García, D. (2013): "Sentiment during Recessions," Journal of Finance, 68(3), 1267-1300.

GLAC, K. (2009): "Understanding Socially Responsible Investing: The Effect of Decision Frames and Trade-Off Options," Journal of Business Ethics, 87(1), 41-55.

GoldberG, L. R., And S. Mouti (2019): "Sustainable Investing and the Cross-Section of Maximum Drawdown," SSRN Electronic Journal.

GSIA (2020): "Global Sustainable Investment Review," www.gsi-alliance.org.

Hartzmark, S. M., And A. B. Sussman (2019): "Do Investors Value Sustainability? A Natural Experiment Examining Ranking and Fund Flows," Journal of Finance, 74(6), $2789-2837$.

Heinkel, R., A. Kraus, and J. Zechner (2001): "The Effect of Green Investment on Corporate Behavior," Journal of Financial and Quantitative Analysis, 36, 431-449.

Hong, H., And L. Kostovetsky (2012): "Red and Blue Investing: Values and Finance," Journal of Financial Economics, 103, 1-19.

Kahneman, D. (1973): Attention and Effort. Prentice-Hall, Englewood Cliffs, New Jearsey.

Kumar, A., And C. M. C. LeE (2006): "Retail Investor Sentiment and Return Comovements," The Journal of Finance, 61(5), 2451-2486.

Lewis, A., AND J. Cullis (1990): "Ethical Investments: Preferences and Morality," Journal of Behavioral Economics, 19(4), 395-411.

Lins, K. V., H. Servaes, and A. Tamayo (2017): "Social Capital, Trust, and Firm Performance: The Value of Corporate Social Responsibility during the Financial Crisis," Journal of Finance, 72(4), 1785-1824.

Lo, A. W., And J. Wang (2000): “Trading volume: Definitions, data analysis, and implications of portfolio theory," Review of Financial Studies, 13(2), 257-300.

McKinsey (2017): "McKinsey Global Sustainability Report," www.mckinsey.com. 
McLachlan, J., and J. Gardner (2004): "A Comparison of Socially Responsible and Conventional Investors," Journal of Business Ethics, 52(1), 11-25.

Morningstar (2021): "Sustainable Funds U.S. Landscape Report 2020," Morningstar Manager Research.

Moskowitz, M. R. (1972): "Choosing Socially Responsible Stocks," Business and Society Review, 1, 72-75.

NAGEL, S. (2005): "Short sales, institutional investors and the cross-section of stock returns," Journal of Financial Economics, 78(2), 277-309.

Nilsson, J. (2009): "Segmenting Socially Responsible Mutual Fund Investors: The Influence of Financial Return and Social Responsibility," International Journal of Bank Marketing, $27(1), 5-31$.

Pástor, L., R. F. Stambaugh, and L. A. Taylor (2020): "Sustainable investing in equilibrium," Journal of Financial Economics.

- (2021): "Dissecting Green Returns," Jacobs Levy Equity Management Center for Quantitative Financial Research Paper.

PÁstor, L., and M. B. Vorsatz (2020): "Mutual Fund Performance and Flows During the COVID-19 Crisis," The Review of Asset Pricing Studies, 10(4), 791-833.

Pedersen, L. H., S. Fitzgibbons, and L. Pomorski (2020): "Responsible investing: The ESG-efficient frontier," Journal of Financial Economics.

Renault, T. (2017): "Intraday online investor sentiment and return patterns in the U.S. stock market," Journal of Banking \&5 Finance, 84, 25-40.

(2019): "Sentiment analysis and machine learning in finance: a comparison of methods and models on one million messages," Digital Finance, pp. 1-13.

Renneboog, L., J. Ter Horst, and C. Zhang (2008): "Socially Responsible Investments: Institutional Aspects, Performance and Investor Behavior," Journal of Banking and Finance, pp. 1723-1742.

Rosen, B. N., D. M. Sandler, and D. Shani (1991): "Social Issues and Socially Responsible Investment Behavior: A Preliminary Empirical Investigation," Journal of Consumer Affairs, 25(2), 221-234.

Serafeim, G. (2020): "Public Sentiment and the Price of Corporate Sustainability," Financial Analysts Journal, 76(2), 26-46.

Stambaugh, R. F. (1999): "Predictive regressions," Journal of Financial Economics, 54(3), 
$375-421$.

Statman, M. (2000): "Socially Responsible Mutual Funds," Financial Analysts Journal, 56(3), $30-39$.

Tetlock, P. C. (2007): "Giving content to investor sentiment: The role of media in the stock market," Journal of Finance, 62(3), 1139-1168.

Torous, W., R. Valkanov, and S. Yan (2004): "On predicting stock returns with nearly integrated explanatory variables," Journal of Business, 77(4), 937-966.

Webley, P., A. Lewis, And C. Mackenzie (2001): "Commitment Among Ethical Investors: An Experimental Approach," Journal of Economic Psychology, 22(1), 27-42.

Welch, I., AND A. Goyal (2008): "A comprehensive look at the empirical performance of equity premium prediction," Review of Financial Studies, 21(4), 1455-1508.

Williams, G. (2007): "Some Determinants of the Socially Responsible Investment Decision: A Cross-Country Study," Journal of Behavioral Finance, 8(2), 43-57.

YuAn, Y. (2015): "Market-Wide Attention," Trading, and Stock Returns," Journal of Financial Economics, 116(3), 548-564. 


\section{Internet Appendix}

\section{A Construction of the keyword lists}

For the construction of the keyword lists we consider all messages published on StockTwits and Twitter between 2010 and 2020. We define a corpus of environmental-related social media messages by selecting all StockTwits and Twitter messages that mention the hashtag "\#environment" or "\#climatechange" (12,508,172 messages). The corpus of social-related messages consists of all messages that mention the hashtags "\#socialresponsability," "\#csr," "\#socimp," or "\#socialimpact" (2,017,588 messages). The 1,360,769 messages that mention the hashtags "\#corpgov" or "\#governance" define the corpus of governance-related messages. Finally, we define a random corpus of 27,055,764 StockTwits messages.

We clean the messages in the four corpora as follows. We lower case all letters and remove URLs, references to other users (“@...”), and casthags (“\$...”). HTML escape codes are unescaped (e.g. "\&amp" becomes "and"). We remove the punctuation and all English stop-words as defined by the Python module NLTK.

For each of the three ESG-related corpora we construct a dictionary of uni- and bi-grams. For each item in the dictionary and each text in a corpus we compute the term frequency, that is the number of times a uni- or bi-gram appears in a text message. We then scale the term-frequencies by multiplying them with their inverse document frequency in the random corpus. More precisely, we multiply each term by $\log (N+1)-\log (d f+1)$ where $N$ is the total number of messages in the random corpus and $d f$ is the number of messages in the random corpus that mention the respective uni- or bi-gram. We then exclude all uni- and bi-grams that are mentioned in less than 10 messages of the random corpus. Next, for each uni- and bigram and each ESG-corpus we sum the scaled term-frequencies across all messages. Intuitively, ESG-specific words such as "climatechange" will have a high term frequency in the corpus of environmental messages and a low document frequency in the random corpus. As such, the aggregated scaled term frequency will be high. On the other hand, the word "bullish" has a high term frequency in all three ESG-related corpora, but also a high document frequency in the corpus of random messages. The aggregated scaled term frequency of the word "bullish" is therefore low.

For each of the three ESG corpora we define an initial keyword list by selecting the 2,000 
uni- and bi-grams with the largest aggregated scaled term frequency. We then manually evaluate each item in the three keyword lists and remove all entries that are not related to the respective topic. Finally, for each of the remaining uni- and bi-grams we randomly select a sample of 100 messages that mention the respective keyword. We remove all uni- and bi-grams which are predominantly not used in the desired context. The final lists of keywords are reported in Table A1.

Table A1: Keywords used to identify ESG-related StockTwits messages

\begin{tabular}{|c|c|c|c|}
\hline \multicolumn{4}{|c|}{ Panel A: Environment keywords } \\
\hline air quality & energyefficiency & hurricane & renewables \\
\hline animal & enviro & hurricanes & reusable \\
\hline animalrights & environment & hydrogen & rising sea \\
\hline animals & environmental & ipcc & rising seas \\
\hline anthropogenic & environmentalism & life earth & save earth \\
\hline atmosphere & environmentalist & methane & save world \\
\hline atmospheric & environmentalists & natural disasters & $\operatorname{sdg}$ \\
\hline biodegradable & environmentally & nature & sea level \\
\hline biodiversity & epa & net zero & sea levels \\
\hline biomass & esg & netzero & smog \\
\hline carbon & extreme weather & nuclear & solar energy \\
\hline clean air & farming & oil spill & solar panels \\
\hline clean energy & farms & oilspill & solar power \\
\hline cleanenergy & fish & organic & solarpower \\
\hline cleaner & fisheries & oxygen & species \\
\hline cleaning & fishing & ozone & sustainability \\
\hline cleanup & food waste & p2 & sustainable \\
\hline cleanwater & footprint & paris agreement & temperature \\
\hline climate & forest & permafrost & temperatures \\
\hline climateaction & forestry & pesticides & tree \\
\hline climatechange & forests & planet & trees \\
\hline climategate & fossil & plantbased & use plastic \\
\hline $\operatorname{co} 2$ & fracking & plastic bags & warm \\
\hline crop & future generations & plastic waste & warmest \\
\hline crops & gases & pollutants & warming \\
\hline deforestation & ghg & polluted & wastemanagement \\
\hline dioxide & globalwarming & polluters & wastewater \\
\hline earth day & gogreen & polluting & water \\
\hline earthday & green energy & pollution & waters \\
\hline earthhour & green living & power plants & weather events \\
\hline eco & greenbuilding & rain & wetlands \\
\hline ecofriendly & greenenergy & rainfall & wilderness \\
\hline ecological & greener & rainforest & wildlife \\
\hline ecology & greenhouse & recycle & wind \\
\hline electricvehicles & groundwater & recycled & windpower \\
\hline emission & heat waves & recycling & \\
\hline emissions & heatwave & renewable & \\
\hline energy efficiency & heatwaves & renewableenergy & \\
\hline
\end{tabular}

(continued) 
Table A1 continued: Keywords used to identify ESG-related StockTwits messages

\begin{tabular}{|c|c|c|c|}
\hline \multicolumn{4}{|l|}{ Panel B: Social keywords } \\
\hline aid & donating & job opening & social entrepreneurship \\
\hline better world & donation & jobsearch & social good \\
\hline business community & donations & labor & social impact \\
\hline business practices & donors & labour & social innovation \\
\hline business social & education & local community & social investment \\
\hline career & employee engagement & mentalhealth & social issues \\
\hline careers & employer & microfinance & social responsibility \\
\hline changemakers & employers & ngo & social value \\
\hline charitable & employment & ngos & socialchange \\
\hline charities & equality & non profit & socialgood \\
\hline charitytuesday & esg & nonprofit & socially \\
\hline child & ethical & nonprofits & societal \\
\hline children & ethics & philanthropic & society \\
\hline citizen & fairtrade & philanthropy & sri \\
\hline citizens & foundation & poverty & supplier \\
\hline communities & foundations & privacy & supplychain \\
\hline community engagement & fundraisers & procurement & sustainability \\
\hline consumer & gender & product & sustainable \\
\hline consumers & girls & products & training \\
\hline corporate responsibility & givingtuesday & publichealth & underprivileged \\
\hline corporate social & gri & purpose driven & voluntary \\
\hline cse & health & responsibility report & volunteer \\
\hline $\operatorname{csr}$ & hiring & scholarship & volunteering \\
\hline customer & homeless & $\mathrm{scm}$ & volunteerism \\
\hline customers & homelessness & $\operatorname{sdg}$ & volunteers \\
\hline customerservice & human & slavery & welfare \\
\hline disability & humanitarian & socent & women \\
\hline diversity & humanity & social business & worker \\
\hline dogood & humanrights & social change & workers \\
\hline doing good & impact investing & social enterprise & workforce \\
\hline donate & impact investment & social enterprises & workplace \\
\hline donated & impact report & social entrepreneur & \\
\hline donates & inequality & social entrepreneurs & \\
\hline
\end{tabular}


Table A1 continued: Keywords used to identify ESG-related StockTwits messages

\begin{tabular}{|c|c|c|c|}
\hline \multicolumn{4}{|c|}{ Panel C: Governance keywords } \\
\hline accountability & ceo pay & erm & pay ratio \\
\hline accountable & $\mathrm{cfa}$ & esg & pension \\
\hline accounting & cfo & ethical & pensions \\
\hline activist investor & cfos & ethics & perspectives \\
\hline activist investors & chair & evaluation & poison \\
\hline activistinvestor & chairs & exec & proposal \\
\hline administration & chro & execs & proxy access \\
\hline advisers & cio & executive & proxy season \\
\hline advisor & ciso & executives & proxy voting \\
\hline advisors & cmo & family business & recruiting \\
\hline advisory & company board & family owned & recruitment \\
\hline agm & company directors & fca & relations \\
\hline appointed & company secretary & fсpa & remuneration \\
\hline appointment & compensation & founder board & retirement \\
\hline appointments & compliance & fraud & shareholder activism \\
\hline appoints & conduct & frc & shareholder proposals \\
\hline audit & conflict & gaap & shareholders vote \\
\hline auditing & conflicts & gender & skills \\
\hline auditor & control & governance & sri \\
\hline auditors & controls & incentive & stakeholder \\
\hline audits & coo & incentives & stakeholders \\
\hline benefits & corp board & independence & succession \\
\hline board composition & corp gov & independent director & sustainability \\
\hline board director & corpgov & independent directors & sustainable \\
\hline board directors & corporate board & inequality & talent \\
\hline board meeting & corporate culture & investorrelations & tenure \\
\hline board meetings & corporate directors & iod & thought leaders \\
\hline board member & corporate secretary & leader & transparency \\
\hline board members & corrupt & leaders follow & trust integrity \\
\hline board non & corruption & leadership & vacancies \\
\hline board seat & corruptly & management business & vote proxy \\
\hline board seats & cso & manager & voted proxy \\
\hline boardroom & csuite & managers & whistle blower \\
\hline boardrooms & cto & managing director & whistleblower \\
\hline boards & directorship & misconduct & women board \\
\hline bonus & disclose & money laundering & worker \\
\hline bonuses & disclosures & nacd & workers \\
\hline boss & diversity & new board & workforce \\
\hline bribery & $\mathrm{ecm}$ & new ceo & workplace \\
\hline career & elected & nominations & \\
\hline careers & elections & oversight & \\
\hline ceo board & engagement & owners & \\
\hline
\end{tabular}

Note: The table reports the keywords used to identify ESG-related messages among all tweets shared on the social media platform StockTwits. The keywords are uni- and bi-grams which are used more frequently in ESG-related messages compared to a random corpus of social media messages. 


\section{B Sentiment classification of social media messages}

We train a penalized logistic regression model to extract the sentimental connotation from the textual messages shared on StockTwits. Since 2012 users of the StockTwits social media platform can label their messages and replies to other messages as being either "bullish" or "bearish." To train our classifier we create a data set from labeled messages that mention ESGrelated keywords (see Table A1) published between 2012 and 2020. Since there are roughly three times more bullish messages in this sample, we apply an under-sampling approach to our data. More precisely, we randomly select (without replacement) bullish messages until our data set is balanced. We then clean the textual data as follows:

Step 1: lower case all letters,

Step 2: remove URLs, references to other users (“@...”) and casthags (“\$..."),

Step 3: un-escape HTML escape codes (e.g. "\&amp" becomes "and"),

Step 4: replace numbers with the tag "number_tag" and separate them from alphabetic endings (e.g. "10am" becomes "number_tag am"),

Step 5: replace emoticons with tags based on the Unicode Common Locale Data Repository ${ }^{16}$ short names (e.g. "simple_smile"),

Step 6: remove punctuation, non-English characters and single-letter words,

Step 7: shorten characters that appear more than two times (e.g. "loooool" becomes "lool"),

Step 8: remove the following stop-words: "an", "the", "and", "or", "of", "at", "for", "as", "to", "on".

We remove only a limited amount of stop-words, since it has been shown, that many words included in standard stop-word lists, such as "up", "down" or "above", have predictive power for sentiment analysis in finance (Renault, 2017,1). Furthermore, we do not lemmatize or stem the word tokens in our data set. Words such as "shorted" and "shorties", for example, share the same common root ("short") but have different connotations in finance. The cleaned data set consists of 1,133,964 observations. We define the training data set by randomly selecting 793,768 observations (70\%). The remaining 340,196 observations are assigned to the test set.

\footnotetext{
${ }^{16}$ http://www . unicode.org/emoji/charts/full-emoji-list.html
} 
After cleaning the textual data, we use a bag-of-words approach to create the feature matrix. Different approaches and parameterizations for these step are used. We determine by means of five-folded cross-validation (i) the number of words in a token (from only uni-grams up to trigrams), (ii) the values populating the feature matrix (term frequency or term frequency-inverse document frequency), (iii) the maximum number of features (from 25,000 to 40,000 in steps of 5,000 ), (iv) the upper threshold of the maximal document frequency ${ }^{17}$ (from $70 \%$ up to $100 \%$ in $10 \%$-steps) and (v) the lower threshold for the minimal document frequency $\left(10^{-4 \%}, 10^{-3} \%\right.$, $10^{-2 \%}, 10^{-1 \%}$ ). Finally, we determine by means of cross-validation also the hyperparameter of the classification model. The values considered for the $L_{1}$ penalization parameter of the logistic regression are $5 \cdot 10^{-7}, 10^{-6}, 10^{-5}$, and $10^{-4}$.

Based on the cross-validation results, we construct the feature matrix using uni-, bi-, and tri-grams, we populate the feature matrix using term frequencies-inverse document frequencies, set the maximum number of features to 35,000 , and remove tokens with a document frequency above $70 \%$ or below $10^{-3 \%}$. The $L_{1}$ penalization parameter is set to $10^{-6}$.

We evaluate the performance of the classification model over the (balanced) test sample of 340,196 observations. We report the overall accuracy (share of correctly classified messages) and Matthews correlation coefficient (MCC), defined as:

$$
M C C=\frac{T P / N-S \cdot P}{\sqrt{P \cdot S \cdot(1-S) \cdot(1-P)}}
$$

where $T P, F P, T N$ and $F N$ are true positives, false positives, true negatives and false negatives, respectively, $S=(T P+F N) / N, P=(T P+F P) / N$, and $N$ is the total number of classified messages. MCC ranges between -1 and +1 , where values close to +1 indicate that the model accurately classifies the observations. The confusion matrix and the two performance metrics are reported in Table B1.

\footnotetext{
${ }^{17}$ Word tokens that appear more than the maximal document frequency are removed from the feature matrix. By doing so, very common words or combinations of words are removed from the feature matrix.
} 
Table B1: Summary of the sentiment classification

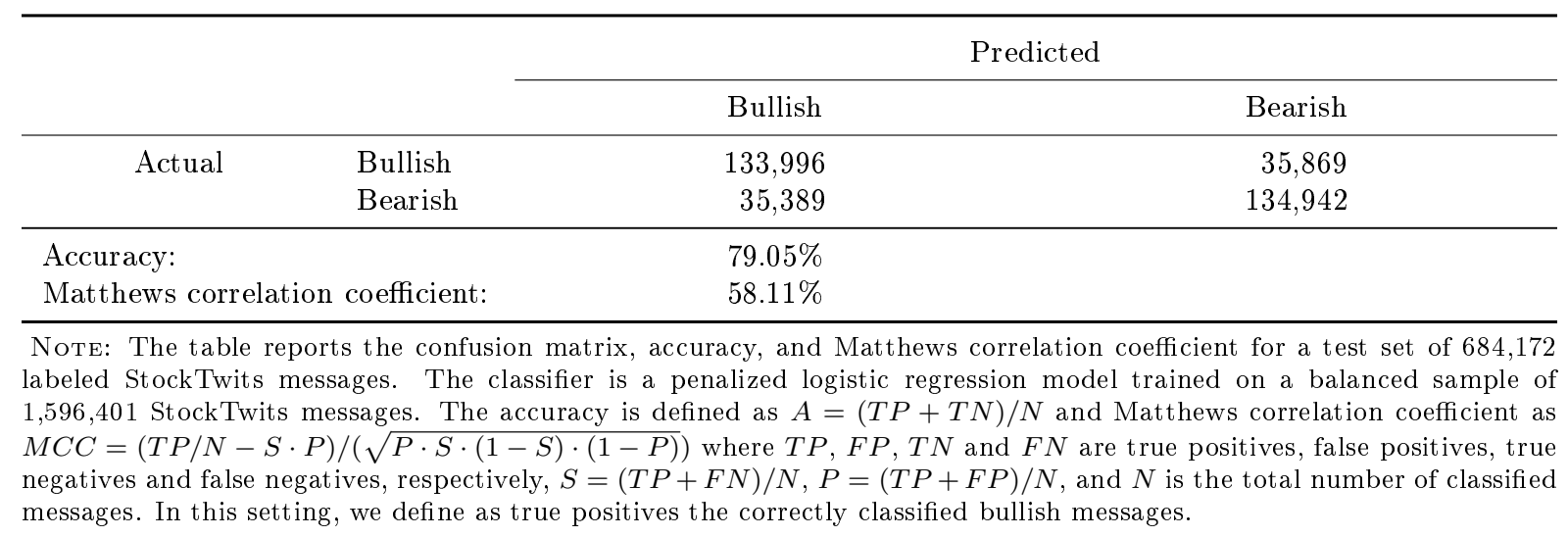




\section{Details about the bootstrapping approach}

In the following we present the bootstrap approach used for the inference of the return forecasts. Let the linear forecasting regression be:

$$
\operatorname{Return}_{t+1}=\alpha+\beta^{\prime} X_{t}+\epsilon_{t+1}
$$

where $X_{t}$ is a vector of predictors. We follow, among others, Welch and Goyal (2008) and obtain the distribution of t-statistics by means of bootstrapping. More precisely, the data generating process under the null hypothesis of no predictability is assumed to be:

$$
\begin{aligned}
\operatorname{Return}_{t+1} & =\alpha+\epsilon_{t+1} \\
X_{t+1} & =\Gamma_{0}+\sum_{i=1}^{p} \Gamma_{i} X_{t-i+1}+u_{t+1}
\end{aligned}
$$

where the predictors are assumed to follow a $\operatorname{VAR}(\mathrm{p})$ process. We determine $p$ with the Bayesian information criterion and estimated the parameters $\alpha, \Gamma_{0}, \ldots, \Gamma_{p}$ to obtain $\left\{\left(\epsilon_{t}, u_{t}\right)\right\}_{t=1}^{T}$. We generate bootstrap samples by randomly drawing residuals from $\left\{\left(\hat{\epsilon}_{t}, \hat{u}_{t}\right)\right\}_{t=1}^{T}$. The $\operatorname{VAR}(\mathrm{p})$ process is initialized by randomly selecting $p$ consecutive observations of $X_{t}$. When $X_{t}$ contains functions of variables, we generate random bootstraps of the raw variable . For example, if the predictor is the squared return, we generate bootstraps of the raw return and compute subsequently the squared return. Finally, bootstrapped t-statistics are obtained by estimating Equation (C1) on the bootstrapped sample. This procedure is repeated 5,000 times. 


\section{Additional tables}

Table D1: The predictive power of ISS $_{t}^{\mathrm{E}}$ for high-minus-low ESG portfolio returns

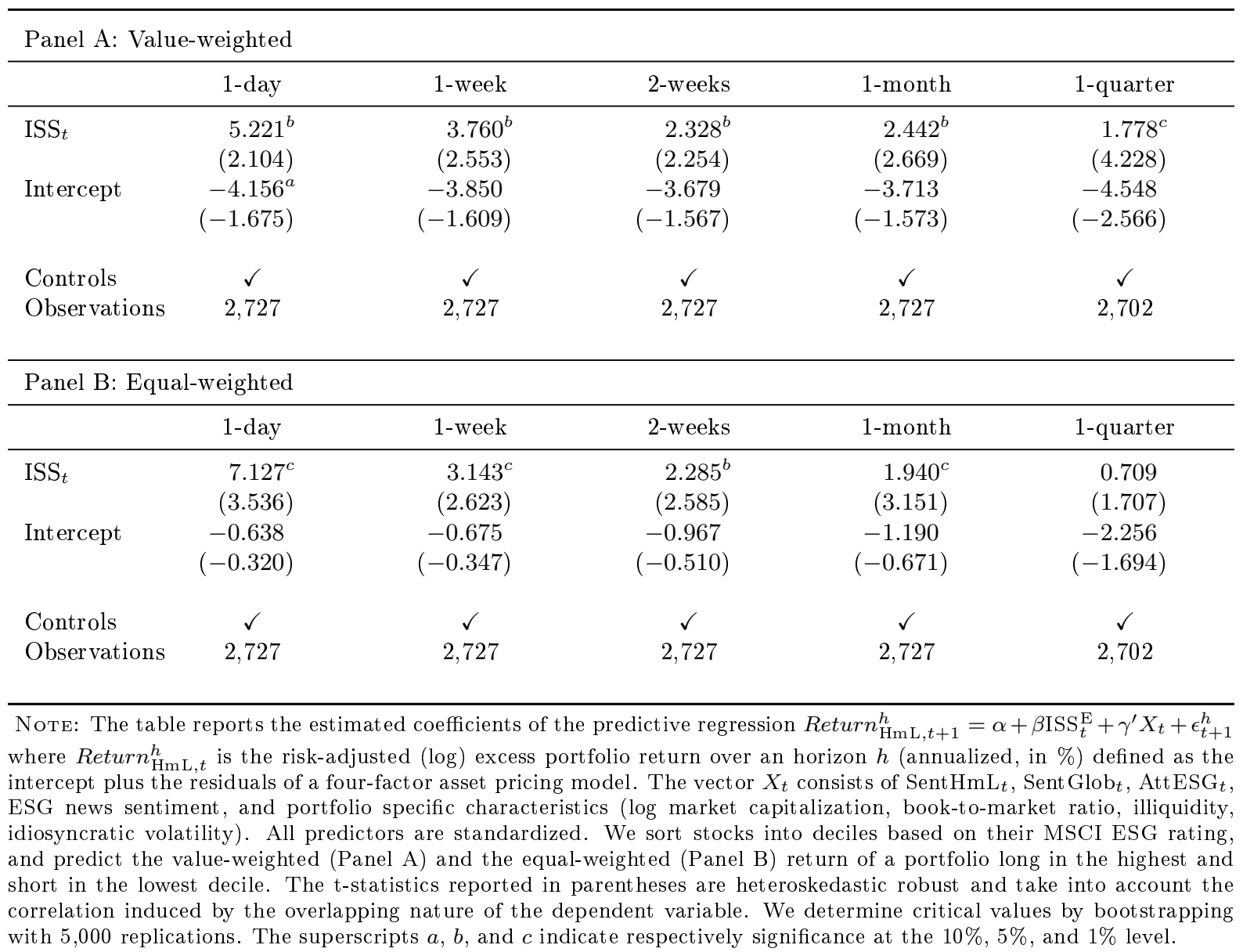


Table D2: The predictive power of ISS $_{t}^{S}$ for high-minus-low ESG portfolio returns

\begin{tabular}{|c|c|c|c|c|c|}
\hline \multicolumn{6}{|c|}{ Panel A: Value-weighted } \\
\hline & 1-day & 1-week & 2-weeks & 1-month & 1-quarter \\
\hline $\mathrm{ISS}_{t}$ & $\begin{array}{c}2.134 \\
(0.827)\end{array}$ & $\begin{array}{r}3.141^{a} \\
(1.700)\end{array}$ & $\begin{array}{r}3.710^{c} \\
(2.826)\end{array}$ & $\begin{array}{r}2.308^{b} \\
(2.592)\end{array}$ & $\begin{array}{r}1.622^{a} \\
(2.110)\end{array}$ \\
\hline Intercept & $\begin{array}{r}-4.202^{a} \\
(-1.693)\end{array}$ & $\begin{array}{c}-3.864 \\
(-1.615)\end{array}$ & $\begin{array}{c}-3.666 \\
(-1.566)\end{array}$ & $\begin{array}{c}-3.718 \\
(-1.572)\end{array}$ & $\begin{array}{c}-4.556 \\
(-2.561)\end{array}$ \\
\hline Controls & $\checkmark$ & $\checkmark$ & $\checkmark$ & $\checkmark$ & $\checkmark$ \\
\hline Observations & 2,727 & 2,727 & 2,727 & 2,727 & 2,702 \\
\hline \multicolumn{6}{|c|}{ Panel B: Equal-weighted } \\
\hline & 1-day & 1-week & 2-weeks & 1-month & 1-quarter \\
\hline $\mathrm{ISS}_{t}$ & $\begin{array}{c}1.851 \\
(0.876)\end{array}$ & $\begin{array}{c}3.718^{b} \\
(2.357)\end{array}$ & $\begin{array}{r}3.370^{c} \\
(3.076)\end{array}$ & $\begin{array}{c}2.089^{c} \\
(3.264)\end{array}$ & $\begin{array}{c}0.709 \\
(1.404)\end{array}$ \\
\hline Intercept & $\begin{array}{c}-0.707 \\
(-0.353)\end{array}$ & $\begin{array}{c}-0.681 \\
(-0.351)\end{array}$ & $\begin{array}{c}-0.966 \\
(-0.511)\end{array}$ & $\begin{array}{c}-1.195 \\
(-0.675)\end{array}$ & $\begin{array}{c}-2.260 \\
(-1.692)\end{array}$ \\
\hline $\begin{array}{l}\text { Controls } \\
\text { Observations }\end{array}$ & $\begin{array}{c}\checkmark \\
2,727\end{array}$ & $\begin{array}{c}\checkmark \\
2,727\end{array}$ & $\begin{array}{c}\checkmark \\
2,727\end{array}$ & $\begin{array}{c}\checkmark \\
2,727\end{array}$ & $\begin{array}{c}\checkmark \\
2,702\end{array}$ \\
\hline
\end{tabular}

Note: The table reports the estimated coefficients of the predictive regression $\operatorname{Return}_{\mathrm{HmL}, t+1}^{h}=\alpha+\beta \operatorname{ISS}_{t}^{\mathrm{S}}+\gamma^{\prime} X_{t}+\epsilon_{t+1}^{h}$ where $\operatorname{Return} n_{\mathrm{HmL}, t}^{h}$ is the risk-adjusted (log) excess portfolio return over an horizon $h$ (annualized, in \%) defined as the intercept plus the residuals of a four-factor asset pricing model. The vector $X_{t}$ consists of SentHmL ${ }_{t}, \operatorname{SentGlob}_{t}, \mathrm{AttESG}_{t}$, ESG news sentiment, and portfolio specific characteristics (log market capitalization, book-to-market ratio, illiquidity, idiosyncratic volatility). All predictors are standardized. We sort stocks into deciles based on their MSCI ESG rating, and predict the value-weighted (Panel A) and the equal-weighted (Panel B) return of a portfolio long in the highest and short in the lowest decile. The t-statistics reported in parentheses are heteroskedastic robust and take into account the correlation induced by the overlapping nature of the dependent variable. We determine critical values by bootstrapping with 5,000 replications. The superscripts $a, b$, and $c$ indicate respectively significance at the $10 \%, 5 \%$, and $1 \%$ level. 
Table D3: The predictive power of ISS $_{t}^{\mathrm{G}}$ for high-minus-low ESG portfolio returns

\begin{tabular}{|c|c|c|c|c|c|}
\hline \multicolumn{6}{|c|}{ Panel A: Value-weighted } \\
\hline & 1-day & 1-week & 2-weeks & 1-month & 1-quarter \\
\hline $\mathrm{ISS}_{t}$ & $\begin{array}{c}3.607 \\
(1.416)\end{array}$ & $\begin{array}{c}2.500 \\
(1.602)\end{array}$ & $\begin{array}{c}3.523^{b} \\
(2.683)\end{array}$ & $\begin{array}{r}3.522^{c} \\
(3.603)\end{array}$ & $\begin{array}{r}3.116^{c} \\
(3.875)\end{array}$ \\
\hline Intercept & $\begin{array}{c}-4.211^{a} \\
(-1.697)\end{array}$ & $\begin{array}{c}-3.891 \\
(-1.623)\end{array}$ & $\begin{array}{c}-3.695 \\
(-1.574)\end{array}$ & $\begin{array}{c}-3.730 \\
(-1.593)\end{array}$ & $\begin{array}{c}-4.552 \\
(-2.677)\end{array}$ \\
\hline $\begin{array}{l}\text { Controls } \\
\text { Observations }\end{array}$ & $\begin{array}{c}\checkmark \\
2,727\end{array}$ & $\begin{array}{c}\checkmark \\
2,727\end{array}$ & $\begin{array}{c}\checkmark \\
2,727\end{array}$ & $\begin{array}{c}\checkmark \\
2,727\end{array}$ & $\begin{array}{c}\checkmark \\
2,702\end{array}$ \\
\hline \multicolumn{6}{|c|}{ Panel B: Equal-weighted } \\
\hline & 1-day & 1-week & 2-weeks & 1-month & 1-quarter \\
\hline $\mathrm{ISS}_{t}$ & $\begin{array}{l}-2.971 \\
(-1.410)\end{array}$ & $\begin{array}{c}1.192 \\
(0.890)\end{array}$ & $\begin{array}{c}1.512 \\
(1.449)\end{array}$ & $\begin{array}{r}2.055^{b} \\
(2.826)\end{array}$ & $\begin{array}{r}0.750^{a} \\
(2.090)\end{array}$ \\
\hline Intercept & $\begin{array}{c}-0.738 \\
(-0.369)\end{array}$ & $\begin{array}{c}-0.706 \\
(-0.362)\end{array}$ & $\begin{array}{c}-0.986 \\
(-0.517)\end{array}$ & $\begin{array}{c}-1.201 \\
(-0.677)\end{array}$ & $\begin{array}{c}-2.259 \\
(-1.696)\end{array}$ \\
\hline Controls & $\checkmark$ & $\checkmark$ & $\checkmark$ & $\checkmark$ & $\checkmark$ \\
\hline Observations & 2,727 & 2,727 & 2,727 & 2,727 & 2,702 \\
\hline
\end{tabular}

Note: The table reports the estimated coefficients of the predictive regression $\operatorname{Return}_{\mathrm{HmL}, t+1}^{h}=\alpha+\beta \operatorname{ISS}_{t}^{\mathrm{G}}+\gamma^{\prime} X_{t}+\epsilon_{t+1}^{h}$ where $\operatorname{Return} n_{\mathrm{HmL}, t}^{h}$ is the risk-adjusted (log) excess portfolio return over an horizon $h$ (annualized, in \%) defined as the intercept plus the residuals of a four-factor asset pricing model. The vector $X_{t}$ consists of SentHmL ${ }_{t}, \operatorname{SentGlob}_{t}, \mathrm{AttESG}_{t}$, ESG news sentiment, and portfolio specific characteristics (log market capitalization, book-to-market ratio, illiquidity, idiosyncratic volatility). All predictors are standardized. We sort stocks into deciles based on their MSCI ESG rating, and predict the value-weighted (Panel A) and the equal-weighted (Panel B) return of a portfolio long in the highest and short in the lowest decile. The t-statistics reported in parentheses are heteroskedastic robust and take into account the correlation induced by the overlapping nature of the dependent variable. We determine critical values by bootstrapping with 5,000 replications. The superscripts $a, b$, and $c$ indicate respectively significance at the $10 \%, 5 \%$, and $1 \%$ level. 
Table D4: Predictive regression for high-minus-low ESG portfolio returns without any controls

\begin{tabular}{|c|c|c|c|c|c|c|c|c|c|c|}
\hline \multicolumn{11}{|c|}{ Panel A: Value-weighted } \\
\hline & \multicolumn{5}{|c|}{ Raw high-minus-low ESG portfolio returns } & \multicolumn{5}{|c|}{ Risk-adjusted high-minus-low ESG portfolio returns } \\
\hline & 1-day & 1-week & 2-weeks & 1-month & 1-quarter & 1-day & 1-week & 2-weeks & 1-month & 1-quarter \\
\hline \multirow[t]{2}{*}{$\mathrm{ISS}_{t}$} & $5.242^{a}$ & $5.049^{c}$ & $4.507^{c}$ & $3.934^{c}$ & $3.508^{b}$ & $6.276^{b}$ & $5.217^{c}$ & $4.748^{c}$ & $4.124^{c}$ & $3.345^{b}$ \\
\hline & $(2.024)$ & $(2.774)$ & $(2.960)$ & $(2.767)$ & $(2.262)$ & $(2.534)$ & $(2.838)$ & $(3.097)$ & $(2.804)$ & $(2.267)$ \\
\hline \multirow[t]{2}{*}{ Intercept } & -3.751 & -3.955 & -3.911 & -3.962 & -3.799 & $-4.604^{a}$ & -4.284 & -4.168 & -4.262 & -4.837 \\
\hline & $(-1.449)$ & $(-1.484)$ & $(-1.458)$ & $(-1.391)$ & $(-1.288)$ & $(-1.859)$ & $(-1.709)$ & $(-1.633)$ & $(-1.552)$ & $(-1.710)$ \\
\hline Controls & $x$ & $\times$ & $x$ & $x$ & $x$ & $x$ & $x$ & $x$ & $x$ & $x$ \\
\hline Observations & 2,768 & 2,763 & 2,758 & 2,746 & 2,702 & 2,768 & 2,763 & 2,758 & 2,746 & 2,702 \\
\hline
\end{tabular}

Panel B: Equal-weighted

\begin{tabular}{|c|c|c|c|c|c|c|c|c|c|c|}
\hline & \multicolumn{5}{|c|}{ Raw high-minus-low ESG portfolio returns } & \multicolumn{5}{|c|}{ Risk-adjusted high-minus-low ESG portfolio returns } \\
\hline & 1-day & 1-week & 2-weeks & 1-month & 1-quarter & 1-day & 1-week & 2-weeks & 1-month & 1-quarter \\
\hline $\mathrm{ISS}_{t}$ & 2.581 & $3.513^{b}$ & $3.059^{b}$ & $3.039^{b}$ & 2.280 & $3.865^{b}$ & $3.726^{b}$ & $3.280^{c}$ & $3.267^{c}$ & $2.018^{a}$ \\
\hline & (1.174) & $(2.307)$ & $(2.478)$ & $(2.557)$ & $(1.786)$ & $(1.950)$ & $(2.632)$ & $(2.921)$ & $(3.083)$ & (1.891) \\
\hline Intercept & -1.196 & -1.235 & -1.146 & -1.144 & -0.700 & -1.280 & -1.126 & -1.335 & -1.445 & -2.372 \\
\hline & $(-0.544)$ & $(-0.554)$ & $(-0.506)$ & $(-0.483)$ & $(-0.307)$ & $(-0.646)$ & $(-0.561)$ & $(-0.663)$ & $(-0.724)$ & $(-1.214)$ \\
\hline Controls & $\times$ & $\times$ & $x$ & $\times$ & $\times$ & $x$ & $\times$ & $x$ & $x$ & $x$ \\
\hline Observations & 2,768 & 2,763 & 2,758 & 2,746 & 2,702 & 2,768 & 2,763 & 2,758 & 2,746 & 2,702 \\
\hline
\end{tabular}

Note: The table reports the estimated coefficients of the predictive regression $\operatorname{Return}_{\mathrm{HmL}, t+1}^{h}=\alpha+\beta \mathrm{ISS}_{t}+\epsilon_{t+1}^{h}$ where in the first five columns $\operatorname{Return}_{\mathrm{HmL}, t}^{h}$ is the (log) excess portfolio return over an horizon $h$ (annualized, in \%), and in the last five columns its risk-adjusted version defined as the intercept plus the residuals of a four-factor asset pricing model. The

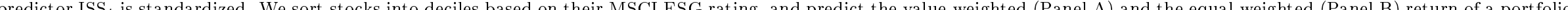
pres in long in the hight and short in the nature of the dependent variable. We determine critical values by bootstrapping with 5,000 replications. The superscripts $a, b$, and $c$ indicate respectively significance at the $10 \%, 5 \%$, and
$1 \%$ level. 
Table D5: Predictive regression for high-minus-low ESG portfolio returns controlling for media climate change concerns

\begin{tabular}{|c|c|c|c|c|c|}
\hline \multicolumn{6}{|c|}{ Panel A: Value-weighted } \\
\hline & 1-day & 1-week & 2-weeks & 1-month & 1-quarter \\
\hline $\mathrm{ISS}_{t}$ & $\begin{array}{c}4.377 \\
(1.663)\end{array}$ & $\begin{array}{r}4.474^{b} \\
(2.363)\end{array}$ & $\begin{array}{r}4.746^{c} \\
(3.470)\end{array}$ & $\begin{array}{c}3.808^{c} \\
(3.550)\end{array}$ & $\begin{array}{r}3.022^{c} \\
(5.507)\end{array}$ \\
\hline Intercept & $\begin{array}{c}-5.490 \\
(-1.463)\end{array}$ & $\begin{array}{c}-5.955 \\
(-1.534)\end{array}$ & $\begin{array}{c}-5.526 \\
(-1.447)\end{array}$ & $\begin{array}{c}-5.213 \\
(-1.306)\end{array}$ & $\begin{array}{c}-6.464 \\
(-2.758)\end{array}$ \\
\hline $\begin{array}{l}\text { Controls } \\
\text { Observations }\end{array}$ & $\begin{array}{c}\checkmark \\
2.138\end{array}$ & $\begin{array}{c}\checkmark \\
2.138\end{array}$ & $\begin{array}{c}\checkmark \\
2.138\end{array}$ & $\begin{array}{c}\checkmark \\
2138\end{array}$ & $\begin{array}{l}\checkmark \\
2138\end{array}$ \\
\hline \multicolumn{6}{|c|}{ Panel B: Equal-weighted } \\
\hline & 1-day & 1-week & 2-weeks & 1-month & 1-quarter \\
\hline $\mathrm{ISS}_{t}$ & $\begin{array}{c}2.824 \\
(1.227)\end{array}$ & $\begin{array}{c}3.731^{b} \\
(2.573)\end{array}$ & $\begin{array}{r}2.877^{b} \\
(2.675)\end{array}$ & $\begin{array}{c}2.120^{b} \\
(2.616)\end{array}$ & $\begin{array}{c}0.658 \\
(1.552)\end{array}$ \\
\hline Intercept & $\begin{array}{c}-3.628 \\
(-1.290)\end{array}$ & $\begin{array}{c}-4.813 \\
(-1.704)\end{array}$ & $\begin{array}{c}-5.807 \\
(-2.038)\end{array}$ & $\begin{array}{c}-5.617 \\
(-2.175)\end{array}$ & $\begin{array}{c}-5.407 \\
(-3.090)\end{array}$ \\
\hline $\begin{array}{l}\text { Controls } \\
\text { Observations }\end{array}$ & $\begin{array}{c}\checkmark \\
2,138\end{array}$ & $\begin{array}{c}\checkmark \\
2,138\end{array}$ & $\begin{array}{c}\checkmark \\
2,138\end{array}$ & $\begin{array}{c}\checkmark \\
2,138\end{array}$ & $\begin{array}{c}\checkmark \\
2,138\end{array}$ \\
\hline
\end{tabular}

Note: The table reports the estimated coefficients of the predictive regression $\operatorname{Return}_{\mathrm{HmL}, t+1}^{h}=\alpha+\beta \mathrm{ISS}_{t}+\gamma^{\prime} X_{t}+\epsilon_{t+1}^{h}$ where $\operatorname{Return}_{\mathrm{HmL}, t}^{h}$ is the risk-adjusted (log) excess portfolio return over an horizon $h$ (annualized, in \%) defined as the intercept plus the residuals of a four-factor asset pricing model. The vector $X_{t}$ consists of SentHmL , SentGlob $_{t}$, $\mathrm{AttESG}_{t}, \mathrm{ESG}$ news sentiment, portfolio specific characteristics (log market capitalization, book-to-market ratio, illiquidity, idiosyncratic volatility), and unexpected changes in the media climate change concern index (Ardia, Bluteau, Boudt, and Inghelbrecht, 2021). All predictors are standardized. We sort stocks into deciles based on their MSCI ESG rating, and predict the value-weighted (Panel A) and the equal-weighted (Panel B) return of a portfolio long in the highest and short in the lowest decile. The t-statistics reported in parentheses are heteroskedastic robust and take into account the correlation induced by the overlapping nature of the dependent variable. We determine critical values by bootstrapping with 5,000 replications. The superscripts $a, b$, and $c$ indicate respectively significance at the $10 \%, 5 \%$, and $1 \%$ level. 
Table D6: Predictive regression for high-minus-low ESG portfolio returns with sustainability sentiment based on a fixed sample of users

\begin{tabular}{|c|c|c|c|c|c|}
\hline \multicolumn{6}{|c|}{ Panel A: Value-weighted } \\
\hline & 1-day & 1-week & 2-weeks & 1-month & 1-quarter \\
\hline $\mathrm{ISS}_{t}$ & $\begin{array}{r}6.007^{b} \\
(2.304)\end{array}$ & $\begin{array}{r}4.723^{b} \\
(2.528)\end{array}$ & $\begin{array}{r}5.559^{c} \\
(4.011)\end{array}$ & $\begin{array}{r}4.506^{c} \\
(4.078)\end{array}$ & $\begin{array}{r}2.826^{c} \\
(3.800)\end{array}$ \\
\hline Intercept & $\begin{array}{r}-4.145^{a} \\
(-1.671)\end{array}$ & $\begin{array}{c}-3.837 \\
(-1.609)\end{array}$ & $\begin{array}{c}-3.634 \\
(-1.568)\end{array}$ & $\begin{array}{c}-3.684 \\
(-1.592)\end{array}$ & $\begin{array}{c}-4.524 \\
(-2.675)\end{array}$ \\
\hline $\begin{array}{l}\text { Controls } \\
\text { Observations }\end{array}$ & $\begin{array}{c}\checkmark \\
2,727\end{array}$ & $\begin{array}{c}\checkmark \\
2,727\end{array}$ & $\begin{array}{c}\checkmark \\
2,727\end{array}$ & $\begin{array}{c}\checkmark \\
2,727\end{array}$ & $\begin{array}{c}\checkmark \\
2,702\end{array}$ \\
\hline \multicolumn{6}{|c|}{ Panel B: Equal-weighted } \\
\hline & 1-day & 1-week & 2-weeks & 1-month & 1-quarter \\
\hline $\mathrm{ISS}_{t}$ & $\begin{array}{c}3.111 \\
(1.437)\end{array}$ & $\begin{array}{r}3.915^{c} \\
(2.805)\end{array}$ & $\begin{array}{r}3.120^{c} \\
(2.893)\end{array}$ & $\begin{array}{c}2.193^{b} \\
(2.280)\end{array}$ & $\begin{array}{c}0.089 \\
(0.152)\end{array}$ \\
\hline Intercept & $\begin{array}{c}-0.665 \\
(-0.333)\end{array}$ & $\begin{array}{c}-0.640 \\
(-0.330)\end{array}$ & $\begin{array}{c}-0.937 \\
(-0.495)\end{array}$ & $\begin{array}{c}-1.172 \\
(-0.662)\end{array}$ & $\begin{array}{c}-2.266 \\
(-1.695)\end{array}$ \\
\hline $\begin{array}{l}\text { Controls } \\
\text { Observations }\end{array}$ & $\begin{array}{c}\checkmark \\
2,727\end{array}$ & $\begin{array}{c}\checkmark \\
2,727\end{array}$ & $\begin{array}{c}\checkmark \\
2,727\end{array}$ & $\begin{array}{c}\checkmark \\
2,727\end{array}$ & $\begin{array}{c}\checkmark \\
2,702\end{array}$ \\
\hline
\end{tabular}

Note: The table reports the estimated coefficients of the predictive regression $\operatorname{Return}_{\mathrm{HmL}, t+1}^{h}=\alpha+\beta \mathrm{ISS}_{t}+\gamma^{\prime} X_{t}+\epsilon_{t+1}^{h}$ where Return $n_{\mathrm{HmL}, t}^{h}$ is the risk-adjusted (log) excess portfolio return over an horizon $h$ (annualized, in \%) defined as the intercept plus the residuals of a four-factor asset pricing model. ISS $\mathrm{I}_{t}$ is constructed using only tweets published by users that shared at least one ESG-related message before 2016. The vector $X_{t}$ consists of SentHmL , SentGlob $_{t}, \mathrm{AttESG}_{t}$, ESG news sentiment, and portfolio specific characteristics (log market capitalization, book-to-market ratio, illiquidity, idiosyncratic volatility). All predictors are standardized. We sort stocks into deciles based on their MSCI ESG rating, and predict the value-weighted (Panel A) and the equal-weighted (Panel B) return of a portfolio long in the highest and short in the lowest decile. The t-statistics reported in parentheses are heteroskedastic robust and take into account the correlation induced by the overlapping nature of the dependent variable. We determine critical values by bootstrapping with 5,000 replications. The superscripts $a, b$, and $c$ indicate respectively significance at the $10 \%, 5 \%$, and $1 \%$ level. 
Table D7: Predictive regression for high-minus-low ESG portfolio returns using an alternative weighting scheme for $\mathrm{ISS}_{t}$

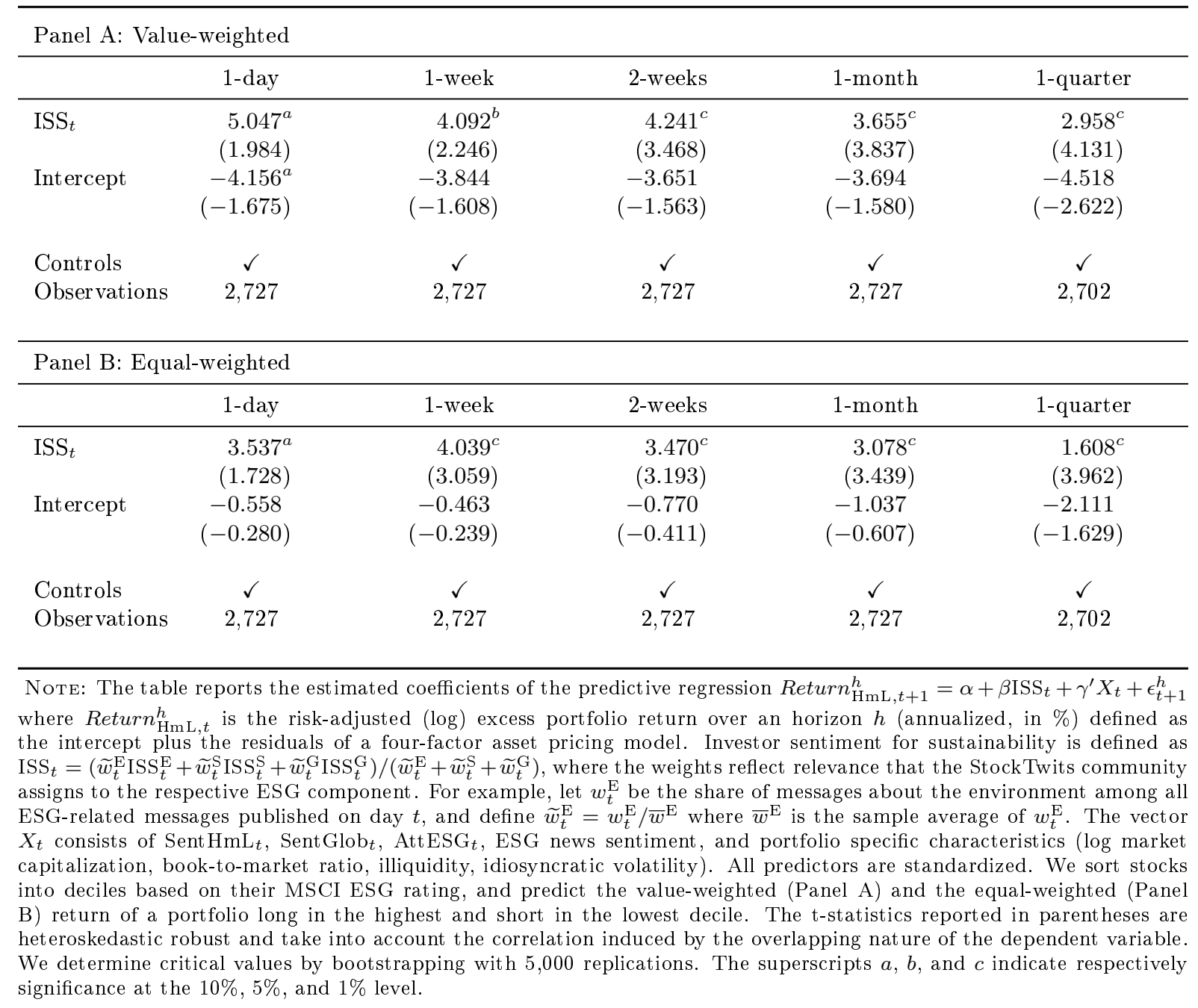


Table D8: Predictive power of environmental, social, and governance sentiment

\begin{tabular}{|c|c|c|c|c|c|c|c|c|c|c|}
\hline \multicolumn{11}{|c|}{ Panel A: Value-weighted } \\
\hline & \multicolumn{5}{|c|}{ Environmental sentiment } & \multicolumn{5}{|c|}{ Social sentiment } \\
\hline & 1-day & 1-week & 2-weeks & 1-month & 1-quarter & 1-day & 1-week & 2-weeks & 1-month & 1-quarter \\
\hline $\mathrm{ISS}_{t}^{\mathrm{E}}$ & $\begin{array}{c}5.380^{b} \\
(2.128)\end{array}$ & $\begin{array}{r}3.638^{b} \\
(2.227)\end{array}$ & $\begin{array}{c}2.172 \\
(1.644)\end{array}$ & $\begin{array}{c}2.560^{b} \\
(2.112)\end{array}$ & $\begin{array}{r}2.348^{b} \\
(2.641)\end{array}$ & & & & & \\
\hline $\mathrm{ISS}_{t}^{\mathrm{S}}$ & & & & & & $\begin{array}{c}3.808 \\
(1.505)\end{array}$ & $\begin{array}{c}4.220^{b} \\
(2.250)\end{array}$ & $\begin{array}{c}4.344^{c} \\
(2.756)\end{array}$ & $\begin{array}{c}3.082^{b} \\
(2.275)\end{array}$ & $\begin{array}{c}2.776^{a} \\
(1.905)\end{array}$ \\
\hline $\mathrm{ISS}_{t}^{\mathrm{G}}$ & & & & & & & & & & \\
\hline Intercept & $\begin{array}{c}0.050 \\
(0.020)\end{array}$ & $\begin{array}{c}-0.028 \\
(-0.010)\end{array}$ & $\begin{array}{c}-0.022 \\
(-0.008)\end{array}$ & $\begin{array}{c}-0.062 \\
(-0.019)\end{array}$ & $\begin{array}{c}0.113 \\
(0.030)\end{array}$ & $\begin{array}{c}0.050 \\
(0.020)\end{array}$ & $\begin{array}{c}-0.029 \\
(-0.010)\end{array}$ & $\begin{array}{c}-0.019 \\
(-0.007)\end{array}$ & $\begin{array}{c}-0.061 \\
(-0.019)\end{array}$ & $\begin{array}{c}0.109 \\
(0.030)\end{array}$ \\
\hline$R^{2}$ & $0.127 \%$ & $0.282 \%$ & $0.184 \%$ & $0.522 \%$ & $1.152 \%$ & $0.046 \%$ & $0.393 \%$ & $0.847 \%$ & $0.774 \%$ & $1.632 \%$ \\
\hline Observations & 2,768 & 2,764 & 2,759 & 2,747 & 2,703 & 2,768 & 2,764 & 2,759 & 2,747 & 2,703 \\
\hline \multicolumn{11}{|c|}{ Panel B: Equal-weighted } \\
\hline & \multicolumn{5}{|c|}{ Environmental sentiment } & \multicolumn{5}{|c|}{ Social sentiment } \\
\hline & 1-day & 1-week & 2-weeks & 1-month & 1-quarter & 1-day & 1-week & 2-weeks & 1-month & 1-quarter \\
\hline $\mathrm{ISS}_{t}^{\mathrm{E}}$ & $\begin{array}{c}7.074^{c} \\
(3.324)\end{array}$ & $\begin{array}{c}2.141 \\
(1.450)\end{array}$ & $\begin{array}{c}1.622 \\
(1.403)\end{array}$ & $\begin{array}{r}1.970^{b} \\
(2.214)\end{array}$ & $\begin{array}{c}1.479^{a} \\
(2.049)\end{array}$ & & & & & \\
\hline $\mathrm{ISS}_{t}^{\mathrm{S}}$ & & & & & & $\begin{array}{c}3.365 \\
(1.579)\end{array}$ & $\begin{array}{r}3.234^{a} \\
(1.886)\end{array}$ & $\begin{array}{c}2.967^{b} \\
(2.385)\end{array}$ & $\begin{array}{r}1.928^{a} \\
(1.781)\end{array}$ & $\begin{array}{c}1.641 \\
(1.503)\end{array}$ \\
\hline $\mathrm{ISS}_{t}^{\mathrm{G}}$ & & & & & & & & & & \\
\hline Intercept & $\begin{array}{c}0.075 \\
(0.035)\end{array}$ & $\begin{array}{c}0.118 \\
(0.051)\end{array}$ & $\begin{array}{c}0.112 \\
(0.047)\end{array}$ & $\begin{array}{c}0.131 \\
(0.052)\end{array}$ & $\begin{array}{c}0.409 \\
(0.176)\end{array}$ & $\begin{array}{c}0.075 \\
(0.035)\end{array}$ & $\begin{array}{c}0.118 \\
(0.052)\end{array}$ & $\begin{array}{c}0.113 \\
(0.048)\end{array}$ & $\begin{array}{c}0.129 \\
(0.051)\end{array}$ & $\begin{array}{c}0.405 \\
(0.177)\end{array}$ \\
\hline$R^{2}$ & $0.362 \%$ & $0.128 \%$ & $0.142 \%$ & $0.486 \%$ & $0.953 \%$ & $0.054 \%$ & $0.338 \%$ & $0.562 \%$ & $0.464 \%$ & $1.187 \%$ \\
\hline Observations & 2,768 & 2,764 & 2,759 & 2,747 & 2,703 & 2,768 & 2,764 & 2,759 & 2,747 & 2,703 \\
\hline
\end{tabular}


Table D8 continued: Predictive power of environmental, social, and governance sentiment

\begin{tabular}{|c|c|c|c|c|c|c|c|c|c|c|}
\hline \multicolumn{11}{|c|}{ Panel A: Value-weighted } \\
\hline & \multicolumn{5}{|c|}{ Governance sentiment } & \multicolumn{5}{|c|}{ All ESG sentiment components } \\
\hline & 1-day & 1-week & 2-weeks & 1-month & 1-quarter & 1-day & 1-week & 2-weeks & 1-month & 1-quarter \\
\hline $\mathrm{ISS}_{t}^{\mathrm{E}}$ & & & & & & $\begin{array}{r}4.509^{a} \\
(1.725)\end{array}$ & $\begin{array}{r}2.741^{a} \\
(1.710)\end{array}$ & $\begin{array}{c}1.075 \\
(0.884)\end{array}$ & $\begin{array}{c}1.699^{a} \\
(1.728)\end{array}$ & $\begin{array}{c}1.532^{b} \\
(2.874)\end{array}$ \\
\hline $\operatorname{ISS}_{t}^{S}$ & & & & & & $\begin{array}{c}2.044 \\
(0.748)\end{array}$ & $\begin{array}{c}3.331^{a} \\
(1.790)\end{array}$ & $\begin{array}{c}3.549^{b} \\
(2.242)\end{array}$ & $\begin{array}{c}1.864 \\
(1.679)\end{array}$ & $\begin{array}{c}1.534 \\
(1.497)\end{array}$ \\
\hline $\mathrm{ISS}_{t}^{\mathrm{G}}$ & $\begin{array}{c}3.849 \\
(1.521)\end{array}$ & $\begin{array}{c}2.354 \\
(1.316)\end{array}$ & $\begin{array}{r}2.972^{a} \\
(1.680)\end{array}$ & $\begin{array}{r}3.419^{a} \\
(1.930)\end{array}$ & $\begin{array}{r}3.482^{a} \\
(2.045)\end{array}$ & $\begin{array}{c}2.306 \\
(0.852)\end{array}$ & $\begin{array}{c}0.757 \\
(0.441)\end{array}$ & $\begin{array}{c}1.603 \\
(0.896)\end{array}$ & $\begin{array}{c}2.499 \\
(1.481)\end{array}$ & $\begin{array}{r}2.707^{a} \\
(1.825)\end{array}$ \\
\hline Intercept & $\begin{array}{c}0.050 \\
(0.020)\end{array}$ & $\begin{array}{c}-0.032 \\
(-0.011)\end{array}$ & $\begin{array}{c}-0.022 \\
(-0.008)\end{array}$ & $\begin{array}{c}-0.060 \\
(-0.018)\end{array}$ & $\begin{array}{c}0.102 \\
(0.028)\end{array}$ & $\begin{array}{c}0.032 \\
(0.013)\end{array}$ & $\begin{array}{c}-0.018 \\
(-0.007)\end{array}$ & $\begin{array}{c}-0.007 \\
(-0.002)\end{array}$ & $\begin{array}{c}-0.043 \\
(-0.013)\end{array}$ & $\begin{array}{c}0.144 \\
(0.040)\end{array}$ \\
\hline$R^{2}$ & $0.047 \%$ & $0.097 \%$ & $0.377 \%$ & $0.961 \%$ & $2.589 \%$ & $0.123 \%$ & $0.513 \%$ & $0.944 \%$ & $1.482 \%$ & $3.634 \%$ \\
\hline Observations & 2,768 & 2,764 & 2,759 & 2,747 & 2,703 & 2,767 & 2,763 & 2,758 & 2,746 & 2,702 \\
\hline
\end{tabular}

Panel B: Equal-weighted

\begin{tabular}{|c|c|c|c|c|c|c|c|c|c|c|}
\hline & \multicolumn{5}{|c|}{ Governance sentiment } & \multicolumn{5}{|c|}{ All ESG sentiment components } \\
\hline & 1-day & 1-week & 2-weeks & 1-month & 1-quarter & 1-day & 1-week & 2-weeks & 1-month & 1-quarter \\
\hline $\mathrm{ISS}_{t}^{\mathrm{E}}$ & & & & & & $\begin{array}{r}7.099^{c} \\
(3.228)\end{array}$ & $\begin{array}{c}1.511 \\
(1.035)\end{array}$ & $\begin{array}{c}1.028 \\
(0.948)\end{array}$ & $\begin{array}{r}1.497^{a} \\
(1.974)\end{array}$ & $\begin{array}{r}1.030^{a} \\
(2.072)\end{array}$ \\
\hline $\mathrm{ISS}_{t}^{\mathrm{S}}$ & & & & & & $\begin{array}{c}3.036 \\
(1.321)\end{array}$ & $\begin{array}{c}2.931 \\
(1.499)\end{array}$ & $\begin{array}{r}2.810^{b} \\
(2.175)\end{array}$ & $\begin{array}{c}1.211 \\
(1.378)\end{array}$ & $\begin{array}{c}0.964 \\
(1.160)\end{array}$ \\
\hline $\mathrm{ISS}_{t}^{\mathrm{G}}$ & $\begin{array}{l}-1.950 \\
(-0.914)\end{array}$ & $\begin{array}{c}0.901 \\
(0.570)\end{array}$ & $\begin{array}{c}0.833 \\
(0.611)\end{array}$ & $\begin{array}{c}1.801 \\
(1.372)\end{array}$ & $\begin{array}{c}1.823 \\
(1.481)\end{array}$ & $\begin{array}{r}-4.145^{a} \\
(-1.822)\end{array}$ & $\begin{array}{c}-0.294 \\
(-0.174)\end{array}$ & $\begin{array}{c}-0.277 \\
(-0.191)\end{array}$ & $\begin{array}{c}1.135 \\
(0.922)\end{array}$ & $\begin{array}{c}1.330 \\
(1.211)\end{array}$ \\
\hline Intercept & $\begin{array}{c}0.075 \\
(0.035)\end{array}$ & $\begin{array}{c}0.115 \\
(0.050)\end{array}$ & $\begin{array}{c}0.109 \\
(0.046)\end{array}$ & $\begin{array}{c}0.128 \\
(0.050)\end{array}$ & $\begin{array}{c}0.399 \\
(0.173)\end{array}$ & $\begin{array}{c}0.121 \\
(0.057)\end{array}$ & $\begin{array}{c}0.146 \\
(0.064)\end{array}$ & $\begin{array}{c}0.124 \\
(0.053)\end{array}$ & $\begin{array}{c}0.141 \\
(0.056)\end{array}$ & $\begin{array}{c}0.429 \\
(0.190)\end{array}$ \\
\hline $\begin{array}{l}R^{2} \\
\text { Observations }\end{array}$ & $\begin{array}{c}-0.006 \% \\
2,768\end{array}$ & $\begin{array}{c}-0.007 \% \\
2,764\end{array}$ & $\begin{array}{c}0.011 \% \\
2,759\end{array}$ & $\begin{array}{c}0.401 \% \\
2,747\end{array}$ & $\begin{array}{c}1.473 \% \\
2,703\end{array}$ & $\begin{array}{c}0.429 \% \\
2,767\end{array}$ & $\begin{array}{c}0.329 \% \\
2,763\end{array}$ & $\begin{array}{c}0.552 \% \\
2,758\end{array}$ & $\begin{array}{c}0.878 \% \\
2,746\end{array}$ & $\begin{array}{c}2.403 \% \\
2,702\end{array}$ \\
\hline
\end{tabular}

Note: The table reports the estimated coefficients of the predictive regression Return $n_{p, t+1}^{h}=\alpha_{p}+\beta_{p}^{\prime} X_{t}+\epsilon_{p, t+1}^{h}$ where Return ${ }_{p, t}^{h}$ is the risk-adjusted (log) excess portfolio return over an horizon $h$ (annualized, in \%). Risk-adjusted returns are the residuals of a four-factor asset pricing model. The predictors $X_{t}$ are standardized. The vector $X_{t}$ consists of either ISS $\mathrm{E}_{t}^{\mathrm{E}}$, $\mathrm{ISS}_{t}^{\mathrm{G}}$, or ISS $\mathrm{S}_{t}^{\mathrm{S}}$, or all three sentiment indexes jointly. We sort stocks into deciles based on their MSCI ESG rating, and predict the value-weighted (Panel A) and the equal-weighted (Panel B) return of a portfolio long in the highest and short in the lowest decile. The t-statistics reported in parentheses are heteroskedastic robust and take into account the correlation induced by the overlapping nature of the dependent variable. We determine critical values by bootstrapping with 5,000 replications. The superscripts $a$, $b$, and $c$ indicate respectively significance at the $10 \%, 5 \%$, and $1 \%$ level. 
Table D9: Predictive power of ESG sentiment controlling for other social media sentiment measures

\begin{tabular}{|c|c|c|c|c|c|c|c|c|c|c|}
\hline \multicolumn{11}{|c|}{ Panel A: Value-weighted } \\
\hline & \multicolumn{5}{|c|}{ Global social media sentiment } & \multicolumn{5}{|c|}{ Portfolio sentiment } \\
\hline & 1-day & 1-week & 2-weeks & 1-month & 1-quarter & 1-day & 1-week & 2-weeks & 1-month & 1-quarter \\
\hline $\mathrm{ISS}_{t}$ & $\begin{array}{c}6.177^{b} \\
(2.452)\end{array}$ & $\begin{array}{r}4.901^{b} \\
(2.585)\end{array}$ & $\begin{array}{r}4.578^{c} \\
(3.128)\end{array}$ & $\begin{array}{r}4.478^{c} \\
(3.245)\end{array}$ & $\begin{array}{r}4.427^{c} \\
(3.654)\end{array}$ & $\begin{array}{r}5.875^{b} \\
(2.315)\end{array}$ & $\begin{array}{r}4.752^{b} \\
(2.425)\end{array}$ & $\begin{array}{r}4.555^{c} \\
(2.658)\end{array}$ & $\begin{array}{r}4.385^{b} \\
(2.564)\end{array}$ & $\begin{array}{r}4.247^{b} \\
(2.550)\end{array}$ \\
\hline SentGlob $_{t}$ & $\begin{array}{l}11.276^{c} \\
(4.476)\end{array}$ & $\begin{array}{l}11.740^{c} \\
(4.557)\end{array}$ & $\begin{array}{l}12.346^{c} \\
(5.189)\end{array}$ & $\begin{array}{l}11.901^{c} \\
(4.500)\end{array}$ & $\begin{array}{l}11.314^{c} \\
(5.360)\end{array}$ & & & & & \\
\hline SentHmL $_{t}$ & & & & & & $\begin{array}{c}3.429 \\
(1.351)\end{array}$ & $\begin{array}{c}1.133 \\
(0.594)\end{array}$ & $\begin{array}{l}-0.745 \\
(-0.448)\end{array}$ & $\begin{array}{c}-1.108 \\
(-0.740)\end{array}$ & $\begin{array}{c}-1.915 \\
(-1.424)\end{array}$ \\
\hline Intercept & $\begin{array}{c}0.050 \\
(0.020)\end{array}$ & $\begin{array}{c}0.005 \\
(0.002)\end{array}$ & $\begin{array}{c}0.065 \\
(0.024)\end{array}$ & $\begin{array}{c}0.131 \\
(0.046)\end{array}$ & $\begin{array}{c}0.583 \\
(0.233)\end{array}$ & $\begin{array}{c}0.031 \\
(0.012)\end{array}$ & $\begin{array}{c}-0.019 \\
(-0.007)\end{array}$ & $\begin{array}{c}-0.007 \\
(-0.003)\end{array}$ & $\begin{array}{c}-0.043 \\
(-0.013)\end{array}$ & $\begin{array}{c}0.150 \\
(0.042)\end{array}$ \\
\hline$R^{2}$ & $0.861 \%$ & $3.806 \%$ & $7.923 \%$ & $13.282 \%$ & $29.681 \%$ & $0.209 \%$ & $0.524 \%$ & $0.894 \%$ & $1.592 \%$ & $4.290 \%$ \\
\hline Observations & 2,768 & 2,764 & 2,759 & 2,747 & 2,703 & 2,767 & 2,763 & 2,758 & 2,746 & 2,702 \\
\hline \multicolumn{11}{|c|}{ Panel B: Equal-weighted } \\
\hline & \multicolumn{5}{|c|}{ Global social media sentiment } & \multicolumn{5}{|c|}{ Portfolio sentiment } \\
\hline & 1-day & 1-week & 2-weeks & 1-month & 1-quarter & 1-day & 1-week & 2-weeks & 1-month & 1-quarter \\
\hline $\mathrm{ISS}_{t}$ & $\begin{array}{r}4.132^{a} \\
(1.942)\end{array}$ & $\begin{array}{r}3.028^{a} \\
(1.908)\end{array}$ & $\begin{array}{c}2.642^{b} \\
(2.126)\end{array}$ & $\begin{array}{c}2.826^{b} \\
(2.527)\end{array}$ & $\begin{array}{r}2.563^{c} \\
(3.321)\end{array}$ & $\begin{array}{r}3.896^{a} \\
(1.822)\end{array}$ & $\begin{array}{c}2.942^{a} \\
(1.738)\end{array}$ & $\begin{array}{r}2.579^{a} \\
(1.812)\end{array}$ & $\begin{array}{c}2.792^{b} \\
(2.096)\end{array}$ & $\begin{array}{r}2.459^{a} \\
(1.950)\end{array}$ \\
\hline SentGlob $_{t}$ & $\begin{array}{r}6.418^{c} \\
(3.016)\end{array}$ & $\begin{array}{r}8.129^{c} \\
(3.352)\end{array}$ & $\begin{array}{r}7.836^{c} \\
(3.768)\end{array}$ & $\begin{array}{r}7.574^{c} \\
(3.419)\end{array}$ & $\begin{array}{r}7.031^{c} \\
(4.806)\end{array}$ & & & & & \\
\hline SentHmL $_{t}$ & & & & & & $\begin{array}{c}2.450 \\
(1.145)\end{array}$ & $\begin{array}{c}0.508 \\
(0.333)\end{array}$ & $\begin{array}{c}0.059 \\
(0.043)\end{array}$ & $\begin{array}{c}-0.989 \\
(-0.745)\end{array}$ & $\begin{array}{c}-1.298 \\
(-1.161)\end{array}$ \\
\hline Intercept & $\begin{array}{c}0.075 \\
(0.035)\end{array}$ & $\begin{array}{c}0.140 \\
(0.062)\end{array}$ & $\begin{array}{c}0.166 \\
(0.073)\end{array}$ & $\begin{array}{c}0.251 \\
(0.109)\end{array}$ & $\begin{array}{c}0.697 \\
(0.424)\end{array}$ & $\begin{array}{c}0.122 \\
(0.057)\end{array}$ & $\begin{array}{c}0.146 \\
(0.064)\end{array}$ & $\begin{array}{c}0.124 \\
(0.052)\end{array}$ & $\begin{array}{c}0.141 \\
(0.056)\end{array}$ & $\begin{array}{c}0.431 \\
(0.192)\end{array}$ \\
\hline$R^{2}$ & $0.391 \%$ & $2.604 \%$ & $4.513 \%$ & $8.456 \%$ & $23.633 \%$ & $0.110 \%$ & $0.255 \%$ & $0.381 \%$ & $1.039 \%$ & $3.170 \%$ \\
\hline Observations & 2,768 & 2,764 & 2,759 & 2,747 & 2,703 & 2,767 & 2,763 & 2,758 & 2,746 & 2,702 \\
\hline
\end{tabular}

NoтE: The table reports the estimated coefficients of the predictive regression $\operatorname{Return}_{p, t+1}^{h}=\alpha_{p}+\beta_{p}^{\prime} X_{t}+\epsilon_{p, t+1}^{h}$ where Return $n_{p, t}^{h}$ is the risk-adjusted (log) excess portfolio return over an horizon $h$ (annualized, in \%). Risk-adjusted returns are the residuals of a four-factor asset pricing model. The predictors $X_{t}$ are standardized. The vector $X_{t}$ consists of ISS $t$, and either SentGlob $t$ (first five columns) or SentHmL (last five columns). We sort stocks into deciles based on their MSCI ESG rating, and predict the value-weighted (Panel A) and the equal-weighted (Panel B) return of a portfolio long in the highest and short in the lowest decile. The t-statistics reported in parentheses are heteroskedastic robust and take into account the correlation induced by the overlapping nature of the dependent variable. We determine critical values by bootstrapping with 5,000 replications. The superscripts $a, b$, and $c$ indicate respectively significance at the $10 \%, 5 \%$, and $1 \%$ level. 
Table D10: Predictive power of ESG sentiment controlling for news sentiment

\begin{tabular}{|c|c|c|c|c|c|c|c|c|c|c|}
\hline \multicolumn{11}{|c|}{ Panel A: Value-weighted } \\
\hline & \multicolumn{5}{|c|}{ ESG news sentiment (RavenPack) } & \multicolumn{5}{|c|}{ Environmental news sentiment (EGLKS) } \\
\hline & 1-day & 1-week & 2-weeks & 1-month & 1-quarter & 1-day & 1-week & 2-weeks & 1-month & 1-quarter \\
\hline $\mathrm{ISS}_{t}$ & $\begin{array}{r}5.453^{b} \\
(2.132)\end{array}$ & $\begin{array}{r}4.055^{b} \\
(2.092)\end{array}$ & $\begin{array}{c}3.904^{b} \\
(2.344)\end{array}$ & $\begin{array}{c}3.699^{b} \\
(2.294)\end{array}$ & $\begin{array}{c}3.381^{b} \\
(2.206)\end{array}$ & $\begin{array}{c}4.123 \\
(1.591)\end{array}$ & $\begin{array}{r}3.800^{a} \\
(1.924)\end{array}$ & $\begin{array}{c}3.608^{b} \\
(2.110)\end{array}$ & $\begin{array}{c}3.484^{a} \\
(2.036)\end{array}$ & $\begin{array}{r}3.423^{a} \\
(1.987)\end{array}$ \\
\hline ESG news & $\begin{array}{r}4.518^{a} \\
(1.765)\end{array}$ & $\begin{array}{r}7.307^{c} \\
(3.261)\end{array}$ & $\begin{array}{r}5.745^{b} \\
(2.615)\end{array}$ & $\begin{array}{r}5.683^{b} \\
(2.547)\end{array}$ & $\begin{array}{r}5.909^{c} \\
(2.950)\end{array}$ & & & & & \\
\hline $\mathrm{NCCN}$ & & & & & & $\begin{array}{c}0.388 \\
(0.139)\end{array}$ & $\begin{array}{c}0.508 \\
(0.216)\end{array}$ & $\begin{array}{c}1.034 \\
(0.417)\end{array}$ & $\begin{array}{c}1.025 \\
(0.378)\end{array}$ & $\begin{array}{c}1.042 \\
(0.398)\end{array}$ \\
\hline Intercept & $\begin{array}{c}0.170 \\
(0.067)\end{array}$ & $\begin{array}{c}0.134 \\
(0.049)\end{array}$ & $\begin{array}{c}0.147 \\
(0.052)\end{array}$ & $\begin{array}{c}0.100 \\
(0.032)\end{array}$ & $\begin{array}{c}0.154 \\
(0.048)\end{array}$ & $\begin{array}{c}-3.163 \\
(-1.128)\end{array}$ & $\begin{array}{c}-3.249 \\
(-1.030)\end{array}$ & $\begin{array}{c}-3.284 \\
(-0.975)\end{array}$ & $\begin{array}{c}-3.439 \\
(-0.900)\end{array}$ & $\begin{array}{c}-3.156 \\
(-0.747)\end{array}$ \\
\hline$R^{2}$ & $0.245 \%$ & $1.772 \%$ & $2.423 \%$ & $4.251 \%$ & $10.878 \%$ & $0.027 \%$ & $0.336 \%$ & $0.674 \%$ & $1.172 \%$ & $2.968 \%$ \\
\hline Observations & 2,726 & 2,726 & 2,726 & 2,726 & 2,702 & 2,116 & 2,116 & 2,116 & 2,116 & 2,116 \\
\hline \multicolumn{11}{|c|}{ Panel B: Equal-weighted } \\
\hline & \multicolumn{5}{|c|}{ ESG news sentiment (RavenPack) } & \multicolumn{5}{|c|}{ Share of negative climate change news (NCCN) } \\
\hline & 1-day & 1-week & 2-weeks & 1-month & 1-quarter & 1-day & 1-week & 2-weeks & 1-month & 1-quarter \\
\hline $\mathrm{ISS}_{t}$ & $\begin{array}{c}3.901^{a} \\
(1.803)\end{array}$ & $\begin{array}{r}2.953^{a} \\
(1.769)\end{array}$ & $\begin{array}{r}2.548^{a} \\
(1.930)\end{array}$ & $\begin{array}{r}2.570^{b} \\
(2.034)\end{array}$ & $\begin{array}{c}1.938 \\
(1.602)\end{array}$ & $\begin{array}{c}3.495 \\
(1.514)\end{array}$ & $\begin{array}{c}2.518 \\
(1.414)\end{array}$ & $\begin{array}{c}1.896 \\
(1.347)\end{array}$ & $\begin{array}{c}2.059 \\
(1.500)\end{array}$ & $\begin{array}{c}2.031 \\
(1.443)\end{array}$ \\
\hline ESG news & $\begin{array}{c}3.492 \\
(1.613)\end{array}$ & $\begin{array}{c}2.519 \\
(1.403)\end{array}$ & $\begin{array}{c}2.280 \\
(1.202)\end{array}$ & $\begin{array}{c}2.411 \\
(1.358)\end{array}$ & $\begin{array}{c}3.455^{b} \\
(2.693)\end{array}$ & & & & & \\
\hline $\mathrm{NCCN}$ & & & & & & $\begin{array}{c}2.255 \\
(0.905)\end{array}$ & $\begin{array}{c}2.545 \\
(1.339)\end{array}$ & $\begin{array}{c}2.538 \\
(1.449)\end{array}$ & $\begin{array}{c}1.460 \\
(0.818)\end{array}$ & $\begin{array}{c}1.116 \\
(0.754)\end{array}$ \\
\hline Intercept & $\begin{array}{c}0.619 \\
(0.288)\end{array}$ & $\begin{array}{c}0.576 \\
(0.251)\end{array}$ & $\begin{array}{c}0.495 \\
(0.210)\end{array}$ & $\begin{array}{c}0.409 \\
(0.167)\end{array}$ & $\begin{array}{c}0.433 \\
(0.213)\end{array}$ & $\begin{array}{c}-1.394 \\
(-0.558)\end{array}$ & $\begin{array}{c}-1.435 \\
(-0.528)\end{array}$ & $\begin{array}{c}-1.465 \\
(-0.517)\end{array}$ & $\begin{array}{c}-1.400 \\
(-0.462)\end{array}$ & $\begin{array}{c}-1.111 \\
(-0.420)\end{array}$ \\
\hline$R^{2}$ & $0.170 \%$ & $0.529 \%$ & $0.816 \%$ & $1.808 \%$ & $7.703 \%$ & $0.058 \%$ & $0.406 \%$ & $0.606 \%$ & $0.794 \%$ & $2.471 \%$ \\
\hline Observations & 2,726 & 2,726 & 2,726 & 2,726 & 2,702 & 2,116 & 2,116 & 2,116 & 2,116 & 2,116 \\
\hline
\end{tabular}

Nоте: The table reports the estimated coefficients of the predictive regression $\operatorname{Return}_{p, t+1}^{h}=\alpha_{p}+\beta_{p}^{\prime} X_{t}+\epsilon_{p, t+1}^{h}$ where $\operatorname{Return} n_{p, t}^{h}$ is the risk-adjusted (log) excess portfolio return over an horizon $h$ (annualized, in \%). Risk-adjusted returns are the residuals of a four-factor asset pricing model. The predictors $X_{t}$ are standardized. The vector $X_{t}$ consists of ISS $t_{t}$, and either ESG news sentiment based on the RavenPack database (first five columns) or the NCCN index (last five columns). We sort stocks into deciles based on their MSCI ESG rating, and predict the value-weighted (Panel A) and the equal-weighted (Panel B) return of a portfolio long in the highest and short in the lowest decile. The t-statistics reported in parentheses are heteroskedastic robust and take into account the correlation induced by the overlapping nature of the dependent variable. We determine critical values by bootstrapping with 5,000 are heteroskedastic robust and take into account the correlation induced by the overlapping nature of the
replications. The superscripts $a, b$, and $c$ indicate respectively significance at the $10 \%, 5 \%$, and $1 \%$ level. 
Table D11: Predictive power of ESG sentiment controlling for ESG attention

\begin{tabular}{|c|c|c|c|c|c|c|c|c|c|c|}
\hline \multicolumn{11}{|c|}{ Panel A: Value-weighted } \\
\hline & \multicolumn{5}{|c|}{ Aggregated ESG attention } & \multicolumn{5}{|c|}{ ESG attention by topic } \\
\hline & 1-day & 1-week & 2-weeks & 1-month & 1-quarter & 1-day & 1-week & 2-weeks & 1-month & 1-quarter \\
\hline $\mathrm{ISS}_{t}$ & $\begin{array}{c}5.861^{b} \\
(2.315)\end{array}$ & $\begin{array}{r}4.776^{b} \\
(2.502)\end{array}$ & $\begin{array}{r}4.451^{c} \\
(2.584)\end{array}$ & $\begin{array}{r}4.207^{b} \\
(2.510)\end{array}$ & $\begin{array}{r}3.961^{b} \\
(2.403)\end{array}$ & $\begin{array}{c}5.907^{b} \\
(2.332)\end{array}$ & $\begin{array}{r}4.710^{b} \\
(2.477)\end{array}$ & $\begin{array}{r}4.392^{c} \\
(2.610)\end{array}$ & $\begin{array}{r}4.164^{b} \\
(2.558)\end{array}$ & $\begin{array}{r}3.933^{b} \\
(2.495)\end{array}$ \\
\hline $\operatorname{AttESG}_{t}$ & $\begin{array}{r}5.370^{b} \\
(2.121)\end{array}$ & $\begin{array}{c}1.200 \\
(0.614)\end{array}$ & $\begin{array}{c}0.599 \\
(0.310)\end{array}$ & $\begin{array}{c}1.273 \\
(0.702)\end{array}$ & $\begin{array}{c}1.884 \\
(1.450)\end{array}$ & & & & & \\
\hline $\operatorname{AttE}_{t}$ & & & & & & $\begin{array}{c}0.005 \\
(0.002)\end{array}$ & $\begin{array}{r}4.082^{a} \\
(1.621)\end{array}$ & $\begin{array}{c}3.254 \\
(1.283)\end{array}$ & $\begin{array}{c}2.304 \\
(0.877)\end{array}$ & $\begin{array}{c}2.233 \\
(1.003)\end{array}$ \\
\hline $\mathrm{AttS}_{t}$ & & & & & & $\begin{array}{c}1.747 \\
(0.624)\end{array}$ & $\begin{array}{l}-1.532 \\
(-0.827)\end{array}$ & $\begin{array}{l}-1.183 \\
(-0.752)\end{array}$ & $\begin{array}{l}-0.203 \\
(-0.156)\end{array}$ & $\begin{array}{c}-0.223 \\
(-0.222)\end{array}$ \\
\hline $\operatorname{AttG}_{t}$ & & & & & & $\begin{array}{r}5.289^{b} \\
(2.071)\end{array}$ & $\begin{array}{l}-0.228 \\
(-0.155)\end{array}$ & $\begin{array}{l}-0.643 \\
(-0.595)\end{array}$ & $\begin{array}{c}0.123 \\
(0.167)\end{array}$ & $\begin{array}{c}0.925 \\
(1.575)\end{array}$ \\
\hline Intercept & $\begin{array}{c}0.030 \\
(0.012)\end{array}$ & $\begin{array}{c}-0.023 \\
(-0.008)\end{array}$ & $\begin{array}{c}-0.010 \\
(-0.003)\end{array}$ & $\begin{array}{c}-0.049 \\
(-0.015)\end{array}$ & $\begin{array}{c}0.144 \\
(0.040)\end{array}$ & $\begin{array}{c}0.030 \\
(0.012)\end{array}$ & $\begin{array}{c}-0.026 \\
(-0.010)\end{array}$ & $\begin{array}{c}-0.015 \\
(-0.005)\end{array}$ & $\begin{array}{c}-0.054 \\
(-0.017)\end{array}$ & $\begin{array}{c}0.143 \\
(0.040)\end{array}$ \\
\hline$R^{2}$ & $0.305 \%$ & $0.528 \%$ & $0.885 \%$ & $1.624 \%$ & $4.258 \%$ & $0.257 \%$ & $0.748 \%$ & $1.206 \%$ & $1.843 \%$ & $4.708 \%$ \\
\hline Observations & 2,767 & 2,763 & 2,758 & 2,746 & 2,702 & 2,767 & 2,763 & 2,758 & 2,746 & 2,702 \\
\hline
\end{tabular}

Panel B: Equal-weighted

\begin{tabular}{|c|c|c|c|c|c|c|c|c|c|c|}
\hline & \multicolumn{5}{|c|}{ Aggregated ESG attention } & \multicolumn{5}{|c|}{ ESG attention by topic } \\
\hline & 1-day & 1-week & 2-weeks & 1-month & 1-quarter & 1-day & 1-week & 2-weeks & 1-month & 1-quarter \\
\hline \multirow[t]{2}{*}{$\mathrm{ISS}_{t}$} & $3.984^{a}$ & $2.980^{a}$ & $2.591^{a}$ & $2.654^{a}$ & 2.184 & $3.948^{a}$ & $2.910^{a}$ & $2.541^{a}$ & $2.602^{a}$ & $2.129^{a}$ \\
\hline & $(1.866)$ & $(1.799)$ & $(1.875)$ & $(2.035)$ & $(1.775)$ & $(1.849)$ & $(1.766)$ & $(1.861)$ & $(2.056)$ & $(1.865)$ \\
\hline \multirow[t]{2}{*}{$\operatorname{AttESG}_{t}$} & 2.172 & 0.094 & -0.100 & 0.800 & $2.594^{b}$ & & & & & \\
\hline & $(1.017)$ & $(0.055)$ & $(-0.059)$ & $(0.568)$ & $(2.299)$ & & & & & \\
\hline \multirow[t]{2}{*}{$\mathrm{AttE}_{t}$} & & & & & & 2.909 & $4.175^{b}$ & $3.468^{a}$ & 3.484 & $3.298^{a}$ \\
\hline & & & & & & $(1.230)$ & $(2.269)$ & $(1.905)$ & $(1.728)$ & $(1.872)$ \\
\hline \multirow[t]{2}{*}{$\operatorname{AttS}_{t}$} & & & & & & -0.542 & -2.362 & $-2.524^{a}$ & $-1.787^{b}$ & 0.182 \\
\hline & & & & & & $(-0.230)$ & $(-1.414)$ & $(-1.901)$ & $(-1.986)$ & $(0.240)$ \\
\hline \multirow[t]{2}{*}{$\operatorname{AttG}_{t}$} & & & & & & 1.047 & -1.045 & -0.686 & -0.131 & $0.771^{a}$ \\
\hline & & & & & & $(0.486)$ & $(-0.780)$ & $(-0.616)$ & $(-0.213)$ & $(1.939)$ \\
\hline \multirow[t]{2}{*}{ Intercept } & 0.121 & 0.145 & 0.124 & 0.137 & 0.424 & 0.121 & 0.142 & 0.123 & 0.134 & 0.418 \\
\hline & $(0.057)$ & $(0.063)$ & $(0.052)$ & $(0.055)$ & $(0.195)$ & $(0.057)$ & $(0.062)$ & $(0.052)$ & $(0.054)$ & $(0.198)$ \\
\hline$R^{2}$ & $0.100 \%$ & $0.246 \%$ & $0.381 \%$ & $0.994 \%$ & $5.428 \%$ & $0.063 \%$ & $0.717 \%$ & $1.072 \%$ & $2.184 \%$ & $8.071 \%$ \\
\hline Observations & 2,767 & 2,763 & 2,758 & 2,746 & 2,702 & 2,767 & 2,763 & 2,758 & 2,746 & 2,702 \\
\hline
\end{tabular}

NoтE: The table reports the estimated coefficients of the predictive regression $\operatorname{Return}_{p, t+1}^{h}=\alpha_{p}+\beta_{p}^{\prime} X_{t}+\epsilon_{p, t+1}^{h}$ where $\operatorname{Return}_{p, t}^{h}$ is the risk-adjusted (log) excess portfolio return over an horizon $h$ (annualized, in \%). Risk-adjusted returns are the residuals of a four-factor asset pricing model. The predictors $X_{t}$ are standardized. The vector $X_{t}$ consists of ISS $t_{t}$, and either AttESG $t_{t}$ (first five columns) or AttE $\mathrm{AttS}_{t}$ and $\mathrm{AttG}_{t}$ (last five columns). We sort stocks into deciles based on their MSCI ESG rating, and predict the value-weighted (Panel A) and the equal-weighted (Panel B) return of a portfolio long in the highest and short in the lowest decile. The t-statistics reported in parentheses are heteroskedastic robust and take into account the correlation induced by the overlapping nature of the dependent variable. We determine critical values by bootstrapping with 5,000 replications. The superscripts $a, b$, and $c$ indicate respectively significance at the $10 \%, 5 \%$, and $1 \%$ level. 
Table D12: Predictive power of ESG sentiment for ESG portfolios with low and high share of institutional holdings

\begin{tabular}{|c|c|c|c|c|c|c|c|c|c|c|}
\hline \multicolumn{11}{|c|}{ Panel A: Value-weighted } \\
\hline & \multicolumn{5}{|c|}{ Low institutional holdings } & \multicolumn{5}{|c|}{ High institutional holdings } \\
\hline & 1-day & 1-week & 2-weeks & 1-month & 1-quarter & 1-day & 1-week & 2-weeks & 1-month & 1-quarter \\
\hline $\mathrm{ISS}_{t}$ & $\begin{array}{c}6.098 \\
(1.474)\end{array}$ & $\begin{array}{r}6.383^{b} \\
(2.119)\end{array}$ & $\begin{array}{r}5.613^{b} \\
(2.173)\end{array}$ & $\begin{array}{r}5.475^{b} \\
(2.557)\end{array}$ & $\begin{array}{r}4.491^{b} \\
(2.752)\end{array}$ & $\begin{array}{c}3.609 \\
(1.056)\end{array}$ & $\begin{array}{c}4.152 \\
(1.508)\end{array}$ & $\begin{array}{r}4.362^{a} \\
(1.771)\end{array}$ & $\begin{array}{r}4.408^{b} \\
(2.605)\end{array}$ & $\begin{array}{c}2.282 \\
(1.616)\end{array}$ \\
\hline Intercept & $\begin{array}{c}0.066 \\
(0.016)\end{array}$ & $\begin{array}{c}-0.281 \\
(-0.065)\end{array}$ & $\begin{array}{c}-0.466 \\
(-0.107)\end{array}$ & $\begin{array}{c}-0.689 \\
(-0.147)\end{array}$ & $\begin{array}{c}-0.200 \\
(-0.039)\end{array}$ & $\begin{array}{c}-0.003 \\
(-0.001)\end{array}$ & $\begin{array}{c}-0.026 \\
(-0.008)\end{array}$ & $\begin{array}{c}-0.077 \\
(-0.024)\end{array}$ & $\begin{array}{c}-0.343 \\
(-0.101)\end{array}$ & $\begin{array}{c}-0.179 \\
(-0.061)\end{array}$ \\
\hline $\begin{array}{l}R^{2} \\
\text { Observations }\end{array}$ & $\begin{array}{c}0.042 \% \\
2,768\end{array}$ & $\begin{array}{c}0.365 \% \\
2,764\end{array}$ & $\begin{array}{c}0.568 \% \\
2,759\end{array}$ & $\begin{array}{c}1.129 \% \\
2,747\end{array}$ & $\begin{array}{c}2.006 \% \\
2,703\end{array}$ & $\begin{array}{c}0.004 \% \\
2,768\end{array}$ & $\begin{array}{c}0.229 \% \\
2,764\end{array}$ & $\begin{array}{c}0.569 \% \\
2,759\end{array}$ & $\begin{array}{c}1.291 \% \\
2,747\end{array}$ & $\begin{array}{c}1.092 \% \\
2,703\end{array}$ \\
\hline \multicolumn{11}{|c|}{ Panel B: Equal-weighted } \\
\hline & \multicolumn{5}{|c|}{ Low institutional holdings } & \multicolumn{5}{|c|}{ High institutional holdings } \\
\hline & 1-day & 1-week & 2-weeks & 1-month & 1-quarter & 1-day & 1-week & 2-weeks & 1-month & 1-quarter \\
\hline $\mathrm{ISS}_{t}$ & $\begin{array}{l}7.023^{a} \\
(2.026)\end{array}$ & $\begin{array}{c}3.242 \\
(1.016)\end{array}$ & $\begin{array}{c}2.105 \\
(0.769)\end{array}$ & $\begin{array}{c}1.234 \\
(0.460)\end{array}$ & $\begin{array}{c}1.227 \\
(0.506)\end{array}$ & $\begin{array}{c}2.674 \\
(0.859)\end{array}$ & $\begin{array}{r}4.702^{a} \\
(1.907)\end{array}$ & $\begin{array}{r}5.329^{c} \\
(2.658)\end{array}$ & $\begin{array}{r}5.095^{c} \\
(3.509)\end{array}$ & $\begin{array}{c}3.146^{b} \\
(2.189)\end{array}$ \\
\hline Intercept & $\begin{array}{c}0.156 \\
(0.045)\end{array}$ & $\begin{array}{c}0.163 \\
(0.045)\end{array}$ & $\begin{array}{c}0.135 \\
(0.038)\end{array}$ & $\begin{array}{c}0.033 \\
(0.009)\end{array}$ & $\begin{array}{c}0.497 \\
(0.138)\end{array}$ & $\begin{array}{c}0.027 \\
(0.009)\end{array}$ & $\begin{array}{c}0.006 \\
(0.002)\end{array}$ & $\begin{array}{c}-0.075 \\
(-0.026)\end{array}$ & $\begin{array}{c}-0.245 \\
(-0.083)\end{array}$ & $\begin{array}{c}0.119 \\
(0.042)\end{array}$ \\
\hline$R^{2}$ & $0.112 \%$ & $0.111 \%$ & $0.087 \%$ & $0.060 \%$ & $0.236 \%$ & $-0.009 \%$ & $0.373 \%$ & $1.096 \%$ & $2.209 \%$ & $2.584 \%$ \\
\hline Observations & 2,768 & 2,764 & 2,759 & 2,747 & 2,703 & 2,768 & 2,764 & 2,759 & 2,747 & 2,703 \\
\hline
\end{tabular}

NoтE: The table reports the estimated coefficients of the predictive regression $\operatorname{Return}_{p, t+1}^{h}=\alpha_{p}+\beta_{p} \operatorname{ISS}_{t}+\epsilon_{p, t+1}^{h}$ where $\operatorname{Return}_{p, t}^{h}$ is the risk-adjusted (log) excess portfolio return over an horizon $h$ (annualized, in \%). Risk-adjusted returns are the residuals of a four-factor asset pricing model. The ESG sentiment ISS $t$ is standardized. We sort stocks into quintiles based on their MSCI ESG rating and within each quintile we split stocks according to their institutional holdings as reported in the quarterly $13 \mathrm{~F}$ filings. We predict the value-weighted (Panel A) and the equal-weighted (Panel B) return of a portfolio long in the highest and short in the lowest quintile separately for stocks with low (first five columns) and high (last five columns) institutional holdings. The t-statistics reported in parentheses are heteroskedastic robust and take into account the correlation induced by the overlapping nature of the dependent variable.

We determine critical values by bootstrapping with 5,000 replications. The superscripts $a, b$, and $c$ indicate respectively significance at the $10 \%, 5 \%$, and $1 \%$ level. 